MAURICIO ROBERTO DE PINHO CHIVANTE

\title{
AVALIAÇÃO EXPERIMENTAL DAS RELAÇÕES TENSÃO-DEFORMAÇÃO DE UM TECIDO DE FIBRA DE VIDRO RECOBERTO COM PTFE
}




\section{MAURICIO ROBERTO DE PINHO CHIVANTE}

\section{AVALIAÇÃO EXPERIMENTAL DAS RELAÇÕES TENSÃO-DEFORMAÇÃO DE UM TECIDO DE FIBRA DE VIDRO RECOBERTO COM PTFE}

Dissertação apresentada à Escola

Politécnica da Universidade de São Paulo como parte dos requisitos para a obtenção do título de Mestre em Engenharia Civil 


\section{MAURICIO ROBERTO DE PINHO CHIVANTE}

\section{AVALIAÇÃO EXPERIMENTAL DAS RELAÇÕES TENSÃO-DEFORMAÇÃO DE UM TECIDO DE FIBRA DE VIDRO RECOBERTO COM PTFE}

Dissertação apresentada à Escola

Politécnica da Universidade de São Paulo como parte dos requisitos para a obtenção do título de Mestre em Engenharia Civil

Área de Concentração:

Engenharia de Estruturas

Orientador:

Ruy Marcelo de Oliveira Pauletti 


\section{FICHA CATALOGRÁFICA}

\section{Chivante, Maurício Roberto de Pinho}

Avaliação experimental das relações tensão-deformação de um tecido de fibra de vidro recoberto com PTFE / M.R.P.

Chivante. -- São Paulo, 2009.

$93 \mathrm{p}$.

Dissertação (Mestrado) - Escola Politécnica da Universidade de São Paulo. Departamento de Engenharia de Estruturas e Geotécnica.

1.Estruturas de membranas 2.Materiais (Ensaios) 3.Deformação e estresses 4.Tensão dos materiais I.Universidade de São Paulo. Escola Politécnica. Departamento de Engenharia de Estruturas e Geotécnica II.t. 


\section{DEDICATÓRIA}

Aos meus pais, Regina e João, à minha irmã Cristiane e às minhas afilhadas de coração, Gigi e Belinha. 


\section{AGRADECIMENTOS}

Primeiramente a Deus, por sempre me levar para o melhor caminho, mesmo que as vezes contra a minha vontade.

Aos meus pais, responsáveis por minha formação, sempre me apoiando e ficando a meu lado em todas as horas, não importando a distância.

À minha irmã e às minhas afilhadas, por conseguirem me mostrar o raio de luz durante os períodos mais nublados da jornada.

Ao meu orientador, Prof. Dr. Ruy Marcelo de Oliveira Pauletti que, antes mesmo que eu começasse o mestrado, já havia aceitado o desafio de me guiar por entre o complexo e fantástico mundo das tensoestruturas, sempre mostrando caminhos embasados pela técnica, criatividade, conhecimento e ética.

Aos amigos da Birdair, Inc, em especial a Shinji Komatsu, presidente da empresa, Martin Augustyniak, diretor de operações, Gerald J. Panfil, responsável pelo Laboratório de Ensaios e seu axiliar Dan Thornton e ao professor Slade Gellin. Graças a estes apoios foi possível executar os ensaios necessários para a realização deste trabalho. Um agradecimento especial deve ser extendido a toda a família Birdair, pela amizade e profissionalismo que eles tiveram comigo durante este período.

À Universidade de São Paulo e ao Departamento de Engenharia de Estruturas e Geotécnica pelo curso de mestrado e a oportunidade de uma vivência acadêmica que me renderá bons frutos pelo resto da minha vida. 
"Supreme means going on; Going on means going far; Going far means returning." (Lao Tzu, Tao Te Ching, séc VI a.C.) "Keep Going." (Shinji Komatsu, Amherst, 2008) 


\section{RESUMO}

Com o crescente uso de estruturas de membrana tensionada, as relações tensãodeformação do tecido utilizado em sua fabricação devem ser bem entendidas. Deste modo, esta dissertação apresenta um estudo sobre o comportamento mecânico de um tecido arquitetônico PTFE-vidro, ressaltando seu complexo mecanismo de deformação que engloba efeitos de anisotropia, não-linearidade física, troca de ondulações, histerese, remoção do espaçamento entre os fios e variação de temperatura. Diferentes métodos para modelagem do material foram estudados, com ênfase no modelo de material ortótropo representado por um funcional energia de deformação hiperelástico. Além disso, vários protocolos para ensaios de tração em tecidos recobertos foram analisados e uma série de ensaios biaxiais com amostras cruciformes foram realizados no Centro de Pesquisa e Desenvolvimento da Birdair, Inc. Um determinado funcional energia de deformação foi então ajustado aos dados de campo obtidos nestes testes, cujos resultados foram então comparados diretamente aos dados obtidos em campo e a um ajuste direto de uma superfície suave tensão-deformação. A performance do modelo ajustado não se encontra ainda em um patamar de aplicação industrial, entretanto este estudo permite um entendimento global dos mecanismos de deformação do tecido PTFEvidro, fornecendo também uma massa de dados consistentes que podem ser utilizados em situações práticas.

Palavras-chave: análise experimental; relação tensão-deformação; material hiperelástico; PTFE-vidro 
Considering the growing use of tensioned membrane structures, the stress-strain relation of the fabric used on its construction must be well understood. This dissertation presents a study of the mechanical behavior of a PTFE coated fiberglass fabric, emphasizing its complex strain mechanism which is influenced by the material anisotropy, physical non-linearity, crimp interchange, hysteresis, removal of yarn spacing and changes in temperature. Different material models were studied, focusing on an orthotropic material model represented by a hyperelastic strain energy function. Also, different test protocols were reviewed and a series of biaxial tests on cruciform samples were performed at the Birdair, Inc.'s Research and Development Center. A strain energy function was adjusted to the collected data and than its results compared to the data itself and to another stress-strain function directly adjusted to the data. The performance of the strain-energy function chosen is not on a level of industrial application; however this study gives a global understanding of the PTFE coated fiberglass strain mechanism and also provides a consistent database that may be used on real situations.

Keywords: Experimental analysis; stress-strain relationship; hyperelastic material; glass-PTFE 


\section{LISTA DE ILUSTRAÇÕES}

Figura 1.1 Seção transversal dos tecidos 16

$\begin{array}{lll}\text { Figura 1.2 Troca de Ondulações (Crimp Interchange) } & 17\end{array}$

$\begin{array}{lll}\text { Figura 2.1 } & \text { Etapa de fiação na produção do tecido arquitetônico. } & 18\end{array}$

Figura 2.2 Diferentes camadas que o tecido arquitetônico recoberto pode possuir 19

Figura 2.3 Etapa do processo de recobrimento do tecido de fibra de vidro 23

Figura 2.4 Gráfico $\sigma-\varepsilon$, em uma amostra cruciforme, com razão $\sigma_{u}: \sigma_{t}=1: 1 \quad 26$

Figura 2.5 Gráfico $\sigma-\varepsilon$ (trama) em uma amostra cruciforme, com razão de carregamento (1:2) 27

Figura 2.6 Gráfico tensão-tempo (a) e $\sigma$ - $\varepsilon$ na trama (b), com razão de carregamento

Figura 2.7 Gráfico $\sigma-\varepsilon$ do primeiro ciclo de carregamento em um tecido

PTFE-vidro

32

Figura 2.8 Gráfico $\tau$ - $\gamma$ em tecidos entrelaçados

Figura 3.1 Suferfícies $\varepsilon_{\mathrm{u}} \times\left(\sigma_{\mathrm{u}}, \sigma_{\mathrm{t}}\right)(\mathrm{a})$ e $\varepsilon_{\mathrm{t}} \times\left(\sigma_{\mathrm{u}}, \sigma_{\mathrm{t}}\right)(\mathrm{b})$, geradas por interpolação. 37

$\begin{array}{lll}\text { Figura } 3.2 & \text { Modelo material reticulado } & 40\end{array}$

Figura 3.3 Modelo material combinado 41

$\begin{array}{lll}\text { Figura 4.1 } & \text { Equipamento para ensaios uniaxiais } & 48\end{array}$

Figura 4.2 Equipamento para ensaio biaxial cilíndrico 50

Figura 4.3 Equipamento de ensaio biaxial de tração utilizado neste trabalho 51

Figura 4.4 Amostra ranhurada em formato de cruz $\quad 55$

Figura 4.5 Preparação das amostras 56

Figura 4.6 Distorção entre os fios e curvatura dos fios 57

Figura 4.7 Detalhe da agarra de fixação com a amostra de tecido não solicitada e amostra instalada no equipamento para o ensaio 58

$\begin{array}{lll}\text { Figura 4.8 Razões de carregamento utilizadas nos ensaios } & 60\end{array}$

$\begin{array}{lll}\text { Figura } 4.9 & \text { Seqüência de carregamento no Tempo } & 61\end{array}$ 
Figura 5.1 Gráfico Tensão $\left(\sigma_{u}, \sigma_{t}\right) \times$ Deformação $\left(\varepsilon_{u}, \varepsilon_{t}\right)$, na razão $\left(\sigma_{u}: \sigma_{t}\right)=(1: 1)$

Figura 5.2 Gráfico Tensão $\left(\sigma_{u}, \sigma_{t}\right) \times$ Deformação $\left(\varepsilon_{u}, \varepsilon_{t}\right)$, na razão $\left(\sigma_{u}: \sigma_{t}\right)=(2: 1)$

Figura 5.3 Gráfico Tensão $\left(\sigma_{u}, \sigma_{t}\right) \times$ Deformação $\left(\varepsilon_{u}, \varepsilon_{t}\right)$, na razão

$\left(\sigma_{u}: \sigma_{t}\right)=(1: 2)$

Figura 5.4 Gráfico Tensão $\left(\sigma_{u}, \sigma_{t}\right) \times$ Deformação $\left(\varepsilon_{u}, \varepsilon_{t}\right)$, na razão

$\left(\sigma_{u}: \sigma_{t}\right)=(3: 1)$

Figura 5.5 Gráfico Tensão $\left(\sigma_{u}, \sigma_{t}\right) \times$ Deformação $\left(\varepsilon_{u}, \varepsilon_{t}\right)$, na razão $\left(\sigma_{u}: \sigma_{t}\right)=(1: 3)$ 66

Figura 5.6 Gráfico $S_{11} \times\left(E_{11}, E_{22}\right)$; Gráfico $S_{22} \times\left(E_{11}, E_{22}\right)$

Figura 5.7 Detalhe do Gráfico $S_{11} \times\left(E_{11}, E_{22}\right)$; Detalhe do gráfico $S_{22} \times\left(E_{11}, E_{22}\right)$

Figura 5.8 Dispersão dos pontos $\left(\sigma_{u}, \varepsilon_{u}, \varepsilon_{t}\right)$ (Dados de Campo) 73

Figura 5.9 Dispersão dos pontos $\left(\sigma_{t}, \varepsilon_{u}, \varepsilon_{t}\right)$ (Dados de Campo) 74

Figura 5.10 Comparação entre as dispersões de pontos $\left(\bar{\sigma}_{u}, \varepsilon_{u}, \varepsilon_{t}\right)$ gerados (linhas vermelhas) e de pontos $\left(\sigma_{u}, \varepsilon_{u}, \varepsilon_{t}\right)$ obtidos experimentalmente (pontos em azul), para a diversas razões de carregamento.

Figura 5.11 Comparação entre as dispersões de pontos $\left(\bar{\sigma}_{t}, \varepsilon_{u}, \varepsilon_{t}\right)$ gerados (linhasvermelhas) e de pontos $\left(\sigma_{t}, \varepsilon_{u}, \varepsilon_{t}\right)$ obtidos experimentalmente (pontos em azul), para a diversas razões de carregamento

Figura 5.12 Comparação entre as dispersões de pontos $\left(\overline{\bar{\sigma}}_{u}, \varepsilon_{u}, \varepsilon_{t}\right)$ gerados pelo ajuste direto (linhas azuis), $\left(\bar{\sigma}_{u}, \varepsilon_{u}, \varepsilon_{t}\right)$ gerados pelo ajuste do funcional (linhas vermelhas) e de pontos $\left(\sigma_{u}, \varepsilon_{u}, \varepsilon_{t}\right)$ obtidos experimentalmente (círculos), para a diversas razões de carregamento 78

Figura 5.13 Comparação entre as dispersões de pontos $\left(\overline{\bar{\sigma}}_{t}, \varepsilon_{u}, \varepsilon_{t}\right)$ gerados pelo ajuste direto (linhas azuis), $\left(\bar{\sigma}_{t}, \varepsilon_{u}, \varepsilon_{t}\right)$ gerados pelo ajuste do funcional (linhas vermelhas) e de pontos $\left(\sigma_{t}, \varepsilon_{u}, \varepsilon_{t}\right)$ obtidos experimentalmente (círculos), para a diversas razões de carregamento 
Figura 5.14 Gráficos $\sigma_{u}-\varepsilon_{u}, \bar{\sigma}_{u}-\varepsilon_{u}, \overline{\bar{\sigma}}_{u}-\varepsilon_{u}$ e $\sigma_{u}-\varepsilon_{t}, \bar{\sigma}_{u}-\varepsilon_{t}, \overline{\bar{\sigma}}_{u}-\varepsilon_{t}$, na razão $\left(\sigma_{u}: \sigma_{t}\right)=(1: 1)$

Figura 5.15 Gráficos $\sigma_{t}-\varepsilon_{u}, \bar{\sigma}_{t}-\varepsilon_{u}, \overline{\bar{\sigma}}_{t}-\varepsilon_{u}$ e $\sigma_{t}-\varepsilon_{t}, \bar{\sigma}_{t}-\varepsilon_{t}, \overline{\bar{\sigma}}_{t}-\varepsilon_{t}$, na razão $\left(\sigma_{u}: \sigma_{t}\right)=(1: 1)$

Figura 5.16 Gráficos $\sigma_{u}-\varepsilon_{u}, \bar{\sigma}_{u}-\varepsilon_{u}, \overline{\bar{\sigma}}_{u}-\varepsilon_{u}$ e $\sigma_{u}-\varepsilon_{t}, \bar{\sigma}_{u}-\varepsilon_{t}, \overline{\bar{\sigma}}_{u}-\varepsilon_{t}$, na razão $\left(\sigma_{u}: \sigma_{t}\right)=(2: 1)$

Figura 5.17 Gráficos $\sigma_{t}-\varepsilon_{u}, \bar{\sigma}_{t}-\varepsilon_{u}, \overline{\bar{\sigma}}_{t}-\varepsilon_{u}$ e $\sigma_{t}-\varepsilon_{t}, \bar{\sigma}_{t}-\varepsilon_{t}, \overline{\bar{\sigma}}_{t}-\varepsilon_{t}$, na razão $\left(\sigma_{u}: \sigma_{t}\right)=(2: 1)$

Figura 5.18 Gráficos $\sigma_{u}-\varepsilon_{u}, \bar{\sigma}_{u}-\varepsilon_{u}, \overline{\bar{\sigma}}_{u}-\varepsilon_{u}$ e $\sigma_{u}-\varepsilon_{t}, \bar{\sigma}_{u}-\varepsilon_{t}, \overline{\bar{\sigma}}_{u}-\varepsilon_{t}$, na razão $\left(\sigma_{u}: \sigma_{t}\right)=(1: 2)$

Figura 5.19 Gráficos $\sigma_{t}-\varepsilon_{u}, \bar{\sigma}_{t}-\varepsilon_{u}, \overline{\bar{\sigma}}_{t}-\varepsilon_{u}$ e $\sigma_{t}-\varepsilon_{t}, \bar{\sigma}_{t}-\varepsilon_{t}, \overline{\bar{\sigma}}_{t}-\varepsilon_{t}$, na razão $\left(\sigma_{u}: \sigma_{t}\right)=(1: 2)$

Figura 5.20 Gráficos $\sigma_{u}-\varepsilon_{u}, \bar{\sigma}_{u}-\varepsilon_{u}, \overline{\bar{\sigma}}_{u}-\varepsilon_{u}$ e $\sigma_{u}-\varepsilon_{t}, \bar{\sigma}_{u}-\varepsilon_{t}, \overline{\bar{\sigma}}_{u}-\varepsilon_{t}$, na razão $\left(\sigma_{u}: \sigma_{t}\right)=(3: 1)$

Figura 5.21 Gráficos $\sigma_{t}-\varepsilon_{u}, \bar{\sigma}_{t}-\varepsilon_{u}, \overline{\bar{\sigma}}_{t}-\varepsilon_{u}$ e $\sigma_{t}-\varepsilon_{t}, \bar{\sigma}_{t}-\varepsilon_{t}, \overline{\bar{\sigma}}_{t}-\varepsilon_{t}$, na razão $\left(\sigma_{u}: \sigma_{t}\right)=(3: 1)$

Figura 5.22 Gráficos $\sigma_{u}-\varepsilon_{u}, \bar{\sigma}_{u}-\varepsilon_{u}, \overline{\bar{\sigma}}_{u}-\varepsilon_{u}$ e $\sigma_{u}-\varepsilon_{t}, \bar{\sigma}_{u}-\varepsilon_{t}, \overline{\bar{\sigma}}_{u}-\varepsilon_{t}$, na razão $\left(\sigma_{u}: \sigma_{t}\right)=(1: 3)$

Figura 5.23 Gráficos $\sigma_{t}-\varepsilon_{u}, \bar{\sigma}_{t}-\varepsilon_{u}, \overline{\bar{\sigma}}_{t}-\varepsilon_{u}$ e $\sigma_{t}-\varepsilon_{t}, \bar{\sigma}_{t}-\varepsilon_{t}, \overline{\bar{\sigma}}_{t}-\varepsilon_{t}$, na razão $\left(\sigma_{u}: \sigma_{t}\right)=(1: 3)$ 


\section{LISTA DE TABELAS}

Tabela $1 \quad$ Valores médios das deformações $\left(\varepsilon_{u}\right.$ e $\left.\varepsilon_{t}\right) \quad 67$

Tabela 2 Valores de $\phi_{i}$ para o Funcional Energia de Deformação 71

Tabela 3 Valores de $\kappa_{j}$ para o Funcional de Ajuste Direto dos Dados de Campo 77 


\section{SUMÁRIO}

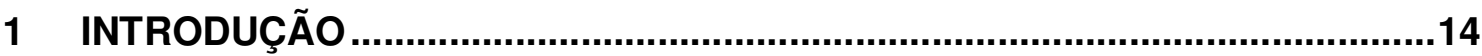

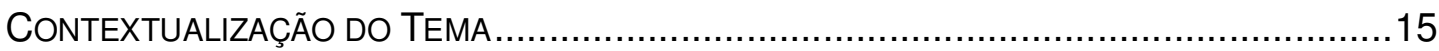

2 O TECIDO COMO ELEMENTO ESTRUTURAL.............................................18

2.1 O TECIDO DE FIBRA DE VIDRO RECOBERTO COM PTFE ................................21

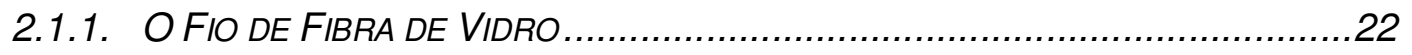

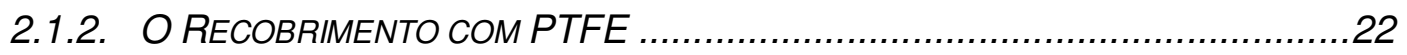

2.2 MECANISMOS de DEFORMAÇÃo do TECIDO PTFE-VIDRO .................................25

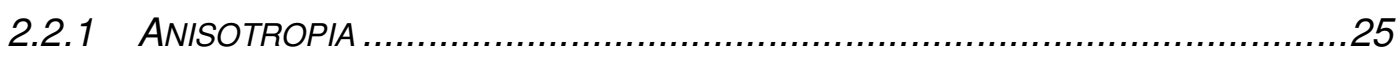

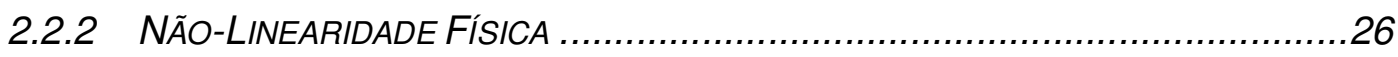

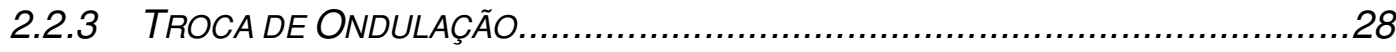

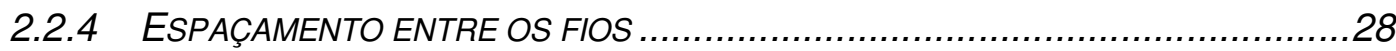

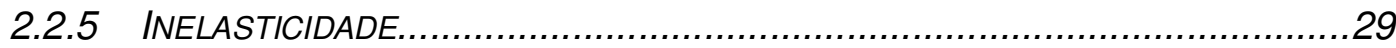

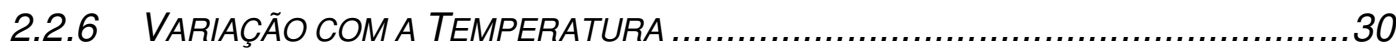

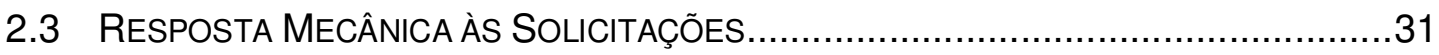

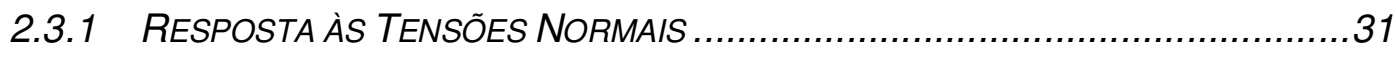

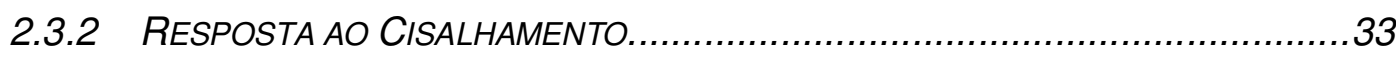

3 MODELAGEM DO MATERIAL PARA ANÁLISE ESTRUTURAL......................36

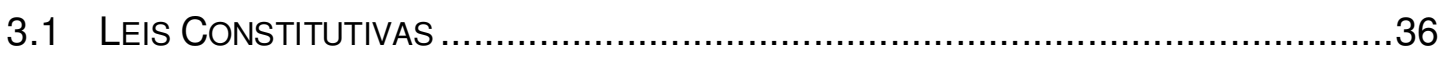

3.1.1 ModELAGEM DIRETA COM DOIS MóDULOS DE ELASTICIDADE.....................36

3.1.2 MODELAGEM COM LINEARIZAÇÃO PASSO A PASSO ...................................

3.1.3 MODELAGEM DIRETA DAS SUPERFÍCIES TENSÃO-DEFORMAÇÃO...................38

3.1.4 FUNÇÃO ENERGIA DE DEFORMAÇÃO ESPECÍFICA ...................................38

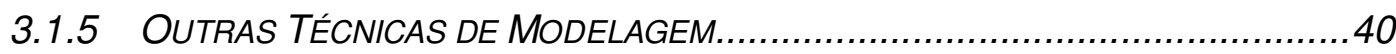

3.2 Material de Membrana Ortótropo para Representação do Tecido..........41

4 PROCEDIMENTO DE TESTE PARA DETERMINAÇÃO DAS RELAÇÕES TENSÃO - DEFORMAÇÃO DOS TECIDOS PTFE-VIDRO …...........................46

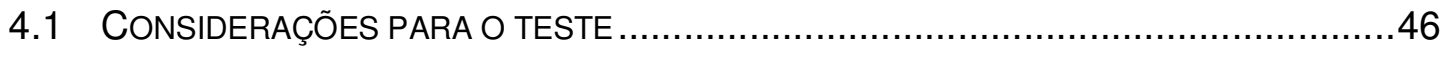

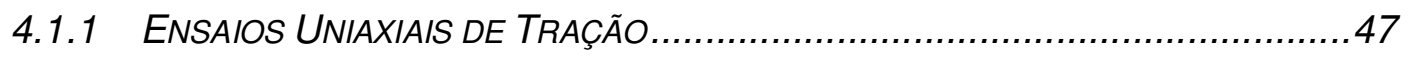




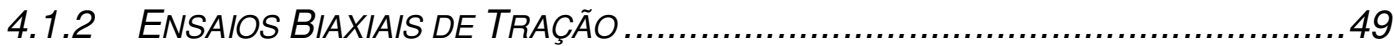

4.1.3 COMPORTAMENTO INICIAL E DE SERVIÇO...............................................51

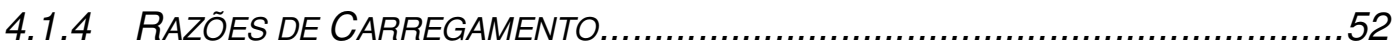

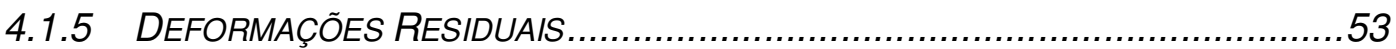

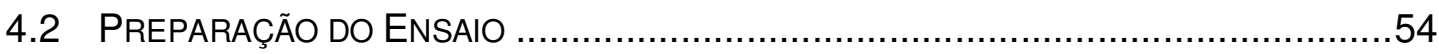

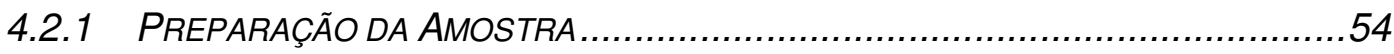

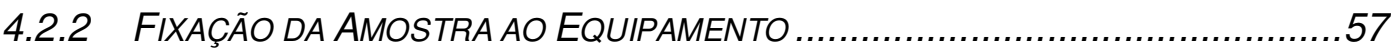

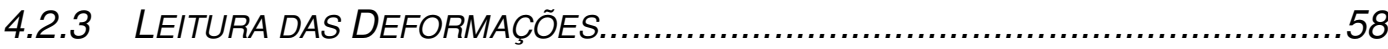

4.3 Procedimento PARA O ENSAIO BIAXIAL de TRAÇÃO .......................................5

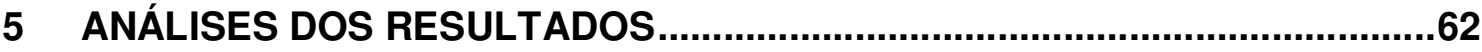

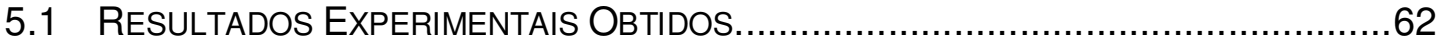

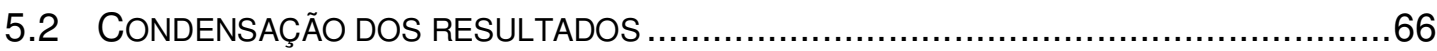

5.3 MÉtodo dos Mínimos Quadrados e o AJuste do Funcional ENERGIA de

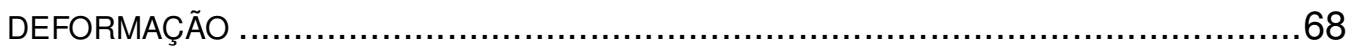

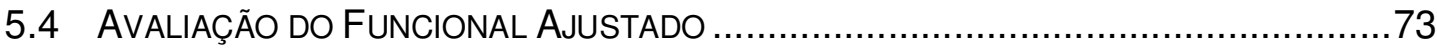

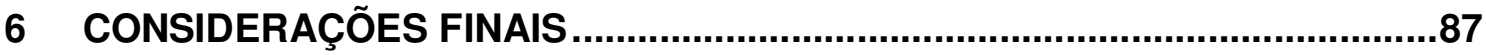

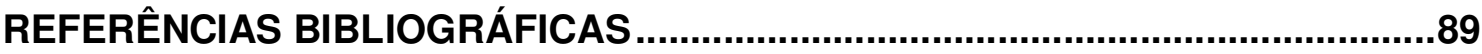




\section{INTRODUÇÃO}

Três características eram comuns às tendas tradicionais: portabilidade, mobilidade e baixo custo. Através da história, proprietários destas estruturas exploraram seu baixo peso e flexibilidade, transportando-as junto das manadas de animais que cuidavam ou procurando novos locais onde pudessem apresentar o entretenimento que ofereciam (como o caso dos circos ou parques temáticos). Quando as tendas se deterioravam devido ao uso excesivo ou umidade, o elemento de cobertura era substituido por novos couros ou tecidos e utilizados novamente.

Entretanto, nenhuma tecnologia construtiva evoluiu mais rapidamente nos últimos 30 anos do que as coberturas com tecidos tencionados. O conceito construtivo tipificado pelas formas rudimentares das tendas vem sendo substituido por uma crescente soma de estruturas que se enquadram entre os maiores vãos livres do mundo, atendendo também às mais exigentes solicitações arquitetônicas (HUNTINGTON, 2004). Estes avanços foram impulsionados em parte pelo desenvolvimento de técnicas de análise estrutural com auxílio de computadores, o que permite uma mais precisa busca da forma e previsão do comportamento da estrutura sob a ação das mais variadas situações de carregamento. Entretanto, a evolução dos tecidos estruturais encontra-se como a força motriz por traz dos grandes avanços em durabilidade, confiabilidade, translucência, segurança em termos de incêndios e uso sustentável de energia. Antes dos últimos cinqüenta anos, as pequenas resistências e durabilidade dos tecidos naturais limitavam tanto a amplitude dos vãos como a permanência das estruturas (PAULETTI, 2003).

Deste modo, este trabalho tem por objetivo principal estudar o comportamento mecânico do principal tecido arquitetônico recoberto empregado nas estruturas de membrana: o tecido de fibra de vidro recoberto com PTFE (politetrafluoretileno).

Para a concretização deste objetivo, algumas etapas específicas devem ser completadas, sendo elas: 
- Carcacterização geral dos tecidos arquitetônicos de fios de fibra de vidro recobertos com PTFE. Nesta caracterização incui-se: constituição das fases do material, etapas na construção do tecido e revisão bibliográfica das características físicas e mecânicas do material;

- Estudo de protocolos de ensaio biaxial de tração para obtensão das curvas tensão - deformação características.

- Obtensão das relações tensão - deformação do tecido PTFE-vidro submetido a diferentes solicitações, a partir dos ensaios de laboratório realizados;

- Análise e ajuste de um funcional energia de deformação para as curvas experimentais encontradas, em caráter de exemplo.

Vale ressaltar que poucos são os estudos de relevância sobre este tema no Brasil. Como referências podemos citar as contribuições de Pauletti (2003), Alvim (2003) e Oliveira (2006), tornando assim este trabalho uma potencial referência para desenvolvimento de projetos de estruturas com tecidos arquitetônicos recobertos no país.

\section{Contextualização do Tema}

Segundo Bridgens et al (2004), os tecidos entramados e recobertos - um dos tipos de tecidos arquitetônicos, são utilizados como elementos de fechamento e cobertura por serem leves - tipicamente com de 0,7 a $1,4 \mathrm{~kg} / \mathrm{m}^{2}$, translúcidos, mais baratos do que o vidro e apresentarem características de impermeabilidade. $O$ baixo peso específico destes materiais implica na adoção de estruturas metálicas de suporte mais leves, quando comparadas com as estruturas de suporte requeridas para uso de materiais convencionais, como as telhas metálicas. Estes materiais apresentam-se como solução não apenas para estruturas novas, mas também para instalações de coberturas em edifícios existentes - que poderiam não suportar a carga adicional advinda de, por exemplo, uma cobertura de vidro. 
Atualmente no mercado, dois são os tipos principais de tecidos arquitetônicos recobertos: a malha de fios de fibra de vidro recoberta com PTFE (politetrafluoretileno, comercialmente reconhecido como Teflon ${ }^{\circledR}$ ) e a malha de fios de poliéster recoberta com PVC (cloreto de polivinila). Ambos os materiais são compostos de uma rede ortogonal de fios com um recobrimento que protege o tecido em ambos o lados. A figura 1 apresenta a seção transversal dos tecidos em discussão.

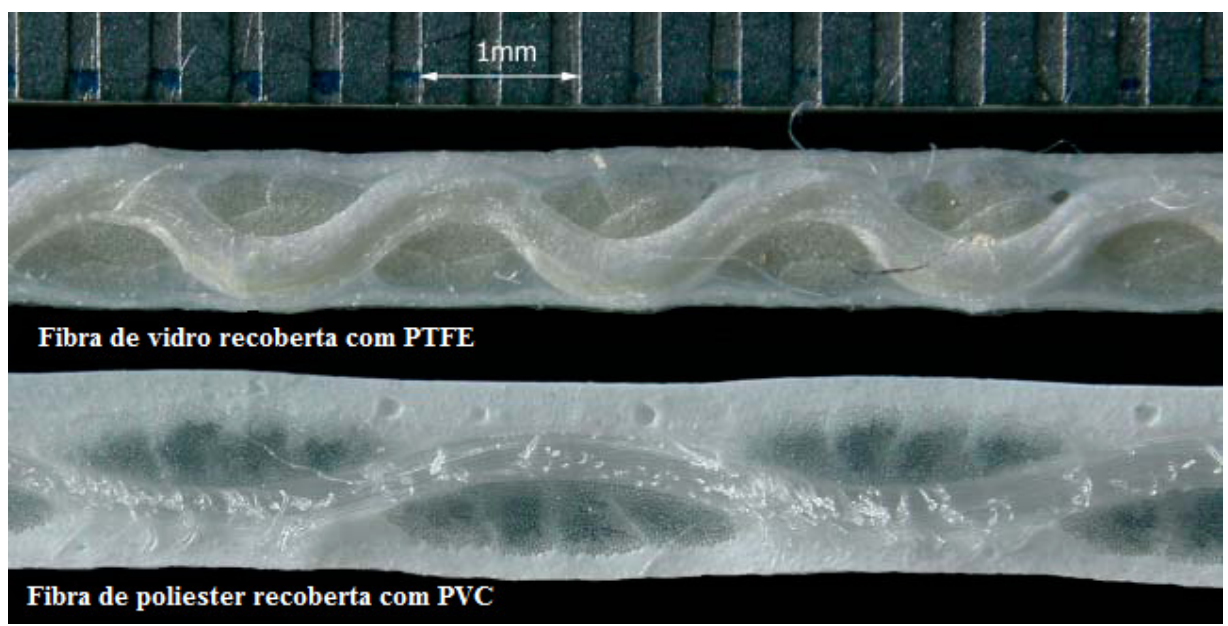

Figura 1.1 - Seção transversal dos tecidos.

Fonte: Adaptado de (BRIDGENS et al, 2004).

Embora estes dois tipos de tecidos possuam características diferentes, seus mecanismos fundamentais de deformação são similares. Sob a ação de um carregamento biaxial de tração, o comportamento dos tecidos recobertos é altamente não-linear e anisotrópico (SKELTON, 1980), (TAN et al, 1980), (BLUM, 2000) e (PAULETTI, 2003). A não-linearidade do material evidencia-se pelas características de deformação de ambas as fibras e seus respectivos recobrimentos. A não-linearidade geométrica ocorre nos fios devido à complexa estrutura de entrelaçamento das fibras e no tecido acabado, devido aos efeitos de acomodação dos fios na malha (sob ação de carregamento), como a remoção dos espaços livres entre os fios e à troca de ondulações (figura 1.2). Este último efeito é caracterizado pela interação entre as fibras ortogonais da trama e do urdume, implicando basicamente em um comportamento tensão-deformação não-linear. Um tecido virgem possui um alto nível de ondulação na direção da trama e um baixo nível na direção do urdume (Figura 1.2a). Um carregamento aplicado na direção da trama 
implica em um alinhamento das fibras da trama e conseqüente aumento das ondulações do urdume (Figura 1.2b). No caso de um carregamento biaxial, a relação entre os carregamentos é quem determinará a configuração final das ondulações. Este tema será melhor explorado no decorrer do trabalho.

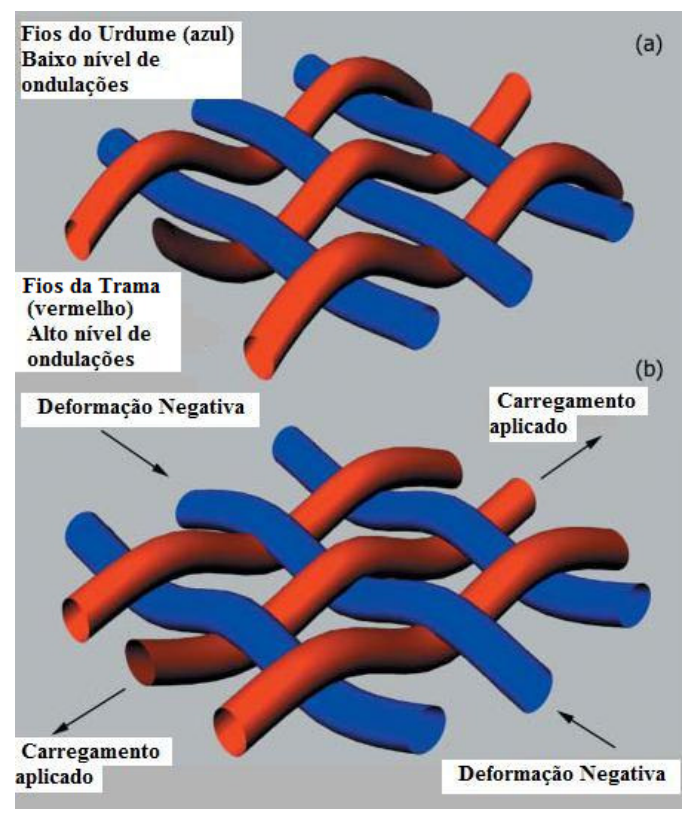

Figura 1.2 - Troca de Ondulações (Crimp Interchange). Fonte: Adaptado de Bridgens, Gosling e Birchall (2004). 


\section{O TECIDO COMO ELEMENTO ESTRUTURAL}

As características físicas e mecânicas dos tecidos estruturais são fundamentais para garantir sua aplicabilidade e sucesso no mercado da construção. Basicamente, o tecido estrutural é constituído por uma malha, na qual fibras ou fios são entrelaçados ortogonalmente, de modo a criar uma rede resistente o bastante para suportar carregamentos. Sobre estes fios, uma camada de recobrimento pode ser aplicada, visando estanqueidade e proteção contra o intemperismo - e conseqüente durabilidade. A resistência dos tecidos recobertos é definida basicamente pela resistência de suas fibras constitutivas. As características de outros tecidos arquitetônicos, como os tecidos construídos com urdume inserido (weft-inserted fabrics), tecidos laminados e filmes estruturais são variantes deste conceito geral. A figura 2.1 apresenta a etapa de fiação, no processo de produção de um tecido arquitetônico.

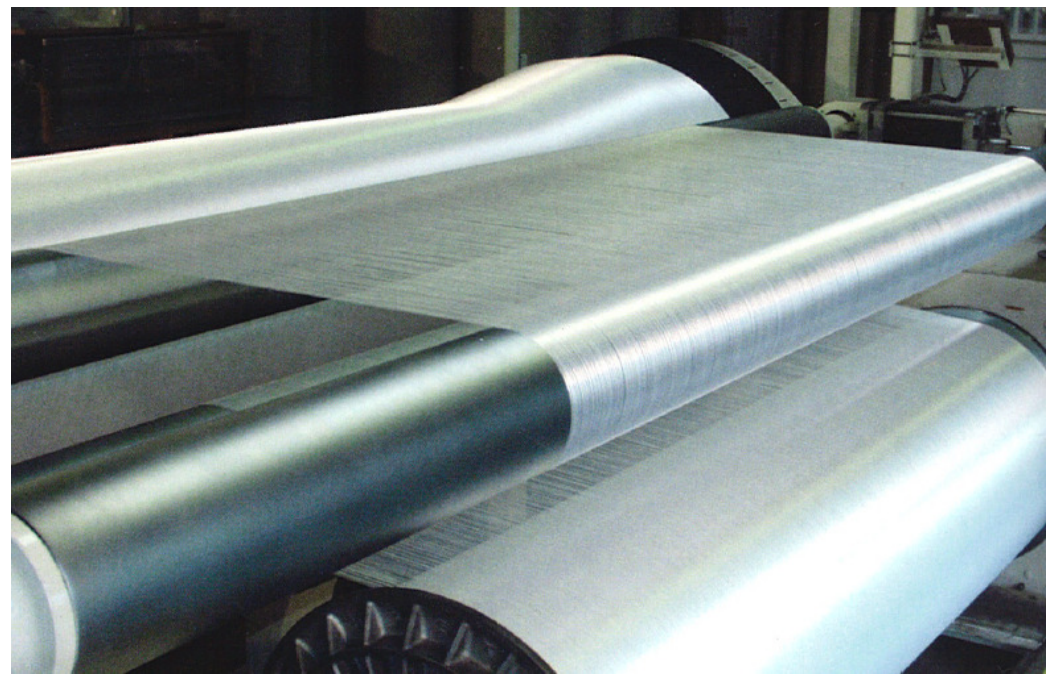

Figura 2.1 - Etapa de fiação na produção do tecido arquitetônico. Fonte: Adaptado de Pudenz (2004), p.50

Quando especificados para o uso externo, os tecidos não-recobertos possuem uma curta vida útil. O tecido é atacado pela ação das intempéries - como umidade e raios ultravioleta (UV), o que fisicamente degrada o material dos fios. Assim, o recobrimento do tecido traz alguns benefícios, como: 
a) Proteção para as fibras contra diferentes fontes de degradação - como os raios UV, a abrasão devido à ação dos ventos e as intempéries;

b) Resistência do conjunto contra a ação da chuva e da umidade atmosférica;

c) Auxilia na estabilização da geometria;

d) Permite ao material a possibilidade de solda a quente - dependendo do recobrimento.

Mais precisamente, o tecido arquitetônico é constituído de diferentes camadas de recobrimento combinadas com o tecido. Além do recobrimento primário, um recobrimento de topo e um tratamento superficial para vedação ou pintura podem também ser aplicados. A figura 2.2 apresenta estas possíveis camadas.

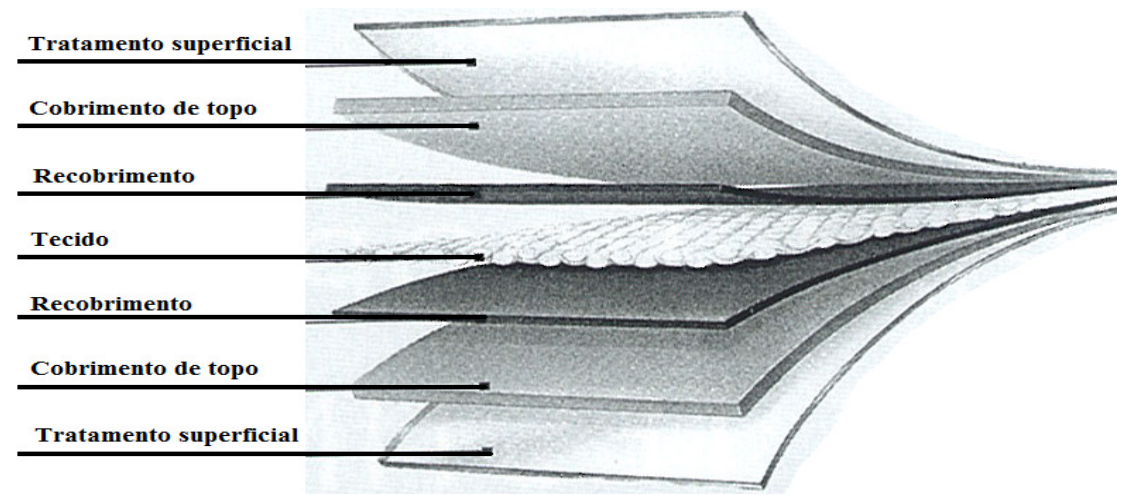

Figura 2.2 - Diferentes camadas que o tecido arquitetônico recoberto pode possuir. Fonte: Adaptado de Blum et al (2004), p.220

O recobrimento primário tem como função principal o preenchimento dos espaços entre os fios e a criação de uma camada física de proteção, a qual por sua vez é protegida por um recobrimento de topo, mais fino. No caso dos tecidos PVCPoliéster, esta camada de topo é quimicamente distinta da camada de recobrimento primário. Já no caso dos tecidos PTFE-Vidro, essa distinção não existe. A camada externa de tratamento superficial possui uma característica de natureza química específica, de modo a permitir a fusão e a solda de pedaços do tecido. Além disso, este tratamento pode possibilitar uma camada extra de proteção (como os recobrimentos em dióxido de titânio - $\mathrm{TiO}_{2}$ ) ou uma superfície para impressões de imagens dependendo da compatibilidade química dos componentes dessas camadas. 
Atualmente, os tecidos recobertos são os materiais mais utilizados para a execução de estruturas retesadas de responsabilidade. Dentre estes, dois tipos se destacam no campo da engenharia estrutural (BLUM, 2000), (PAULETTI, 2003), (HUNTINGTON, 2004):

a) Tecidos com fios de fibras de poliéster recobertas com PVC (polivinilclorido) - também conhecido pelo nome de tecido "PVC-Poliéster";

b) Tecidos com fios de fibras de vidro recobertas com PTFE (Politetrafluoretileno) - também conhecido pelo nome de tecido "PTFE-Vidro".

Como o foco deste trabalho encontra-se nos tecidos estruturais PTFE-vidro, a seguir é apresentada uma caracterização mais detalhada destes. Outros materiais, embora não abordados neste texto, também encontram uso em tensoestruturas. Dentre eles podemos destacar:

C) Tecidos com fios de fibras de vidro recobertas com silicone;

d) Tecidos com fios de fibras de PTFE recobertas com PTFE;

e) Filmes de ETFE (copolímero etileno-tetrafluoretileno).

Como se nota, mesmo nos dias de hoje, a variedade de materiais adequados para a construção de estruturas de membrana é restrita. Conforme apresentado por Pauletti (2003), a aplicabilidade de um material é limitada por uma série de fatores, como a resistência mecânica, a flexibilidade, a trabalhabilidade, a durabilidade e o custo. É difícil fazer comparações entre estes fatores, uma vez que os fabricantes tratam os dados sigilosamente. No entanto, pode-se afirmar que os tecidos de poliéster recobertos com PVC encontram-se entre os mais baratos, entretanto deterioram-se sob a ação dos raios ultravioleta. Por outro lado, os tecidos PTFE-vidro são quimicamente estáveis, resistentes às intempéries, a altas variações de temperatura, a altas tensões de tração, ao corte e à perfuração, sendo ainda capazes de serem dotados de diferentes graus de translucidez. Em contrapartida, estes tecidos são mais caros que os PVC-Poliéster e requerem maiores cuidados de manuseio. 


\subsection{O TECIDO de Fibra de VIDRO ReCoberto com PTFE}

O ano de 1969 foi um marco no desenvolvimento de tecidos arquitetônicos. Neste ano, a empresa DuPont, em parceria com as empresas Birdair, Chemfab e OwensCorning, desenvolveram o tecido de fibra de vidro recoberto com PTFE - conhecido também pelo seu nome comercial Teflon ${ }^{\circledR}$ (HUNTINGTON, 2004).

O PTFE é um polímero com características únicas que não são superadas por outros materiais atualmente conhecidos. Dentre estas características podemos ressaltar sua resistência química universal, sua estabilidade térmica, sua ampla gama de temperaturas de serviço, sua não-suscetibilidade ao ataque dos raios $\mathrm{UV}$, a ausência de envelhecimento sob ação de baixas temperaturas e seu comportamento não-pegajoso ao longo do tempo (DOBNIK, 2000). Tais características garantem a longevidade e a boa aparência da estrutura.

O PTFE não pode servir de recobrimento para fibras sintéticas, devido às altas temperaturas envolvidas no processo de sua aplicação ao tecido. Apenas fibras resistentes a tais condições podem ser utilizadas, como é o caso das fibras de vidro e, mais atualmente, as fibras de PTFE. Este trabalho trata apenas do tecido de fibra de vidro recoberto com PTFE.

As fibras de vidro apresentam resistência à tração da ordem de 3,5GPa, superior a muitos dos aços disponíveis, porém com peso 65\% inferior (HUNTINGTON, 2004), sendo também mais rígida que as demais fibras sintéticas

Embora o tecido de fibra de vidro recoberto com PTFE possua vantagens quando em comparação com outros tecidos arquitetônicos, seu custo, bem como sua suscetibilidade à danos decorrentes de repetidas montagens e desmontagens, excluem este material da aplicação em tendas portáteis de baixo custo. A seguir é apresentada uma descrição da composição e produção dos fios de fibra de vidro, bem como do PTFE utilizado em seu recobrimento. 


\subsubsection{O FIO DE FIBRA DE VIDRO}

Os filamentos de vidro para composição do fio do tecido arquitetônico são fornecidos em vários diâmetros, como 3, 6, 9 e 11 micra. A resistência unitária do filamento é fortemente dependente do seu diâmetro, uma vez que este determina a grandeza tanto dos defeitos superficiais quanto das tensões residuais nos filamentos. A distribuição das tensões residuais é decorrente do seu processo de produção: os filamentos de vidro são obtidos através de um processo de derretimento. Durante a posterior solidificação do fio, a camada externa esfria mais rapidamente que o núcleo. Após a solidificação, o núcleo continua resfriando mas sua contração é restrita pela camada externa. Conseqüentemente, o núcleo desenvolve tensões residuais de tração contrabalançadas por tensões de compressão na camada externa, reduzindo a presença de fissuras na camada externa.

O tipo de vidro utilizado para a construção dos fios para tecidos arquitetônicos é do tipo E-glass, com uma composição química de $53 \%$ a $54 \%$ de dióxido de silício $\left(\mathrm{SiO}_{2}\right), 14 \%$ a $15 \%$ de óxido de alumínio II $\left(\mathrm{Al}_{2} \mathrm{O}_{3}\right), 20 \%$ a $24 \%$ de Óxido de Cálcio $(\mathrm{CaO}), 6 \%$ a $9 \%$ de boro anidro $\left(\mathrm{B}_{2} \mathrm{O}_{3}\right)$ e óxido de magnésio (MgO) (BLUM et al, 2004).

O vidro é um material resistente à ação dos raios UV e à ação das intempéries e garante uma boa estabilidade dimensional. Por outro lado, os filamentos de vidro são sensíveis à umidade e suscetíveis a danos à sua superfície. Para garantir a proteção do tecido, as fibras são então recobertas. Além disso, o vidro perde resistência quando dobrado ou fletido, restringindo seu uso em estruturas que requeiram sucessivas montagens e desmontagens, como dito anteriormente.

\subsubsection{O RECOBRIMENTO COM PTFE}

Os tecidos de fibra de vidro são recobertos a partir de sua imersão em uma dispersão de PTFE. Uma secagem entre $350^{\circ} \mathrm{C}$ e $380^{\circ} \mathrm{C}$ dá o acabamento no 
processo de recobrimento. A figura 2.3 apresenta uma etapa do processo de recobrimento de tecido de fibra de vidro.

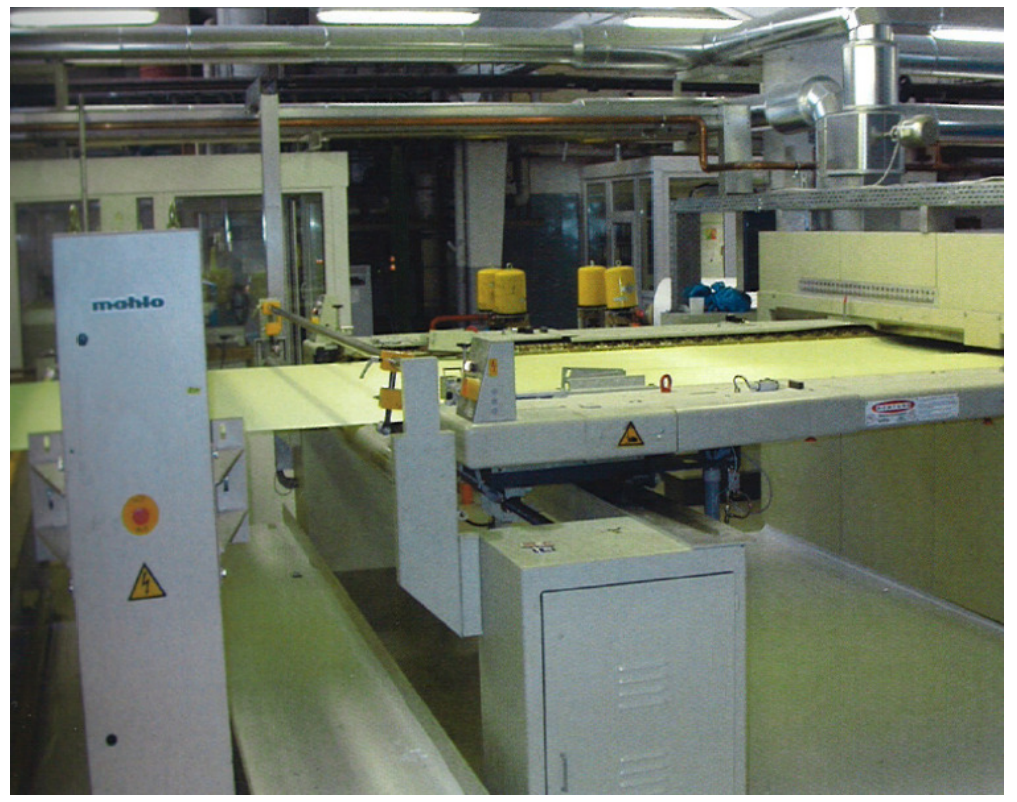

Figura 2.3 - Etapa do processo de recobrimento do tecido de fibra de vidro Fonte: Adaptado de Pudenz (2004), p.51

O PTFE é um polímero com propriedades singulares, que não consegue ser superado pela maioria dos demais polímeros. Estas propriedades são diretamente ligadas à estrutura molecular, caracterizada por longas cadeias de monômeros de tetrafluoretileno. As ligações flúor-carbono requerem uma energia de dissociação de $460 \mathrm{~kJ} / \mathrm{Mol}$, representando assim uma das mais fortes ligações encontradas na química orgânica. A cadeia de PTFE apresenta uma geometria em hélice levemente torcida com uma base em cadeia carbônica e ramificações externas com átomos de flúor - o que acaba por proteger a cadeia de ataques químicos.

Como o limite superior da temperatura de serviço contínuo do PTFE é de $260^{\circ} \mathrm{C}$, ele pode ser utilizado em zonas climáticas quentes. O limite inferior desta temperatura de serviço contínuo é de $-200^{\circ} \mathrm{C}$. Variações de temperatura dentro deste intervalo não afetam a vida útil do material. O PTFE também possui baixa condutividade térmica $(0,25-0,50 \mathrm{~W} / \mathrm{Km})$, o que garante características de isolamento térmico. 
O PTFE em condições normais não é inflamável. Ele apresentará condições de flamabilidade apenas em casos onde o ambiente contiver concentração de oxigênio superior a 95\%. Os tecidos recobertos com PTFE passam na maioria dos testes internacionais de inflamabilidade com excelentes resultados (BLUM et al, 2004). Estes testes são especificados nos seguintes documentos:

a) Normas americanas: ASTM E84 (Standard Test Method for Surface Burning: Characteristics of Building Materials), ASTM E108 (Standard Test Methods for Fire: Tests of Roof Coverings) e NFPA 701 (Standard Methods of Fire: Tests for Flame Propagation of Textiles and Films);

b) Normas britânicas: BS 476, Parte 3 (Fire Tests on Building Materials and Structures: Classification and Method of Test for External Fire Exposure to Roofs), Parte 5 (Method of Test for Ignitability), Parte 6 (Fire Tests on Building Materials and Structures: Method of Test for Fire Propagation for Products) e Parte 7 (Fire Tests on Building Materials and Structures: Method of Test to Determine the Classification of the Surface Spread of Flame of Products);

c) Norma francesa NF P 92-503 M1 (Teste com queimador elétrico);

d) Norma alemã DIN 4102 B1/A2 (Flamabilidade e Segurança

Além disso, o PTFE apresenta alta viscosidade quando derretido (1,0 kPa.s), o que previne a formação de goteiras de material derretido e quente em uma situação de incêndio.

O PTFE é resistente às substâncias corrosivas mais fortes, como o ácido hidroclorídrico, ácido fluorídrico, ácido sulfúrico, ácido nítrico, solução quente de hidróxido de sódio, hidrazina e óxidos de nitrogênio. O PTFE também não é solúvel pela maioria dos solventes comuns, tais como alcoóis e ésteres. Assim sendo, ele se demonstra inerte à maioria dos ataques de poluentes ambientais, tais como os gases emitidos por indústrias e veículos.

Suas moléculas são macroscopicamente não-polares. Sua energia superficial é uma das mais baixas conhecidas (aproximadamente $18,5 \mathrm{mN} / \mathrm{m}$ ), implicando na natureza anti-adesiva do PTFE. Assim sendo, os tecidos recobertos com PTFE apresentam propriedades auto-limpantes e hidrofóbicas. Essas propriedades hidrofóbicas do 
PTFE fazem dele uma escolha natural para recobrimento de tecidos de fibra de vidro, uma vez que estes perdem sua resistência à tração quando expostos à umidade.

O PTFE é totalmente resistente à radiação UV (ultravioleta) e IV (infravermelha), não apresentando características de envelhecimento ou ressecamento sob ação destes raios. Diferentemente do PVC, este desempenho é alcançado sem a necessidade de plastificantes, antioxidantes, bloqueadores-UV ou produtos similares que podem se degenerar com o tempo.

\subsection{MeCANISmos de DeformaÇão do TeCido PTFE-VIDro}

As propriedades mecânicas do tecido PTFE-vidro são completamente diferentes daquelas dos materiais de construção convencionais, como o aço e o concreto (BLUM, 2000). Este tipo de tecido recoberto apresenta características de anisotropia e não-linearidade física, além de outras que também serão discutidas a seguir.

\subsubsection{ANISOTROPIA}

A fiação dos tecidos que constituem as membranas é geralmente lançada segundo duas direções principais: o urdume e a trama. Desta construção resultam propriedades mecânicas anisotrópicas para a membrana - uma vez que seu comportamento dependerá da orientação dos esforços a que o conjunto fica sujeito, em relação às direções dos fios. A figura 2.4 apresenta um gráfico de curvas tensão normal $(\sigma-\mathrm{N} / \mathrm{cm})$ versus deformação linear ( $\varepsilon$ - \%), que ilustra esta afirmação. Este trabalho adotará a notação $\sigma-\varepsilon$ ao se referir a estas curvas. Este gráfico apresenta os resultados obtidos através de um ensaio biaxial em uma amostra cruciforme submetido a uma razão de carregamento $\sigma_{u}: \sigma_{t}=1: 1$. O termo razão de carregamento diz respeito a razão entre o carregamento aplicado na direção do urdume $\left(\sigma_{u}\right)$ e na direção da trama $\left(\sigma_{t}\right)$, respectivamente. Mais detalhes sobre o procedimento para realização deste ensaio é apresentado adiante no trabalho. 


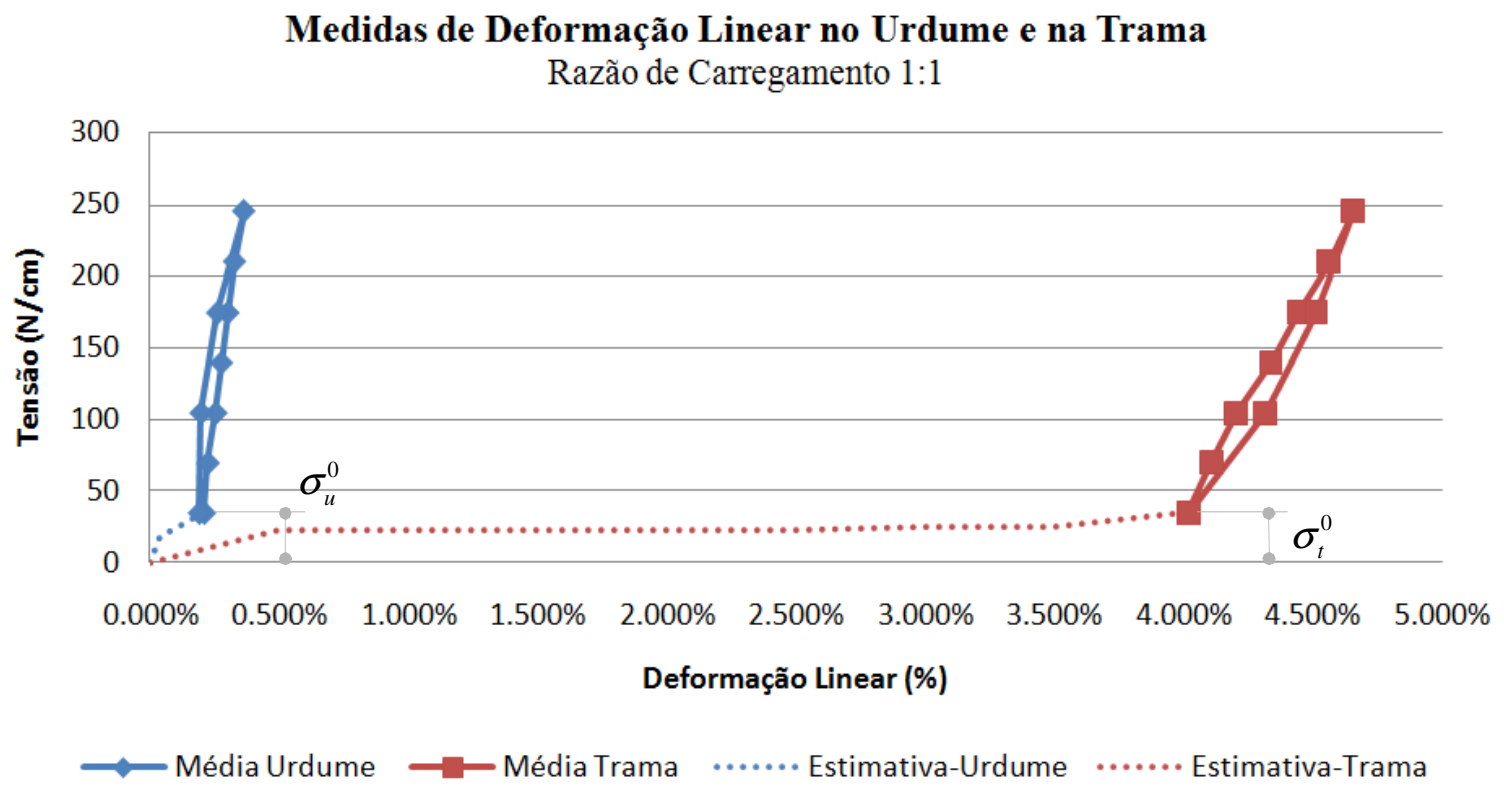

Figura 2.4 - Gráfico $\sigma-\varepsilon$, em uma amostra cruciforme, com razão $\sigma_{u}: \sigma_{t}=1: 1$

Fonte: Acervo Pessoal

Analisando o gráfico anterior pode-se notar que, como resultado da configuração específica do entrelaçamento do tecido, as características do material dependem de sua orientação. É importante observar que as curvas $\sigma-\varepsilon$ apresentadas dizem respeito à ciclos de carregamento e descarregamento na faixa de solicitações de 35 $\mathrm{N} / \mathrm{cm}$ a $245 \mathrm{~N} / \mathrm{cm}$, devido à algumas restrições intrínsecas ao procedimento de ensaio utilizado para obtenção dos dados. Desta maneira, as curvas $\sigma-\varepsilon$ não partem da origem dos eixos e sim de pontos $\sigma_{0}-\varepsilon_{0}$ distintos. Para o urdume, $\sigma_{0}=35 \mathrm{~N} / \mathrm{cm}$ e $\varepsilon_{0, \mathrm{u}}=0,21 \%$; para a trama, $\sigma_{0}=35 \mathrm{~N} / \mathrm{cm}$ e $\varepsilon_{0, \mathrm{t}}=4,02 \%$. Tomando por basea a literatura disponível, por exemplo Kato et al (1999), a figura 2.4 sugere, por meio de linhas pontilhadas, as excursões típicas das curvas $\sigma-\varepsilon$, desde a origem até os pontos $\sigma_{0}-\varepsilon_{0}$

\subsubsection{NÃO-LINEARIDADE FÍSICA}

O comportamento não-linear do tecido refere-se à relação tensão-deformação que este apresenta. Sendo os tecidos materiais compósitos nos quais as forças de tração são transferidas pelos fios do urdume e da trama, é usual definir-se uma 
tensão superficial nominal (em N/m), equivalente à somatória das forças aplicadas aos fios presentes em uma faixa de tecido de largura unitária. Neste trabalho, nos referiremos a esta tensão superfícial nominal simplesmente por "tensão" $(\sigma)$.

A deformação linear é caracterizada pela razão entre o alongamento (ou encurtamento) do tecido, devido à solicitação atuante, medida em relação a um comprimento inicial de referência. Neste trabalho, nos referiremos a esta deformação linear simplesmente por "deformação" $(\varepsilon)$.

Em materiais lineares, um aumento da tensão no material corresponde a um aumento proporcional da deformação. No caso dos tecidos PTFE-vidro, esta relação é não-linear. A figura 2.5 ilustra esta afirmação.

\section{Medidlas de Deformação Linear na Trama}

Razão de Carregamento 1:2

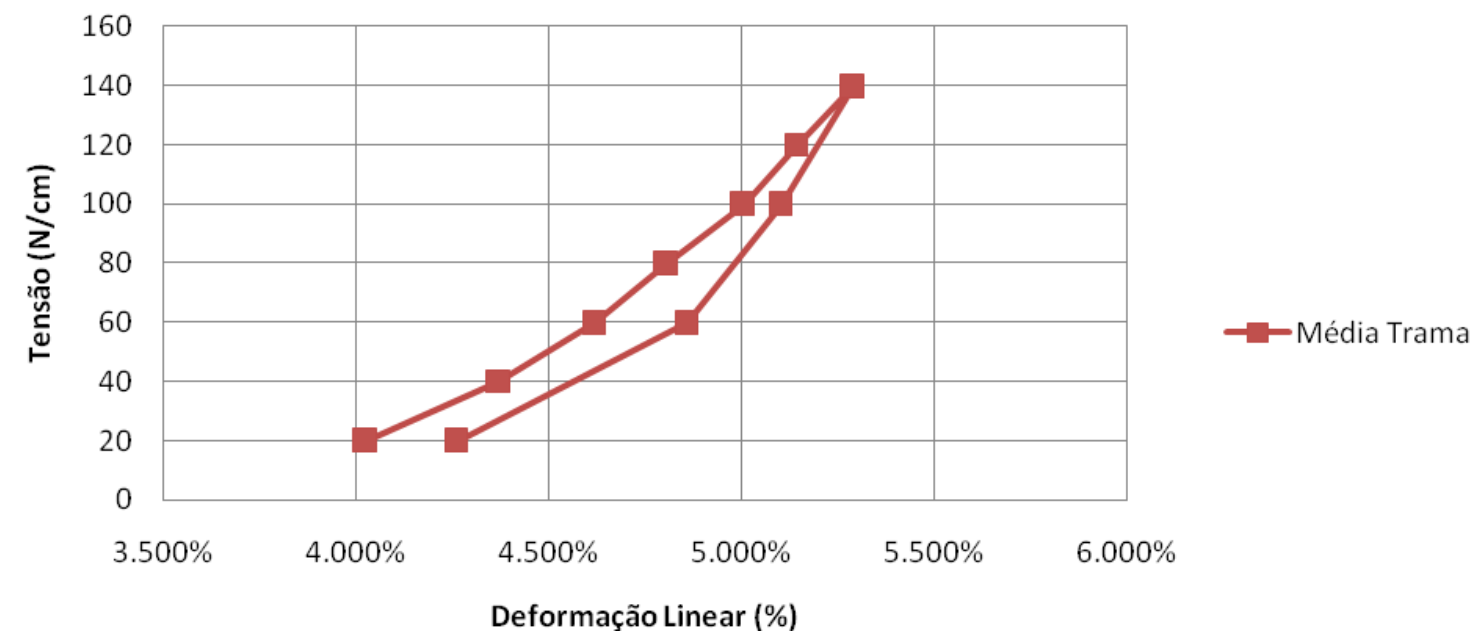

Figura 2.5 - Gráfico $\sigma-\varepsilon$ (trama) em uma amostra cruciforme, com razão de carregamento (1:2) Fonte: Acervo Pessoal

No gráfico, temos a relação $\sigma-\varepsilon$ na direção da trama, obtida através de um ensaio biaxial em uma amostra cruciforme, com razão de carregamento de (1:2). Como podemos notar, um aumento linear da tensão não representa um aumento proporcional na deformação. 


\subsubsection{TROCA DE ONDULAÇÃO}

Durante o processo de fiação do tecido, os fios do urdume são mantidos retos, retesados por rolos tratores, e os fios da trama são passados alternadamente por cima e por baixo de cada fio do urdume, apresentando portanto uma ondulação mais acentuada que estes últimos, que porém também acabam por ondular-se, em menor grau, como efeito da interação com os primeiros. Quando o tecido é solicitado, esta interação se torna mais pronunciada, com a trama tendendo a retificar-se adicionalmente, enquanto aumenta a ondulação do urdume (PAULETTI, 2003).

Como se nota, o efeito acima descrito não diz respeito às propriedades físicas do material, mas sim à uma variação geométrica chamada de troca de ondulação (crimp interchange). As condições de ondulação dos fios influenciam as propriedades mecânicas macroscópicas do tecido estrutural.

Além disso, em uma situação de solicitação do tecido, durante o intervalo de tempo enquanto o urdume e a trama progressivamente acomodam suas ondulações, a resina de recobrimento afeta a relação tensão-deformação do material, que passa a apresentar um comportamento macroscopicamente viscoelástico (MSAJ/M-021995). Contudo, este mecanismo somente é relevante nas fases iniciais de retesamento do tecido, enquanto os fios do urdume e da trama ainda buscam acomodar-se, ficando portanto fora da faixa de trabalho de interesse para o presente estudo.

\subsubsection{ESPAÇAMENTO ENTRE OS FIOS}

Também devido ao processo de fiação do tecido, cria-se um espaçamento entre os fios. Este espaçamento, embora preenchido pelo material de recobrimento, acaba sendo removido parcial ou totalmente quando o tecido é solicitado. Trata-se de um fenômeno complicado, que ocorre simultaneamente à troca de entrelaçamento e à deformação dos fios e do recobrimento, sendo difícil quantificar as frações da deformação total que corespondem a cada um destes mecanismos. Por esta razão, 
é usual simplificar o problema adotando-se relações nominais entre as tensões aplicadas e as deformações totais resultantes.

\subsubsection{INELASTICIDADE}

Quando um material com comportamento elástico é carregado e em seguida descarregado, o caminho de descarregamento coincide com o de carregamento. Deste modo, o material não apresenta hiterese e sua deformação residual é nula.

Por outro lado, tecidos estruturais apresentam características inelásticas. O caminho de descarregamento não coincide com o de carregamento. Assim, após um ciclo de carga, o tecido apresenta uma deformação residual permanente. Quando ciclos de carregamentos são repetidos, a deformação residual adicional diminui, até que um máximo de deformação permanente é alcançado (ASSELT, 2007). Mesmo assim, o tecido pode ainda apresentar histerese, isto é, os caminhos de carregamento e descarregamento continuam não coincidindo e o material dissipa energia a cada ciclo de carga.

Novamente, este fenômeno não atua isoladamente, mas simultaneamente aos demais fenômenos descritos anteriormente, o que torna difícil sua visualização isolada. A figura 2.6 ilustra a resposta inelástica da direção da trama do tecido PTFE-vidro, quando solicitado a um carregamento cíclico, para uma razão de carregamento constante $(1: 1)$.

A partir dos resultados apresentados na figura 2.6, podemos concluir que o comportamento do tecido é afetado tanto por efeitos de plasticidade como de histerese. Nota-se que o tecido apresenta uma significativa deformação plástica (residual) no primeiro ciclo de carregamento, incrementada por quantidades consideravelmente menores nos sucessivos ciclos, e tentendo a um valor estável após um certo número de ciclos. 


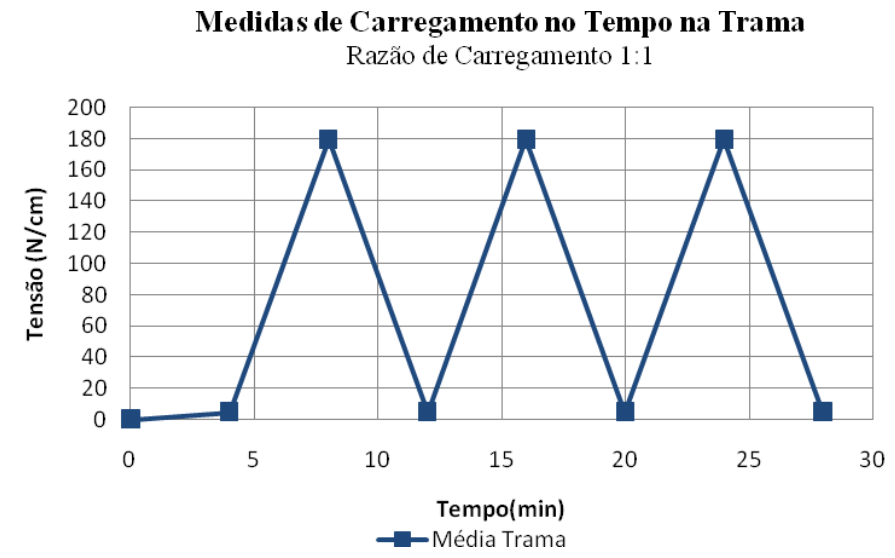

(a)

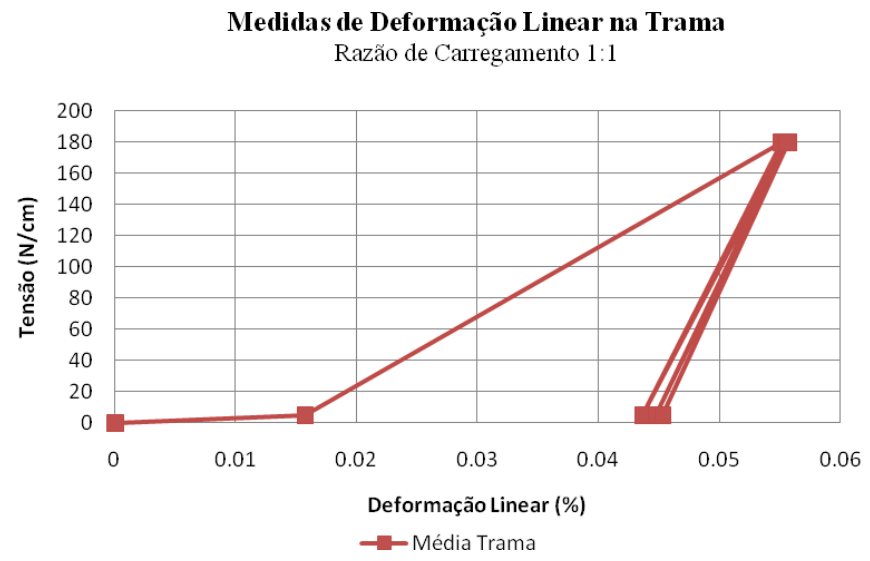

(b)

Figura 2.6 - Gráfico tensão-tempo (a) e $\sigma-\varepsilon$ na trama (b), com razão de carregamento (1:1) Fonte: Acervo Pessoal

Assim sendo, no caso de ensaios para determinação de constantes do material, os ciclos de carregamentos repetidos inicialmente - denominados de condicionamento do material, são adotados no intuito de minimizar a influência destes efeitos nos resultados dos ensaios, a partir dos quais se buscam definir as propriedades mecânicas médias do tecido, necessárias para a prática do projeto.

\subsubsection{VARIAÇÃO COM A TEMPERATURA}

A resina polimérica de PTFE que recobre o tecido possui um intervalo de temperatura de serviço que varia de $-200^{\circ} \mathrm{C}$ a $260^{\circ} \mathrm{C}$ (BLUM et al, 2004). Isto garante que mesmo em baixas temperaturas o PTFE mantém suas características de flexibilidade. Em contra partida, as características mecânicas de outros materiais 
de recobrimento e fibras sintéticas em geral são afetadas pela variação da temperatura ambiente. Como exemplo, testes com tecidos PVC-Poliéster em intervalos de temperatura de $20^{\circ} \mathrm{C}$ a $30^{\circ} \mathrm{C}$, apresentaram uma diferença de aproximadamente $7 \%$ em sua rigidez à tração. O mesmo teste realizado em tecidos PTFE-vidro não apresentou diferenças significativas em função da variação de temperatura (MSAJ/M-02-1995). Este trabalho apresentará resultados obtidos em ensaios a uma temperatura ambiente de $20 \pm 2^{\circ} \mathrm{C}$, conforme indicado pela (MSAJ/M02-1995).

\subsection{Resposta MECÂNICA Às SOLICIT AÇÕES}

A resposta mecânica de uma membrana recoberta submetida a uma solicitação biaxial pode ser entendida como a combinação da resposta dos fios do urdume e da trama sujeitos às forças normais, com a resposta do material de recobrimento sujeito à esforços normais e de cisalhamento. Contudo, o material de recobrimento possui uma rigidez muito menor que a dos fios, de modo que a sua resposta aos esforços normais é, em geral, desprezada e sua resposta ao cisalhamento pode ser considerada desacoplada da resposta dos fios (PARGANA et al, 2007). A resposta final biaxial pode ser então entendida como a sobreposição destes dois efeitos. $A$ seguir estes dois estados de tensão em tecidos PTFE-vidro são discutidos.

\subsubsection{RESPOSTA Às TENSÕES NORMAIS}

Um exemplo de resposta de uma membrana PTFE-vidro sujeita à tensões normais de tração aplicadas diretamente nas direções principais é apresentado na figura 2.7, que apresenta apenas o primeiro ciclo de carregamento e descarregameto de uma amostra. Embora as respostas ao segundo e ao terceiro ciclo de carregamento não estejam representadas nesta figura, estes ciclos de carregamento seguem aproximadamente o caminho de descarregamento do primeiro ciclo, apresentando pequena histerese. 


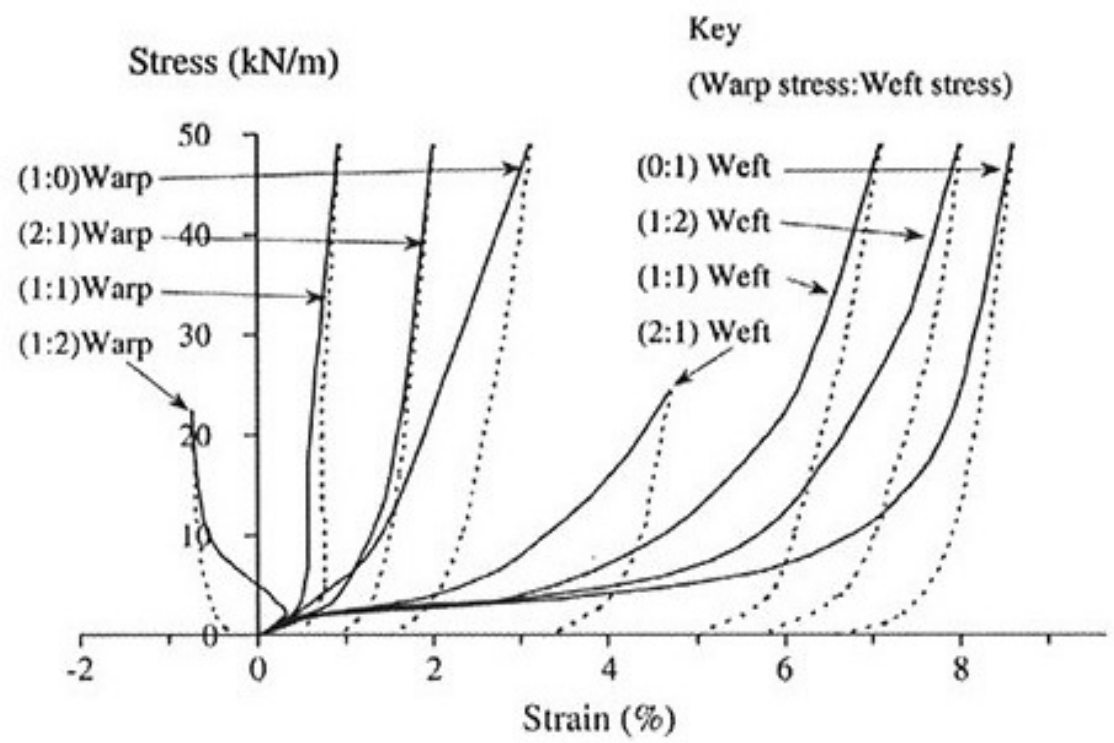

Figura 2.7 - Gráfico $\sigma$ - $\varepsilon$ do primeiro ciclo de carregamento em um tecido PTFE-vidro (warp $=$ urdume; weft $=$ trama $)$

Fonte: Kato et al (1999)

Analisando as curvas tensão-deformação apresentadas na figura 2.7, percebe-se que o tecido PTFE-vidro apresenta claramente as características citadas por Bradshaw (1996):

- Existe uma diferença no comportamento mecânico entre as direções da trama e do urdume;

- A resposta da membrana é influenciada pela razão de carregamento nas duas direções;

- A membrana não retorna à sua configuração inicial após o primeiro carregamento;

- As respostas nas direções da trama e do urdume são não-lineares.

Estas características decorrem da combinação de diferentes mecanismos de deformação, como discutido no item 2.2. Este comportamento sob ação de forças normais será abordado com mais detalhes ao longo deste trabalho.

Além destas características, quando o tecido é submetido a tensões normais, há uma tendência de diminuição do diâmetro do fio. Estudos sobre o que fisicamente ocorre nos pontos de cruzamento de fios nos tecidos indica que a redução do diâmetro do fio (ou seu achatamento) é causado pelo efeito conjunto da força de 
esmagamento com a força normal atuante. Este efeito encontra-se descrito com mais detalhes no trabalho de Ansell et al (1983).

\subsubsection{REsposta aO Cisalhamento}

Tecidos entrelaçados planos e não-recobertos são capazes de se adequar a diferentes superfícies de dupla curvatura basicamente por distorção ou seja, o tecido se ajusta a uma dada geometria transformando a geometria inicialmente retangular de sua malha para uma geometria rombiforme (MACK e TAYLOR, 1956). $\mathrm{Na}$ ausência de atrito, rigidez de flexão dos fios ou intertravamento entre os mesmos, não haveria resistência a esta deformação. Na prática, mesmo tecidos não recobertos apresentam rigidez à distorção como se pode notar na figura 2.8, que apresenta a resposta característica de um tecido entrelaçado não recoberto, conforme apresentado por Skelton (1979 apud PARGANA et al, 2007). O gráfico apresenta a relação tensão de cisalhamento $(\tau)$ versus deformação angular $(\gamma)$.

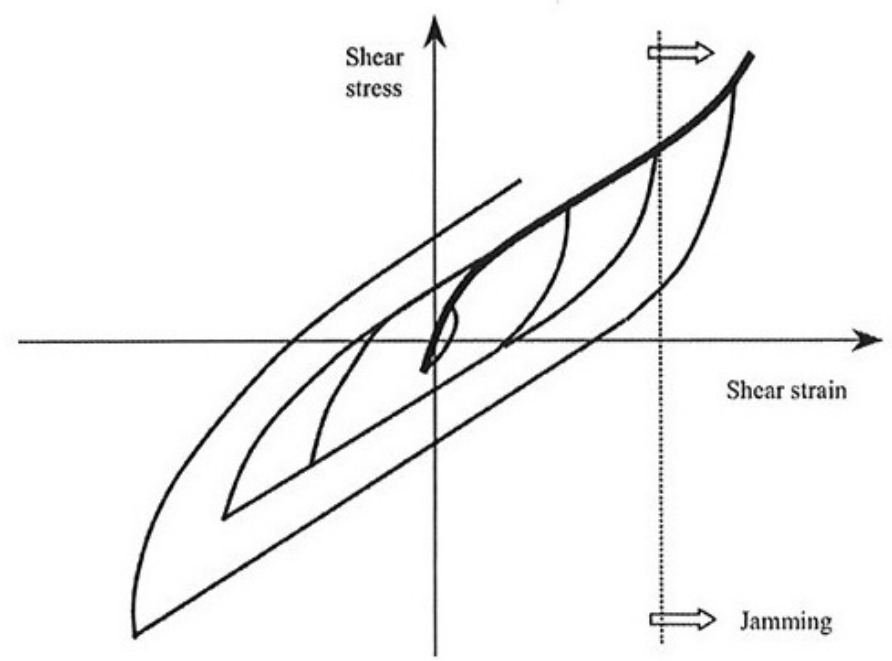

Figura 2.8 - Gráfico $\tau-\gamma$ em tecidos entrelaçados Fonte: SKELTON (1979) apud PARGANA et al (2007)

Considerando as regiões da curva próximas ao estado inicial e próximas aos pontos de reversão de tensão e deformação, temos que o atrito tende a restringir a rotação entre os fios nos cruzamentos da malha. Conforme o atrito é superado nos muitos pontos adjacentes de contato entre os fios, o tecido macroscopicamente apresenta 
uma curva $\tau-\gamma$ típica da elastoplaticidade, com progressiva perda de rigidez. Por outro lado, os fios começam a se curvar entre pontos adjacentes de contato, passando a solicitar sua rigidez à flexão. Ao se generalizar o escorregamento entre os fios, a rigidez do tecido se torna constante, proporcional à rigidez à flexão dos fios, basicamente elástica.

Finalmente, com o aumento das distorções, começa a ocorrer o intertravamento (jamming) entre os fios, ou seja, fios adjacentes entram em contato uns com os outros e travam o fio transversal entre eles. Este fenômeno se reflete macroscopicamente num efeito de ulterior enrigencimento do tecido à distorção, também denominado "Rigidez ao cisalhamento pós-travamento" (post jamming shear stiffness). Foi analiticamente provado por SKELTON (1979 apud PARGANA et al 2007) que o ângulo no qual este travamento ocorre está relacionado à razão entre o diâmetro do fio e o espaçamento entre eles. Quanto maior esta razão, menor a deformação de cisalhamento onde ocorre este travamento.

Em tecidos recobertos, como é o caso do tecido PTFE-vidro, o recobrimento contribui diretamente na rigidez ao cisalhamento do material, por sua própria natureza, e também por confinar o movimento dos fios em adição ao seu intertravamento. O trabalho de Kato et al (1999) apresenta resultados relativos ao ensaio de amostras de tecido PTFE-vidro submetidas a diversos modos de deformação - inclusive de deformações de cisalhamento, propondo um modelo reticulado composto de barras e molas, capaz de qualitativamente reproduzir os resultados experimentais com uma aproximação satisfatória. Uma observação dos resultados de Kato para amostras de tecido PTFE-vidro, submetidas a níveis máximos de distorção entre 0.02 rad e 0.09 rad, indica um decréscimo de rigidez ao cisalhamento para valores crescentes de distorção.

Embora o estudo da resposta de tecidos recobertos ao cisalhamento seja importante para o completo entendimento do comportamento deste tipo de material, o presente trabalho se concentra no exame de estados biaxiais de solicitação normal, com as direções principais de esforços alinhadas às direções do urdume e da trama. Tal limitação de escopo se justifica, em parte, pela intenção de se empregar os dados experimentais obtidos para calibrar um funcional que presupõe o desacoplamento 
entre a energia de deformação por estiramento daquela devida à distorção. Desta maneira, entende-se que o estudo mais detalhado da resposta ao cisalhamento também pode ser feito, de modo independente, em futuros trabalhos. Além das referências aqui citadas, protocolos internacionais de ensaio de cisalhamento (como a MSAJ/M-01-1993) podem ser utilizados no intuito de se obter resultados experimentais.

Além da hipótese do desacoplamento entre os efeitos de estiramento e distorção, contribui para a restrição de escopo adotado neste trabalho o fato do processo de produção de estruturas de membrana envolver técnicas de padronagem às quais procuram, justamente, minimizar tanto as deformações lineares quanto as distorções a que o tecido é submetido durante o seu retesamento. 


\section{MODELAGEM DO MATERIAL PARA ANÁLISE ESTRUTURAL}

Um modelo matemático que descreve as idéias de comportamento de um material é chamado de lei constitutiva. Conforme afirma (DESAI e SIRIWARDANE, 1984), a principal vantagem do estabelecimento de uma lei constitutiva é a possibilidade do encontro de uma solução quantitativa para os problemas. Porém, a qualidade do modelo depende de como o fenômeno físico foi entendido e simulado. Além disso, é difícil estabelecer uma equação constitutiva geral para descrever todas as possibilidades de comportamento do material e, sendo assim, é necesário confinar as considerações a interesses específicos.

\subsection{LeIS Constitutivas}

A seguir são apresentadas algumas ténicas de modelagem das constante de engenharia de tecidos estruturais.

\subsubsection{ModeLAGEM DIRETA COM DoIs Módulos DE ELASTICIDADE}

Uma representação primitiva para o material de membrana é feita a partir da definição de dois módulos de elásticidade (um para cada direção principal) e um ou dois coeficientes de Poisson. Neste caso, os módulos de elasticidade são obtidos a partir de módulos secantes da curva tensão-deformação, em ambas as direções.

Este modelo pode ser aceitável em situações onde se conhece com algum grau de certeza a faixa de solicitação a que a membrana será submetida, seja em termos de intensidade, seja em termos de proporcionalidade dos esforços aplicados nas direções da trama e do urdume. As propriedades mecânicas macroscopicas do tecido decorrem de interações complexas entre o urdume e a trama, associadas à efeitos como a troca de ondulações e a remoção das folgas, redundando macroscopicamente em relações não-lineares fortemente dependentes da razão 
entre os carregamentos nas direções do urdume e da trama. Assim, para cada faixa de solicitação, diferentes módulos secantes e coeficientes de Poisson podem ser definidos, de sorte que esta representação, embora encontre uso freqüente nas práticas de projeto, claramente não é a mais adequada para a análise de uma estrutura de tecidos PTFE-vidro, sujeitas à uma multiplicidade de carregamentos a que uma estrutura deste tipo pode ser submetida ao longo de sua vida útil, conforme reconhecem Bridgens (2004) e Nederpelt (2004).

\subsubsection{MOdELAGEM COM LINEARIZAÇÃo PASSO A PASSO}

Em seu trabalho, Minami et al (1986) testaram um tecido sob diferentes razões de carregamento. Com base em seus resultados, foram produzidas duas superfícies não-analítcas, colocando as deformações no urdume e na trama em função das tensões em ambas as direções. Estas superfícies, as quais neste trabalho nos referiremos por " $\varepsilon_{u} \times\left(\sigma_{u}, \sigma_{t}\right)$ " e " $\varepsilon_{t} \times\left(\sigma_{u}, \sigma_{t}\right)$ ", não foram represenatdas analiticamente, mas sim por interpolação bilinear de pontos $\left(\varepsilon_{\mathrm{u}}, \sigma_{\mathrm{u}}, \sigma_{\mathrm{t}}\right)$ ou $\left(\varepsilon_{\mathrm{t}}, \sigma_{\mathrm{u}}, \sigma_{\mathrm{t}}\right)$ adjacentes. Desta maneira, para cada região, podem ser definidos diferentes módulos de elasticidade tangentes representativos e pontos $\left(\varepsilon_{\mathrm{u}}, \sigma_{\mathrm{u}}, \sigma_{\mathrm{t}}\right)$ ou $\left(\varepsilon_{\mathrm{t}}, \sigma_{\mathrm{u}}, \sigma_{\mathrm{t}}\right)$ podem ser obtidos por interpolação. A figura 3.1 apresenta estas superfícies.
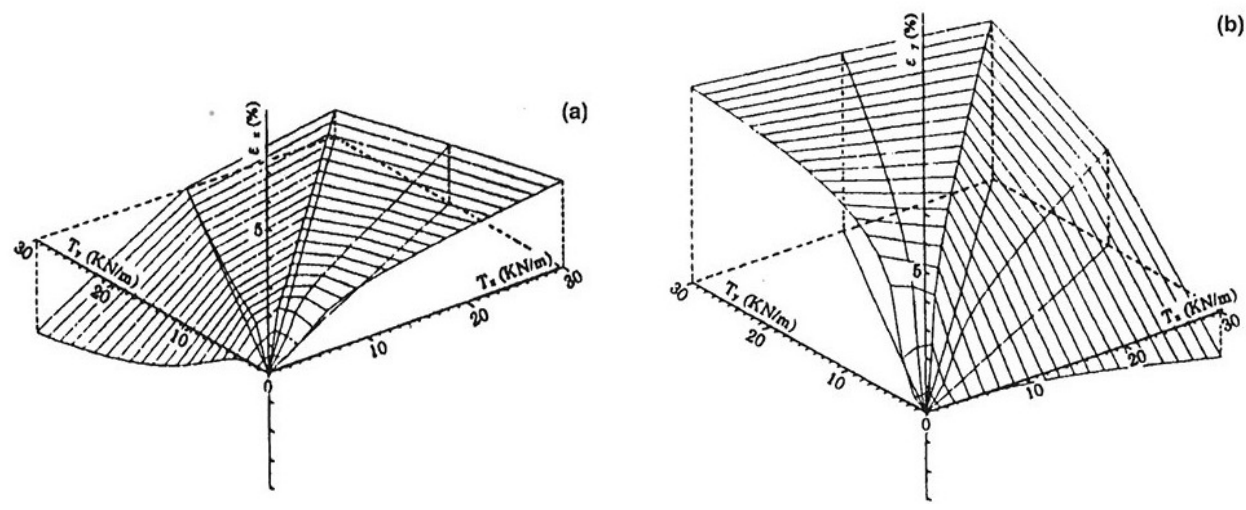

Figura 3.1 - Suferfícies $\varepsilon_{\mathrm{u}} \times\left(\sigma_{\mathrm{u}}, \sigma_{\mathrm{t}}\right)(\mathrm{a})$ e $\varepsilon_{\mathrm{t}} \times\left(\sigma_{\mathrm{u}}, \sigma_{\mathrm{t}}\right)(\mathrm{b})$, geradas por interpolação. Fonte: Minami et al (1986)

Tal modelo representa uma aproximação mais precisa do comportamento do tecido retesado do que o modelo anterior. Por outro lado, o recurso de linearização pode 
requerer um grande número de pontos de amostragem para se atingir suficiente precisão.

\subsubsection{MODELAGEM DIRETA DAS SUPERFíCIES TENSÃO-DEFORMAÇÃO}

Uma outra técnica para representação do comportamento do tecido encontra-se baseada na técnica anterior (item 3.1.2). Porém, ao invés de linearizar os dados obtidos em ensaios biaxiais, um ajuste direto de uma curva suave pode ser feito, com uso de diferentes técnicas de aproximação. Esse processo foi o adotado por Asselt (2007). Em seu trabalho, inversamente a Minami et al (1986), foram geradas superfícies $\sigma_{\mathrm{u}} \times\left(\varepsilon_{\mathrm{u}}, \varepsilon_{\mathrm{t}}\right)$ e $\sigma_{\mathrm{t}} \times\left(\varepsilon_{\mathrm{u}}, \varepsilon_{\mathrm{t}}\right)$, descrevendo a variação das tensões em relação às deformações.

De posse destas superfícies, Asselt (2007) construiu um modelo de elementos finitos no programa Ansys em que um material não-linear é representado com seus resultados. Embora seja uma modelagem mais sintética e prática do que a de Minami et al (1986), esta é ainda uma abordagem empírica dos resultados, que não garante que o material siga um modelo reológico conhecido, com características definidas. Uma solução para este questionamento encontra-se na adoção de um modelo reológico compatível com o comportamento do material. Esta abordagem é apresentada a seguir.

\subsubsection{FUNÇÃo ENERGIA DE DEFORMAÇÃO ESPECÍFICA}

Atualmente existe um grande esforço no intuito de se desenvolver modelos analíticos e numéricos capazes de reproduzir o comportamento das membranas, como alternativa à imposição de expressões de base empírica. Nesta linha de estudo, temos a teoria para a definição do funcional energia de deformação para materiais de membrana ortótropa, com base nos trabalhos de Pimenta (1993), Pauletti e Pimenta (2002), Campelo, Pimenta \& Wriggers (2003) e Oliveira(2006). 
Os materiais hiperelástico, ou elásticos de Green, possibilitam grandes deformações e postulam a existência de uma função energia livre de Helmholtz $\psi$, que é definida por unidade de volume de referência ou por unidade de massa. Quando $\psi$ é apenas função do gradiente das deformações ou de outro tensor das deformações, a função energia livre de Helmholtz é chamada de função energia de deformação específica [HOLZAPFEL, 2000 apud OLIVEIRA, 2006].

Sendo um material hiperelástico descrito pela função $\psi=\psi(\mathbf{E})$, o segundo tensor das tensões de Piola-Kirchhoff é então obtido por:

$$
\mathbf{S}=\frac{\partial \psi}{\partial \mathbf{E}}
$$

sendo $\mathbf{E}$ o tensor das deformações de Green-Lagrange.

Podemos perceber então que a relação entre tensões e deformações pode ser obtida pela definição de uma função $\psi$ apropriada. Temos também que em materiais homogêneos, a distribuição dos constituintes internos é assumida uniforme numa escala contínua. Sendo assim, a expressão de $\psi$ depende apenas do tensor das deformações e não da posição do ponto no sólido. Isso não acontece no caso de materiais heterogêneos (quando $\psi$ depende também da posição do ponto no sólido) e de materiais anisótropos (onde a função $\psi$ depende dos vetores que representam as direções consideradas).

Com base nesta teoria, o item 3.3 apresenta um modelo de material de membrana hiperelástico e ortótropo para representação do tecido PTFE-vidro. No Capítulo 5, este modelo é calibrado com base nos resultados dos ensaios biaxiais realizados neste trabalho.

Deve-se mencionar que, conforme apresentado em Pimenta (1993), a partir da equação (3.1), um material hiperelástico é necessariamente elástico e reversível. Além disso, um material hiperelástico é dito conservativo pois, em um ciclo de de deformações, a função energia de deformação volta ao seu valor inicial, se conservando. Deste modo mostra-se que em materiais como as membranas 
arquitetônicas de PTFE-vidro é importante o condicionamento inicial da amostra antes da realização do ensaio biaxial, de modo a se minimizar os efeitos de plasticidade e histerese. Com este cuidado, temos que o comportamento do material pode se aproximar das condições espressas pela equação (3.1).

\subsubsection{OUTRAS TÉCNICAS DE MODELAGEM}

Outras técnicas de modelagem que também vem se desenvolvendo levam em consideração não apenas as características físicas dos materiais envolvidos, mas procuram incorporar os mecanismos de deformação atuantes no material.

Como exemplo podemos citar o modelo apresentado por Kato et al (1999), onde o tecido recoberto é modelado por um sistema reticulado trapezoidal, representativo da interação dos fios entre si e com o recobrimento, conforme apresenta a figura 3.2. Para calibrar seu modelo, uma série de ensaios biaxiais de tração e de cisalhamento em tecido são realizados. Como resultado, as curvas tensão-deformação geradas são aderentes aos resultados de campo, salvo algumas localizadas discrepâncias.

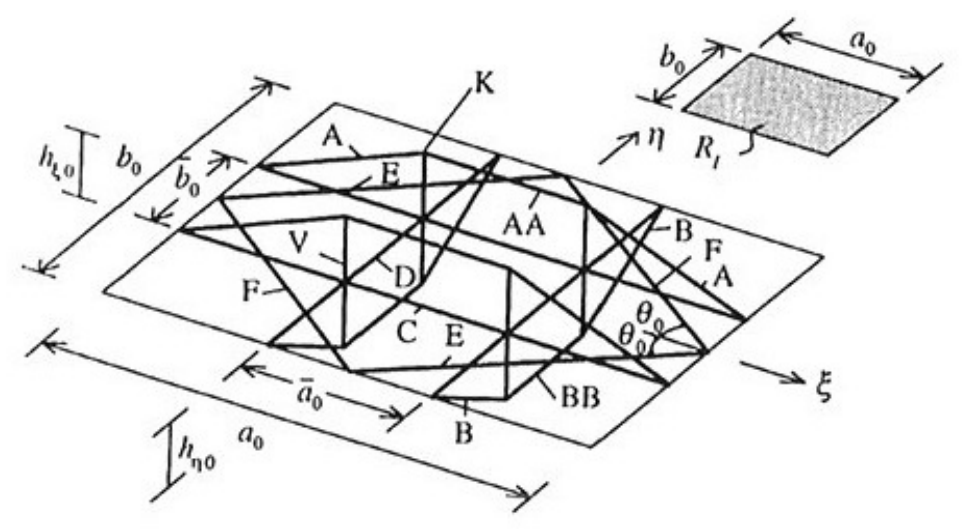

Figura 3.2 - Modelo material reticulado Fonte: Kato et al (1999)

Outro modelo material desenvolvido para representar o tecido PTFE-vidro, e que pode ser utilizado como exemplo, foi desenvolvido por Pargana et al (2006). Seu modelo material combinado representa o tecido utilizando uma série de elementos elásticos não-lineares e de atrito associados a elementos rígidos para representar os 
fios e uma placa isotrópica para representar o recobrimento. A Figura 3.3 apresenta este modelo. Seu modelo também foi calibrado com dados de campo. Como resultado, Pargana obtém um modelo material com alta capacidade de precisão, principalmente devido ao cuidado tido na modelagem dos mecanismos preponderantes de deformação que influenciam o comportamento do material (como a troca de ondulações, as deformações nos fios e seus travamentos, as deformações no recobrimento e o atrito. Esta linha de modelagem do material PTFEvidro, embora tenha se mostrado eficiente, não se encontra como o foco deste trabalho.

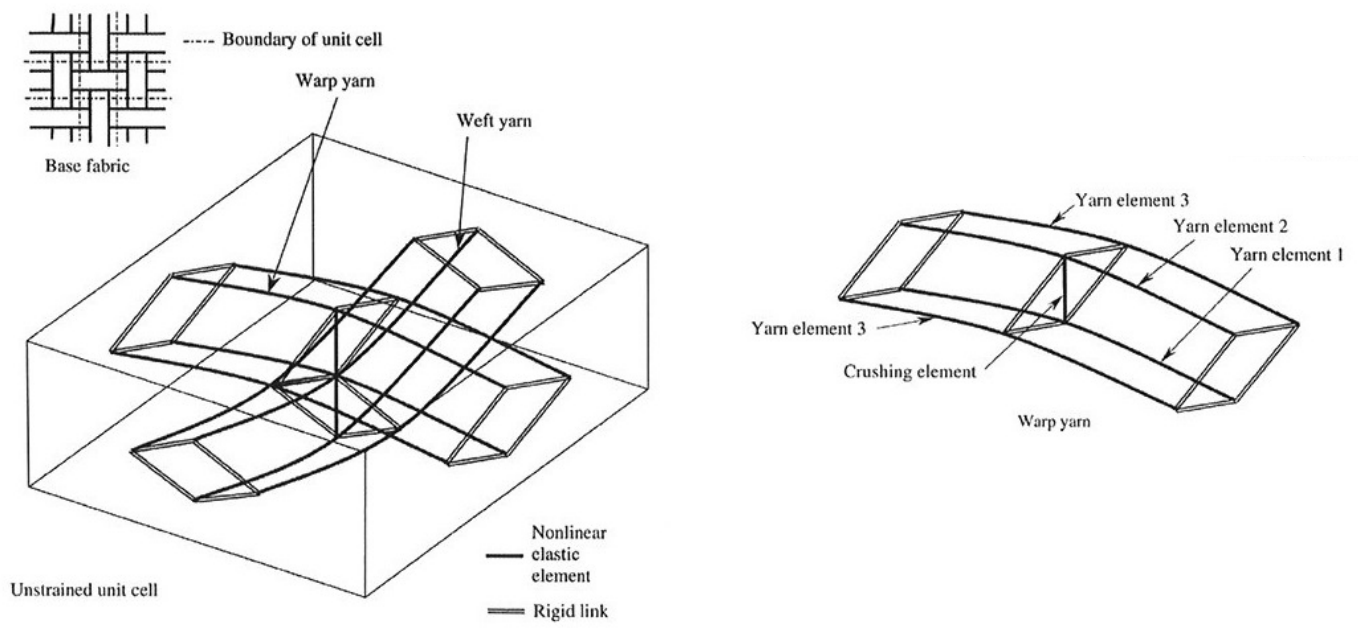

Figura 3.3 - Modelo material combinado Fonte: Pargana et al (2006)

\subsection{Material de Membrana Ortótropo para Representação do Tecido}

Conforme apresentado em Pimenta (1993) e Pauletti e Pimenta (2002) a equação constitutiva elástica pode ser expressa pela função energia de deformação específica $\psi(\mathbf{E})$, de tal modo que a equação (3.1) seja obedecida. Esta equação deve cuidar para que seja possível uma protensão inicial e para que o enrugamento ou encurtamento em uma direção esteja adequadamente descrito. Além disso, como visto, também a consideração da ortotropia é importante para a boa representação do comportamento mecânico do tecido (PAULETTI e PIMENTA, 2002). 
Uma grandeza relevante para o estudo é o tensor dos módulos hiperelásticos de rigidez tangente:

$$
\mathbf{D}=\frac{\partial^{2} \psi}{\partial \mathbf{E}^{2}}
$$

o qual descreve as propriedades inerentes ao material.

No intuito de se considerar a ortotropia no modelo material hiperelástico, a função energia de deformação específica deve ser uma fução ortótropa do tensor das deformações. Como em sua configuração inicial as membranas são planas, podemos particularizar as propriedades dos materiais hiperelásticos para o caso bidimensional, ao se colocar a membrana em sua configuração de referência no plano. Deste modo, adota-se $\mathbf{m}_{1}^{r}$ e $\mathbf{m}_{2}^{r},\left(\mathbf{m}_{1}^{r} \cdot \mathbf{m}_{2}^{r}\right)=0$, como as direções locais da ortotropia na configuração de referência. As direções da trama e do urdume do tecido da membrana são escolhas naturais para estas direções locais ortogonais. Assim, definindo os tensores:

$$
\mathbf{M}_{i}=\mathbf{m}_{i} \otimes \mathbf{m}_{i}
$$

uma membrana elástica ortótropa tem a sua energia de deformação descrita por $\psi\left(\mathbf{I}_{k i}\right)$, onde:

$$
\mathrm{I}_{k i}=\mathbf{M}_{i}: \mathbf{E}^{k}
$$

e sendo i, $k=1,2, \mathbf{I}_{\mathrm{ki}}$ representa o invariante $(\mathrm{k})$ na direção (i).

Considerou-se que $\mathbf{M}_{1}, \mathbf{M}_{2}$ e $\mathbf{E}$ são dados no sistema local da ortotropia por:

$$
\mathbf{M}_{1}=\left[\begin{array}{ll}
1 & 0 \\
0 & 0
\end{array}\right] \quad ; \quad \mathbf{M}_{2}=\left[\begin{array}{ll}
0 & 0 \\
0 & 1
\end{array}\right] \quad ; \quad \mathbf{E}=\left[\begin{array}{ll}
E_{11} & E_{12} \\
E_{12} & E_{22}
\end{array}\right]
$$

onde $E_{11}, E_{12}$ e $E_{22}$ são termos do tensor das deformações de Green que podem ser obtidos por: 


$$
\mathbf{E}=\frac{1}{2}\left(\mathbf{F}^{T} \mathbf{F}-\mathbf{I}\right)
$$

onde $\mathbf{F}=\frac{\partial \mathbf{x}}{\partial \mathbf{X}}$ é o gradiente das deformações (PIMENTA, 1993).

Assim, os invariantes $I_{k i}$ podem ser escritos como:

$$
\begin{aligned}
& I_{11}=\mathbf{E}_{11} \\
& I_{12}=\mathbf{E}_{22} \\
& I_{21}=\mathbf{E}_{11}^{2}+\mathbf{E}_{12}^{2} \\
& I_{22}=\mathbf{E}_{22}^{2}+\mathbf{E}_{12}^{2}
\end{aligned}
$$

A partir destas considerações, e com a ajuda de:

$$
\begin{aligned}
& \frac{\partial I_{1 i}}{\partial \mathbf{E}}=\mathbf{M}_{i} \\
& \frac{\partial I_{2 i}}{\partial \mathbf{E}}=\mathbf{M}_{i} \mathbf{E}+\mathbf{E M}_{i}
\end{aligned}
$$

os termos do segundo tensor das tensões de Piola-Kirchhoff podem então ser apresentados como:

$$
\mathbf{S}=\sum_{k=1}^{2} \sum_{i=1}^{2} \frac{\partial \psi}{\partial I_{k i}} \frac{\partial I_{k i}}{\partial \mathbf{E}}=\sum_{i=1}^{2}\left[\frac{\partial \psi}{\partial I_{1 i}} \mathbf{M}_{i}+\frac{\partial \psi}{\partial I_{2 i}}\left(\mathbf{M}_{i} \mathbf{E}+\mathbf{E} \mathbf{M}_{i}\right)\right]
$$

Conforme discutido no capítulo anterior (item 2.3), a resposta biaxial de uma membrana recoberta pode ser dividida na resposta das tensões normais nas direções do urdume e da trama, em conjunto com a resposta ao cisalhamento. Estas duas parcelas podem ser consideradas desacopladas, devido à própria natureza do material. Desse modo, podemos definidir a função energia de deformação específica $\psi$ como sendo: 


$$
\psi=\psi^{\prime}+\psi^{\prime \prime}
$$

Uma função energia de deformação específica que pode ser apropriada para membranas ortótropas existentes do mercado é apresentada por Pauletti e Pimenta (2002):

$$
\psi=\varphi\left(I_{11}, I_{12}, I_{21}, I_{22}\right)+2 G I_{4}
$$

O invariante $I_{4}$ é responsável por correlacionar as distorções às tensões de cisalhamento. Na equação (3.11) pode-se reconhecer as parcelas desacopladas:

$$
\begin{gathered}
\psi^{\prime}=\varphi\left(I_{11}, I_{12}, I_{21}, I_{22}\right) \\
\psi^{\prime \prime}=2 G I_{4}
\end{gathered}
$$

A resposta ao cisalhamento representada por (3.13), já discutida no item 2.3.2, pode ser calibrada a partir de resultados experimentais específicos de deformação ao cisalhamento, como aqueles definidos pelo protocolo MSAJ (M-01-1993). Como também mencionado anteriormente, esta parcela do funcional não se encontra no foco deste trabalho.

Por outro lado, a resposta às deformações normais do funcional energia de deformação representada por (3.12) será calibrada neste trabalho utilizando os resultados obtidos por ensaios biaxiais, conforme será apresentado no capítulo 5 . Segundo Oliveira (2006), uma classe de materiais elásticos ortótropos que pode ser adequada à análise dos tecidos revestidos usuais é representada por:

$$
\psi^{\prime}=\phi\left(I_{11}, I_{12}\right)+\bar{\mu}\left(I_{21}+I_{22}\right)
$$

onde $\phi$ é uma função e $\bar{\mu}$ é um parâmetro escalar. Em seu tabalho, Oliveira (2006) adota $\bar{\mu}=0,0$, desprezando deste modo a influência das deformações $E_{12}$ e $E_{21}$ 
sobre os termos do segundo tensor de Piola-Kirchhoff. A mesma hipótese será adotada neste trabalho. Deste modo, podemos reescrever (3.14) como sendo:

$$
\psi^{\prime}=\phi\left(I_{11}, I_{12}\right)
$$

A função $\phi$ adotada por Oliveira em sua modelagem foi um polinômio incompleto do quarto grau (apenas com termos de segunda e quarta ordem). Neste trabalho, verificou-se a conveniência de se adotar uma função $\phi$ definida como um polinômio completo do quarto grau, representado por:

$$
\begin{aligned}
& \phi\left(I_{11}, I_{12}\right)=\phi_{1} I_{11}+\phi_{2} I_{12}+\frac{1}{2} \phi_{3} I_{11}^{2}+\phi_{4} I_{11} I_{12}+\frac{1}{2} \phi_{5} I_{12}^{2}+\frac{1}{3} \phi_{6} I_{11}^{3}+\phi_{7} I_{11}^{2} I_{12}+\phi_{8} I_{11} I_{12}^{2}+ \\
& +\frac{1}{3} \phi_{9} I_{12}^{3}+\frac{1}{4} \phi_{10} I_{11}^{4}+\phi_{11} I_{11}^{3} I_{12}+\phi_{12} I_{11}^{2} I_{12}^{2}+\phi_{13} I_{11} I_{12}^{3}+\frac{1}{4} \phi_{14} I_{12}^{4}
\end{aligned}
$$

Os parâmetros $\phi_{j}, j=1, \ldots, 14$, são coeficientes constitutivos. Com estas considerações, temos que as componentes do tensor $\mathbf{S}$ são então definidas como:

$$
\begin{gathered}
S_{11}=\phi_{1}+\phi_{3} I_{11}+\phi_{4} I_{12}+\phi_{6} I_{11}^{2}+2 \phi_{7} I_{11} I_{12}+\phi_{8} I_{12}^{2}+\phi_{10} I_{11}^{3}+3 \phi_{11} I_{11}^{2} I_{12}+2 \phi_{12} I_{11} I_{12}^{2}+\phi_{13} I_{12}^{3} \\
S_{22}=\phi_{2}+\phi_{4} I_{11}+\phi_{5} I_{12}+\phi_{7} I_{11}^{2}+2 \phi_{8} I_{11} I_{12}+\phi_{9} I_{12}^{2}+\phi_{11} I_{11}^{3}+2 \phi_{12} I_{11}^{2} I_{12}+3 \phi_{13} I_{11} I_{12}^{2}+\phi_{14} I_{12}^{3} \\
S_{12}=S_{21}=0
\end{gathered}
$$

Com a função energia de deformação definida, bem como suas relações com as tensões e as deformações, utilizaremos um método numérico para o ajuste da função aos dados coletados nos ensaios com o material. 


\section{PROCEDIMENTO DE TESTE PARA DETERMINAÇÃo DAS RELAÇÕES TENSÃO - DEFORMAÇÃO DOS TECIDOS PTFE- VIDRO}

Os tecidos PTFE-vidro, conforme discutido anteriormente, possuem características peculiares, uma vez que materiais distintos são postos juntos para formar um material compósito altamente anisotrópico (TODA et al, 1986). Por outro lado, os procedimentos e resultados do estudo deste material se encontram muitas vezes guardados em sigilo, seja pelas empresas fabricantes do tecido ou pelas construtoras das estruturas que o empregam. O conhecimento do comportamento deste material pode ser a chave que separa o sucesso do fracasso de um projeto de estrutura de membrana.

Para este trabalho, foi escolhido como protocolo de ensaio o procedimento japonês definido em Testing Method for Elastic Constants of Membrane Materials (MSAJ/M-02-1995). Trata-se de um método internacionalmente consagrado de ensaio biaxial para determinação de relações tensão-deformação, adequado para o material PTFE-vidro. Outras fontes também foram consultadas no intuito de complementar o protocolo de referência. Dentre elas, citamos ASTM (1975), Day (1986), Toda (1986), Minami et al (1986), Kato et al (1999), Bridgens et al (2004), Asselt (2007) e Bögner-Balz e Blum (2007).

\subsection{CONSIDERAÇÕES PARA O TESTE}

No intuito de se coletar dados experimentais compatíveis com este trabalho, alguns pontos devem ser levados em consideração: comportamento do material em ensaios uni e biaxiais, métodos de ensaios biaxiais, comportamento inicial e de serviço, razões de carregamento e deformações residuais. A seguir estes conceitos são explorados em maior detalhe. 


\subsubsection{ENSAIOS UNIAXIAIS DE TRAÇÃO}

Até poucos anos atrás, métodos para ensaios uniaxiais de tração eram utilizados no intuito de definir o módulo de elasticidade e o coeficiente de Poisson para tecidos estruturais. O módulo de elasticidade neste caso era obtido pela medição do carregamento e da deformação na direção dos fios tensionados, e o coeficiente de Poisson obtido a partir da medição do encurtamento do tecido na direção perpendicular à solicitação. Deste modo, o teste uniaxial proporciona uma referência quanto ao comportamento tensão-deformação até a ruptura do tecido. Por não levar em consideração o efeito correlacionado entre as direções principais do material, este teste não é o mais apropriado para se definir seu comportamento mecânico nas situacões usuais de serviço. Mesmo assim, vale ressaltar que este teste ainda é utilizado no intuito de se definir a resistência à ruptura do tecido (conhecido como resistência à ruptura uniaxial), utilizado como referência para desenvolvimento de projetos.

Uma inspeção atenta da figura 4.1, na qual se apresenta um tipo de equipamento de ensaio uniaxial, permite observar algumas características importantes sobre os procedimentos para realização deste ensaio: neste caso, a carga é aplicada por efeito de alavanca, sendo transferida ao corpo de prova através de bainhas, no intuito de se evitar a concentração de tensão na amostra (a utilização de equipamentos hidráulicos para aplicação deste carregamento também é uma opção); temos também as marcas para medição direta do comprimento inicial de referência e dos comprimentos deformados após a aplicação de cada carregamento pois, como o tecido é um material compósito, é preferível se fazer uma medição direta de seus deslocamentos (com o uso de um paquímetro digital, por exemplo) do que a utilização de equipamentos mais sensíveis, como as células de deformação, que nos fornecem medições mais precisas das deformações locais do recobrimento no ponto instalado ao invés das deformações nominais (médias) de interesse para o modelo. 


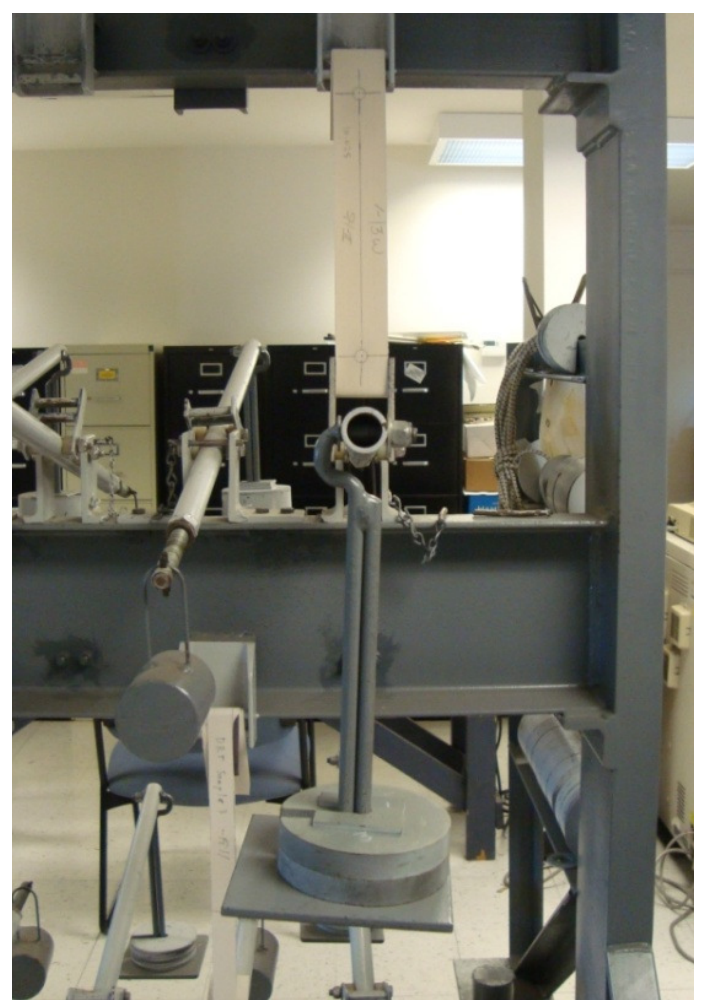

Figura 4.1 - Equipamento para ensaios uniaxiais.

Fonte: Acervo Pessoal.

Algumas tentativas foram feitas no intuito de se incorporar os efeitos correlacionados entre as direções do tecidos em ensaios uniaxiais. Em um ensaio (uniaxial) convencional, no intuito de se remover a folga inicial entre os fios da direção oposta a que está sendo ensaida, um carregamento preliminar é aplicado em três ciclos, sendo que as medições para a determinação dos coeficientes é efetuada no quarto carregamento. Este processo de ensaio alonga os fios na direção do ensaio, induzindo a um aumento da ondulação na direção perpendicular a solicitada (um tipo de troca de ondulação forçada). Este procedimento acaba por superestimar o módulo de elasticidade na direção ensaiada (uma vez que a fibra em estudo pode se encontrar mais alongada que nas situações reais de aplicação), bem como impede a obtenção de um coeficiente de Poisson preciso (por desprezar as solicitações transversais que ocorrem na prática).

Uma solução encontrada para evitar o impacto deste alongamento da fibra ensaiada consiste na aplicação destes carregamentos preliminares de modo biaxial, para a remoção simultânea das folgas iniciais, nas direções do urdume e da trama. Deste modo, o espaçamento entre os fios pode ser removido, sem a geração de 
ondulações excessivas em uma direção. A partir desta preparação, o ensaio uniaxial convencional pode ser feito na amostra. Entretanto, neste caso, os valores das deformações obtidas na direção perpendicular incluirão o efeito da troca de ondulação, aumentando assim o valor do coeficiente de Poisson obtido para valores que podem chegar a 1.0 ou superá-lo. Assim sendo, um possível valor máximo para o coeficiente de Poisson pode ser obtido, mas o seu uso em situações de projeto é questionável, por ser obtido em condições distintas daquelas atuantes em serviço (MSAJ/M-02-1995).

Podemos concluir então que não é adequada a determinação dos módulos de elasticidade e do coeficiente de Poisson real do material a partir das deformações obtidas pelo ensaio uniaxial de tração. Torna-se necessária a utilização de uma metodologia de teste que propicie a aplicação da tração em ambas as direções principais (urdume e trama), simultaneamente.

\subsubsection{ENSAIOS BIAXIAIS DE TRAÇÃO}

Existem atualmente três métodos para realização de ensaios biaxiais: o ensaio cilíndrico, o ensaio tipo tambor e o ensaio plano com amostra crucifome.

O ensaio cilíndrico é realizado em uma amostra retangular de tecido, a partir da qual se constrói um corpo de prova cilíndrico, soldando duas extremidades paralelas da amostra. Este cilindro é preso então a um equipamento de ensaio que aplica uma pressão interna na amostra, gerando deformações nas direções axial e circunferencial. A figura 4.2 apresenta este ensaio. Percebe-se que o uso combinado da pressão interna com um equipamento de ensaio uniaxial permite aplicar à amostra qualquer razão de carregamento necessária. 


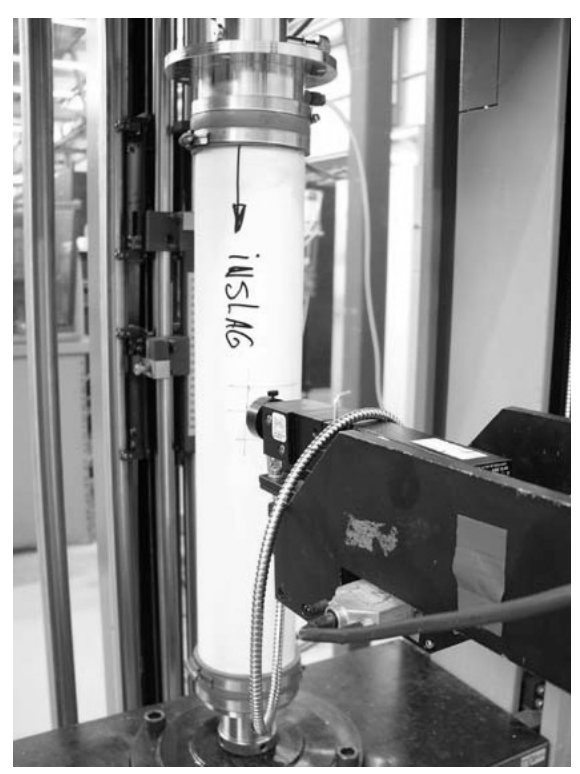

Figura 4.2 - Equipamento para ensaio biaxial cilíndrico. Fonte: Nederpelt (2004).

Um outro procedimento de ensaio similar a esse é o ensaio tipo tambor, onde uma amostra circular de material é fixada ao longo da borda de um anel metálico. A partir da aplicação de uma pressão interna a este tambor, podemos medir as deformações superficiais no material.

Entretanto, estes dois métodos de ensaio possuem algumas desvantagens. No caso do primeiro ensaio, não temos como evitar uma solda na construção da amostra cilíndrica de tecido, o que afeta diretamente os resultados obtidos. No caso do ensaio tipo tambor, existem dificuldades para o levantamento preciso das tensões, além de que a razão de carregamento não pode ser variada, permanecendo sempre em 1:1.

O método atualmente mais utilizado na indústria é o ensaio biaxial plano com amostra cruciforme tracionada nas duas direções principais das fibras do tecido. $A$ intensidade das forças aplicadas, bem como sua razão de aplicação, podem ser definidas de acordo com o interesse do ensaio. Através do monitoramento das forças aplicadas e da medição dos deslocamentos, é possível obter as relações tensão-deformação procuradas. Existem duas posições básicas para instalação do equipamento para ensaio bi-axial: a horizontal e a vertical. Nenhuma destas duas 
posições apresenta problemas que impeçam o ensaio com amostras de tecidos arquitetônicos (MSAJ/M-02-1995).

Devido à sua maior generalidade, bem como a disponibilidade deste equipamento para utilização durante esta pesquisa, este trabalho adota o ensaio biaxial de tração. A figura 4.3 a seguir apresenta o equipamento empregado. Os ensaios realizados neste trabalho foram executados no laboratório de ensaios e tecnologia dos materiais da empresa Birdair, Inc., sediado na cidade de Amherst, Nova lorque, EUA.
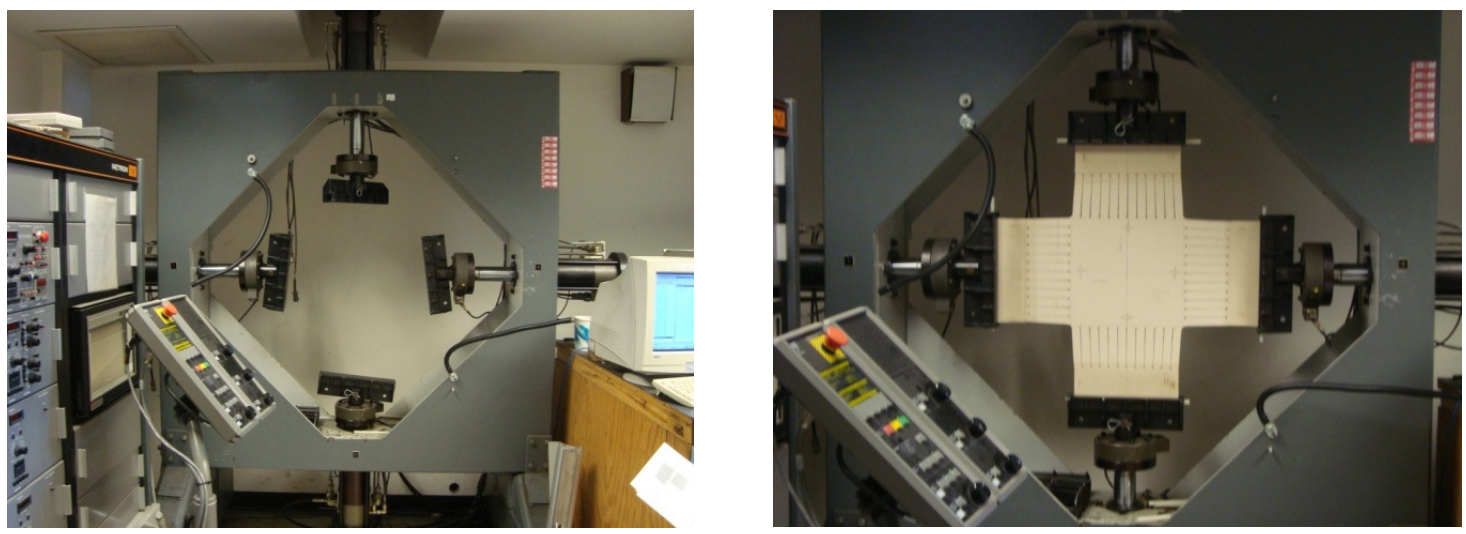

Figura 4.3 - Equipamento de ensaio biaxial de tração utilizado neste trabalho Fonte: Acervo pessoal.

Uma observação importante é que os ensaios biaxiais de amostra cruciforme tendem a subestimar a resposta do tecido à ruptura, pois o tecido tende à rasgar antes, na região do canto das amostras cruciformes - ponto de fragilidade devido à sua geometria (MSAJ/M-02-1995). Deste modo, o ensaio seguirá até um valor limite que é apresentado adiante no item 4.1.4.

\subsubsection{COMPORTAMENTO INICIAL E DE SERVIÇO}

Devido à natureza física do tecido PTFE-vidro (fios entrelaçados e recobertos), temos que seu comportamento inicial (primeira reação a um dado carregamento) e seu comportamento em serviço (ao longo do tempo) são diferentes, conforme justificado no capítulo 2, ao se discutir o processo de fabricação do tecido. 
Como também mencionado no capítulo 2, um carregamento inicial no tecido implica em um rearranjo de seus fios. Em virtude da folga existente entre eles, o tecido, quando tracionado, desenvolve deformações irreversíveis, que porém decrescem a cada ciclo de carregamento, até encontrar um ponto onde os espaçamentos entre os fios nas duas direções entram em equilíbrio (não mais gerando deformações adicionais relevantes em comparação com a deformação total).

Para garantir resultados adequados ao teste da amostra, o ideal é que esta se encontre em um estado que simule a resposta do material em campo. Neste trabalho denominamos este estado como estado de serviço. A importância de se ter o material testado no estado de serviço encontra-se no fato de que, com a remoção do espaçamento entre os fios, diferentes amostras de tecidos tenderão à apresentar resultados semelhantes em um dado estado de tensão.

O protocolo japonês (MSAJ/M-02-1995) prescreve a realização de uma série de três ciclos de carregamentos, com razão de carregamento $1: 1$, denominados de carregamentos de condicionamento, com o objetivo de aproximar o comportamento do material em laboratório ao estado de serviço a que a amostra será submetida. Este procedimento de condicionamento é o adotado neste trabalho.

Importante mencionar que outros autores consideram que o estado de serviço do material não se encontra situado no terceiro ciclo de carregamento de condicionamento. Este é o caso Bridgens et al (2004), que desenvolveu um protocolo de ensaio no qual ele descreve um processo de condicionamento de 17 horas em seu estado de retesamento de projeto, seguido por um número de ciclos de carregamentos necessários para se encontrar o ponto em que a deformação adicional na amostra seja inferior a $5 \%$ da deformação total.

\subsubsection{RAZÕES DE CARREGAMENTO}

Após ser condicionada, a amostra é submetida a uma seqüência de carregamentos aplicados com diferentes razões de carregamento. O termo razão de carregamento 
diz respeito à razão entre $\sigma_{u}$ e $\sigma_{t}$, conforme definido no item 2.2.1. Essas diferentes razões garantem a inclusão da troca de ondulações à resposta do tecido em solicitações biaxiais. Esta consideração é importante pois a troca de ondulações não é um efeito constante, mas sim diretamente dependente da razão de carregamento aplicada.

O número de diferentes razões de carregamento a serem ensaiadas depende das necessidades específicas de cada projeto. O protocolo japonês (MSAJ/M-02-1995) aponta que o conjunto de razões de carregamento $\{1: 1,1: 2,2: 1,1: 3,3: 1\}$ é adequado para tecidos de PTFE-vidro, quando levado em consideração a distribuição das tensões no centro da amostra.

Cada ciclo de carregamento parte de um valor mínimo de carga que é acrescido, conforme a razão em ensaio, até um valor máximo, onde a partir de então ocorre o descarregamento da amostra até o retorno ao seu valor mínimo. Importante mencionar que o descarregamneto deve seguir a mesma razão utilizada no carregamento.

O valor de carregamento máximo é de $25 \%$ (um quarto) da resistência à ruptura uniaxial do material em teste. Conforme ressalta Bridgens (2004), a propagação de rasgos não ocorre até aproximadamente este valor, garantindo assim uma amostra íntegra para os testes. Outra razão encontra-se no fato de que, como decorrência dos coeficientes de segurança usualmente empregados (na faixa de 5 a 8, dependendo das especificidades de projeto), o valor de carregamento máximo de ensaio é superior ao máximo intervalo de solicitação de projeto.

\subsubsection{DEFORMAÇÕES RESIDUAIS}

Conforme discutido no item 2.2, devido ao rearranjo das fibras em cada razão de carregamento, a amostra apresentará deformações residuais ao final de cada ciclo de carga e descarga. 
No intuito de minimizar a influência que uma dada razão de carregamento pode ter sobre a subseqüente, o protocolo de referência (MSAJ/M-02-1995) orienta o acréscimo de um intervalo de três carregamentos de condicionamento entre cada ciclo de carregamento que possua razão diferente de 1:1. Deste modo temos o retorno da malha à uma situação próxima do condicionamento inicial (na razão 1:1), minimizando a influência do efeito de deformação residual de um ciclo de carga sobre o resultado final do ciclo subseqüente.

\subsection{Preparação do Ensaio}

Os itens a seguir apresentam a seqüência de preparação adotada para a realização dos ensaios biaxiais de tração deste trabalho. O material a ser ensaiado é um tecido de fibra de vidro recoberto com PTFE, da marca Sheerfill, Tipo II, produzido pela empresa Saint-Gobain. Em sua especificação técnica, este material apresenta uma resistência à tração média-mínima de $137,5 \mathrm{kN} / \mathrm{m}$ na direção do urdume e 98,1 kN/m na direção da trama, considerando o fio seco. Deste modo, seguindo as orientações descritas no item 4.1.4, temos que o máximo valor do carregamento de ensaio para estas amostras de material é de $24,5 \mathrm{kN} / \mathrm{m}$ - equivalente a um quarto da mínima resistência à tração, entre a trama e o urdume.

Importante ressaltar que todo material testado neste trabalho foi gentilmente cedido pela empresa americana Birdair, Inc.

\subsubsection{PreparaçÃo da Amostra}

A amostra ensaida possui o formato de cruz, com os braços orientados nas direções do urdume e da trama, de acordo com a geometria sugerida pelo protocolo MSAJ/M02 (1995), que também sugere que se adotem braços com largura mínima de $16 \mathrm{~cm}$ e comprimento mínimo de $16 \mathrm{~cm}$, conforme esquematizado na figura 4.4. No entanto, devido às caracteristicas da maquina de ensaio utilizada, foram empregadas amostras em que cada braço possuia uma largura e um comprimento 
de $30 \mathrm{~cm}$. A adoção de amostras com largura maior não compromete a qualidade dos resultados nominais finais.

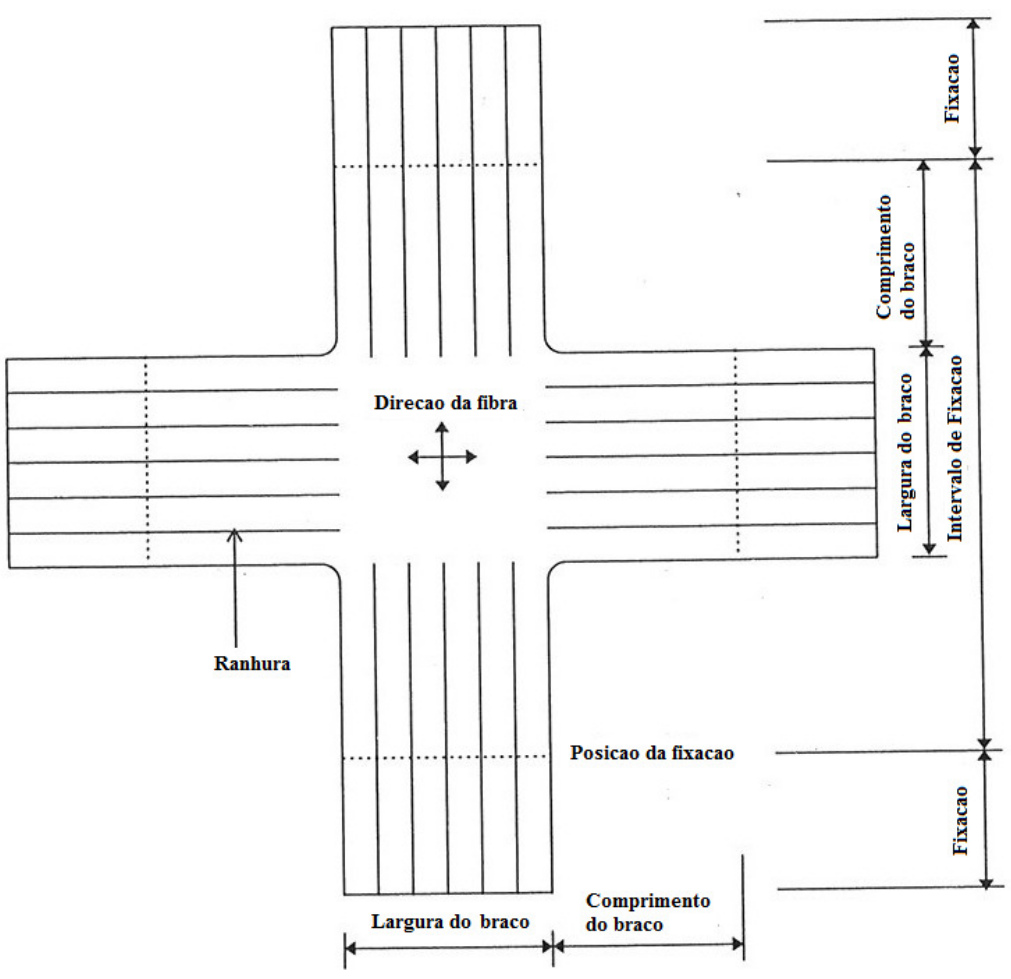

Figura 4.4 - Amostra ranhurada em formato de cruz. Fonte: Adaptado de MSAJ/M-02 (1995).

Um comprimento adicional deve ser incorporado a cada braço para a construção da bainha para fixação da amostra ao equipamento, uma vez que o tipo de fixação adotado pode ter influência sobre o resultado final do ensaio. O protocolo japonês aponta um comprimento extra mínimo de $24 \mathrm{~cm}$ em cada braço para a construção desta bainha. Neste trabalho, o equipamento de ensaio biaxial utilizado possui um sistema de fixação da amostra por agarras. Assim sendo, foi construida uma bainha nas extremidades da amostra a partir do dobramento e da solda do material. A figura 4.5 apresenta as etapas da preparação da amostra.

Conforme se nota na figura 4.5(b), ranhuras longitudinais são cortadas em cada braço, no intuito de eliminar as tensões de cisalhamento no centro da amostra. Assim, se garante que o centro da amostra apresentará condições de carregamento similares àquelas prescritas pelo protocolo (MSAJ/M-02-1995). 

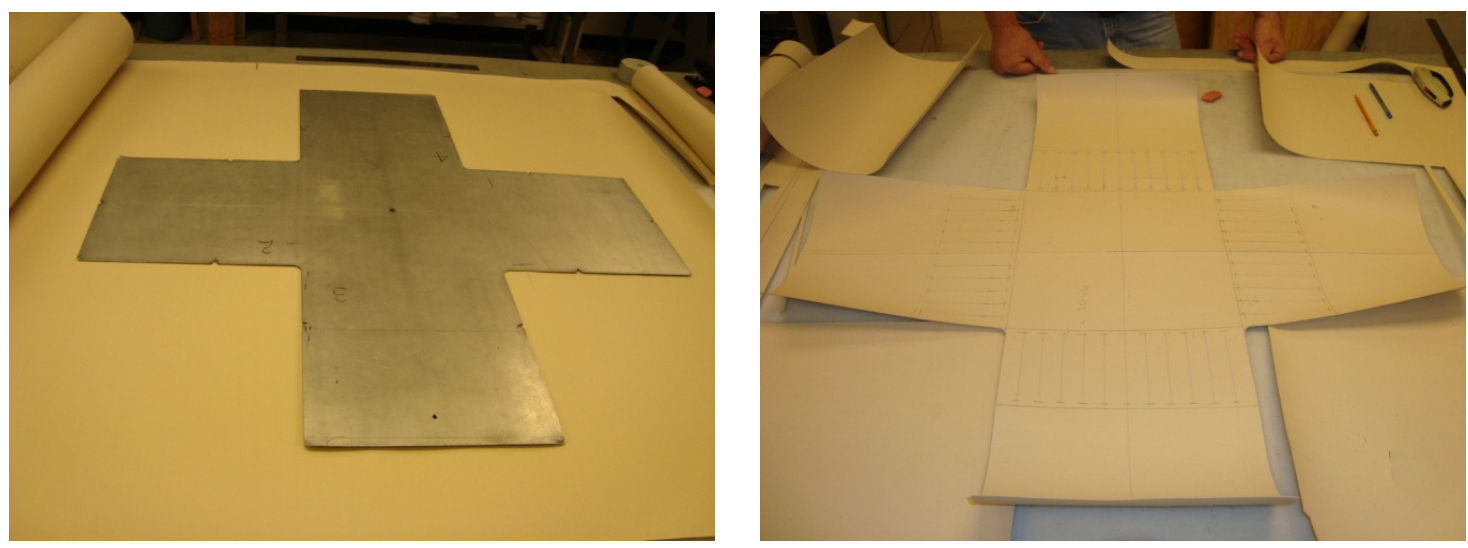

Figura 4.5 - Preparação das amostras

(a) esquerda: Posicionamento do gabarito no rolo

(b) direita: Amostra cortada e marcada
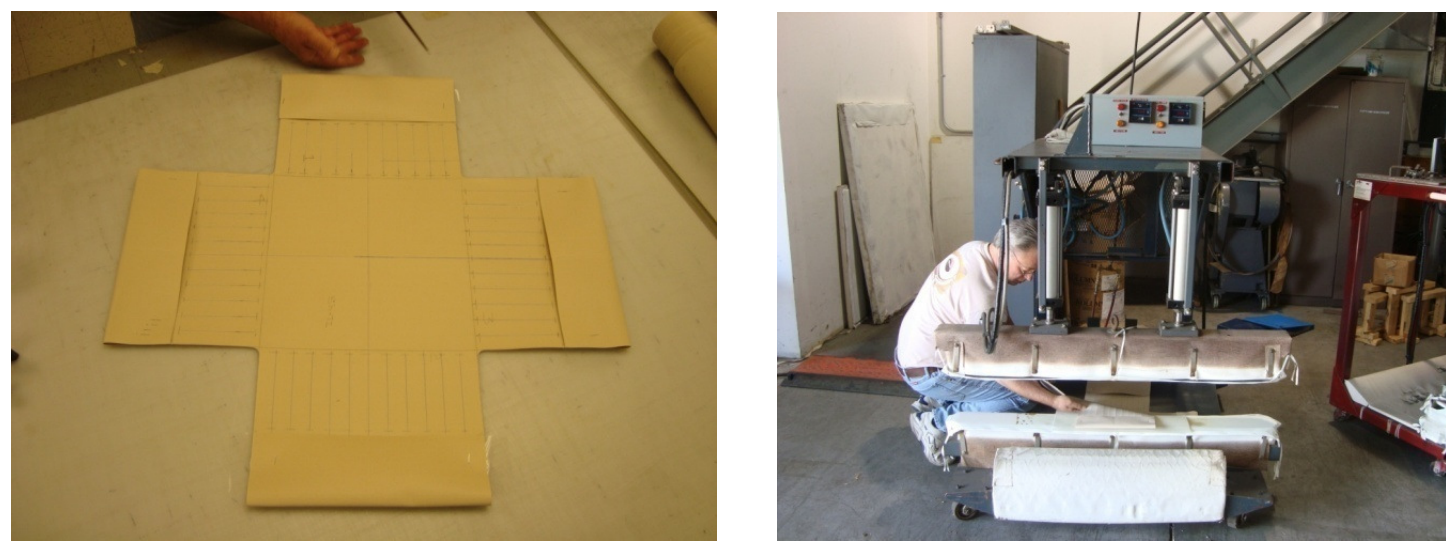

Figura 4.5 - (c) esquerda: Amostra com a bainha construida, antes de soldar (d) direita: equipamento de solda
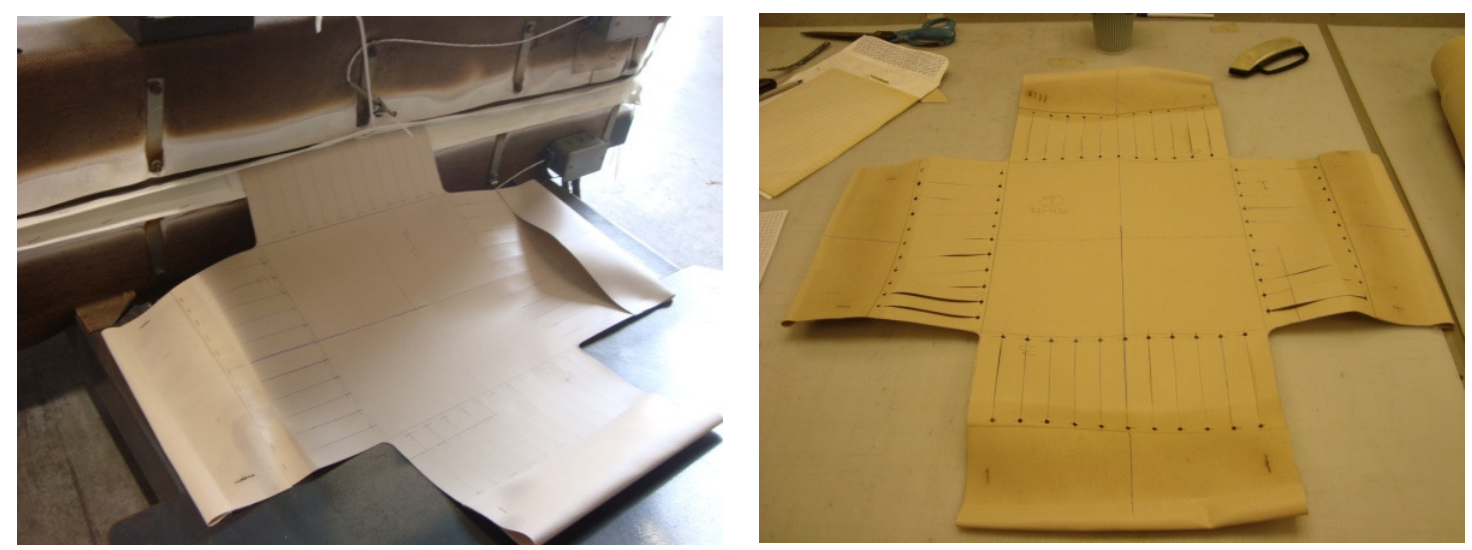

Figura 4.5 - (e) esquerda: Amostra sendo soldada

(f) direita: Amostra preparada para o ensaio Fonte: Acervo pessoal. 
Outra característica importante quanto à preparação da amostra encontra-se na região do rolo da qual a ela será cortada. Conforme mostrado na figura 4.5(a), a amostra a ser ensaiada é retirada de uma região próxima ao centro do rolo do tecido. Nesta região temos que os efeitos das distorções nos alinhamentos dos fios do urdume e da trama (bias filling) e a curvatura do próprio fio em relação à direção principal (bow) são mínimos ou inexistentes. Estes dois efeitos estão apresentados na figura 4.6. A precisão no corte da amostra também deve garantir que nenhum dano ocorra aos fios na direção em que o carregamento será aplicado.
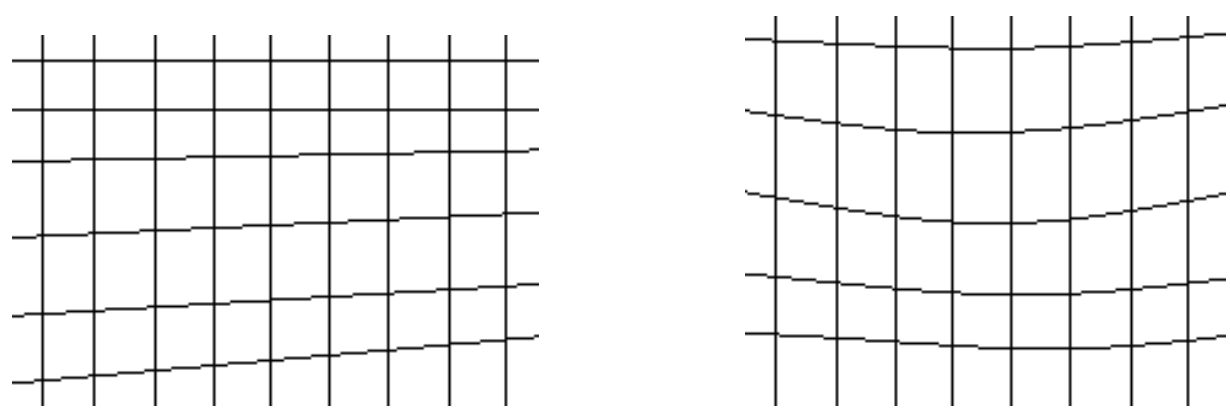

Figura 4.6 - Distorção entre os fios (esq.) e curvatura dos fios (dir.)

Fonte: Acervo pessoal.

\subsubsection{FIXAÇÃO DA AMOSTRA AO EQUIPAMENTO}

Como as condições de fixação da amostra afetam diretamente os valores das deformações, especialmente quando o intervalo de carregamento de interesse é baixo, estas amostras devem ser fixadas com cuidado. Quando as direções dos fios do urdume e da trama se cruzarem em um ângulo diferente de $90^{\circ}$, cuidado extra deve ser tomado no intuito de se manterem idênticos os comprimentos dos braços da amostra (a distância entre a fixação no equipamento e a região central da amostra ensaiada). Deste modo, podemos garantir que as direções das forças aplicadas correspondem às direções do urdume e da trama.

Além disso, a fixação propriamente dita do material ao equipamento deve ser feita com cuidado para serem evitados erros de medição durante o ensaio. Caso a amostra escorregue da agarra de fixação, as medidas contemplarão tanto a deformação do tecido quanto seu escorregamento. A figura 4.7 apresenta o equipamento de ensaio biaxial utilizado neste trabalho, que dispõe de um sistema de 
fixação por agarras únicas - detalhe (a) na figura 4.7. Nota-se que um perfil extrudado de nylon foi inserido dentro da bainha, garantindo o travamento da amostra ao equipamento, evitando tambem pontos de concentração de tensão.
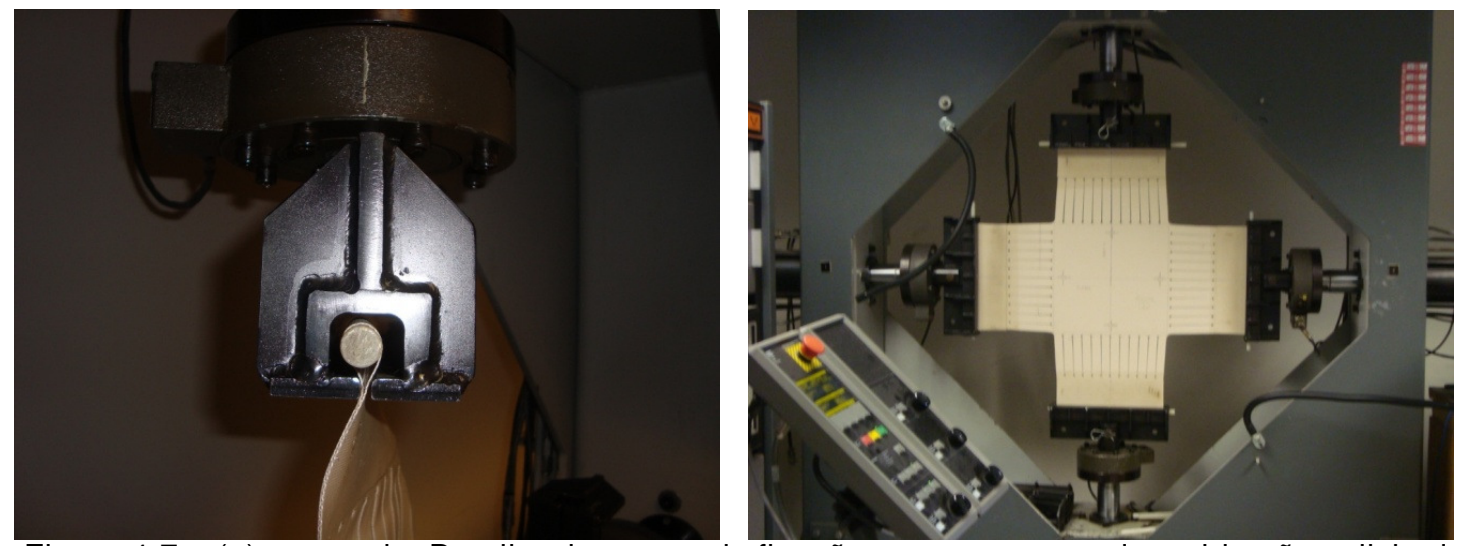

Figura 4.7 - (a) esquerda: Detalhe da agarra de fixação com a amostra de tecido não solicitada

(b) direita: Amostra instalada no equipamento para o ensaio

Fonte: Acervo pessoal.

No intuito de se reduzir a influência do escorregamento durante o ensaio, os ciclos retornarão sempre à um carregamento inicial $\sigma_{0}$ (superior à zero), garantindo um mínimo de tensionamento na amostra que impede este escorregamento.

\subsubsection{LEITURA DAS DEFORMAÇÕES}

A temperatura ambiente é um dos fatores mais importantes para a correta medição das deformações em ensaios com tecidos arquitetônicos. Conforme discutido no item 2.2.6, uma vez que os materiais de recobrimento e as fibras sintéticas são facilmente afetadas pelas variações térmicas, a temperatura no ambiente de ensaio deve ser mantida estável. O protocolo (MSAJ/M-02-1995) define esta temperatura como sendo entre $20 \pm 2^{\circ} \mathrm{C}$, sendo adotada como padrão tanto no ambiente de ensaio como no ambiente de armazenagem das amostras.

Quando a amostra é carregada, as deformações geradas no centro da amostra devem ser medidas nas direções do urdume e da trama, simultaneamente com o carregamento. Como já discutido, devido ao seu processo construtivo, os tecido arquitetônicos são suscetíveis a uma série de não-uniformidades. Assim, com o intuito de se obter valores médios representativos para as deformações, a distância 
entre os pontos iniciais de referência deve ser definida com um valor equivalente $a$, no mínimo, 10 cruzamentos de fios. A precisão na medição destas deformações é relevante para a qualidade dos resultados finais. Quando a distância para a medida da extensão for longa, a tensão normal tende a diminuir com o aumento da distância em relação ao centro da amostra. Por outro lado, quando esta distância for curta, a precisão nos resultados tende a diminuir. Neste trabalho, esta distância é de medição é de $25 \mathrm{~cm}$.

Para a medição das deformações, vários são os métodos que podem ser utilizados. Dentre eles, podemos citar a fotografia, o uso de células de deformação, uso de equipamento para medição direta das deformações e o uso de equipamento óptico para medida da distância entre pontos de referência. Porquanto mais preciso, o uso de células de deformação fornece medidas de deformação por demais localizadas para a obtenção das propriedades nominais médias de interesse. As medições realizadas neste trabalho foram determinadas de modo direto, com auxílio de um paquímetro digital.

\subsection{Procedimento para o Ensaio BiaXial de Tração}

Uma vez que os diferentes aspectos do comportamento do tecido sob solicitação biaxial foram discutidos, bem como as características do equipamento de ensaio utilizado, uma seqüência de carregamentos pode ser estabelecida para o ensaio das amostras.

No intuito de eliminar a influência dos efeitos da viscoelasticidade da resina de recobrimento, bem como manter estáveis as condições para as medições, 0 protocolo (MSAJ/M-02-1995) determina uma faixa de velocidades de aplicação de carregamento. Os eixos devem ser carregados a uma velocidade padrão de 2 a 4 $\mathrm{mm} / \mathrm{min}$ até o limite de ensaio (conforme apresentado no item 4.1.4, com valor da ordem de $25 \%$ da resistência a tração do tecido). Antes do início dos ensaios, uma medida de comprimento de referência deve ser tomada. A partir deste ponto a amostra esta pronta para ser condicionada e então ensaiada para as diversas razões de carregamento especificadas. 
Inicialmente, o ciclo de condicionamento da amostra deve ser realizado com razão 1:1. Após alcançar o valor máximo para teste (definido no item 4.2 deste trabalho como sendo $24,5 \mathrm{kN} / \mathrm{m}$ ), o carregamento deve ser imediatamente removido, respeitando-se a razão de condicionamento. Quando obtido o valor de carga igual ao mínimo, o procedimento de carregamento e descarregamento na razão 1:1 deve ser repetido, até um total de 3 ciclos (conforme discutido no item 4.1.3).

Após a realização desta etapa inicial, os carregamentos nas razões de teste devem ser aplicados, e as medições devem ser realizadas. Deste modo, temos que a seqüência para aplicação de carregamento pode ser definida como \{1:1, 2:1, [1:1], 1:2, [1:1], 3:1 e [1:1], 1:3\}. Nesta seqüência, os ciclos de carga indicados por [1:1], aplicados entre os intervalos de carregamentos desigüais são efetuados com o intuito de retornar a malha às condições iniciais. Esta seqüência de carregamentos é adequada para materiais do de PTFE-vidro (MSAJ/M-02-1995).

A Figura 4.8 a seguir apresenta os casos de carregamento utilizados nos ensaios realizados no âmbito do presente trabalho. Cada razão de carragamento encontrase subdivida em 6 intervalos. Medições das deformações no urdume e na trama são efetuadas cada vez que o carregamento atinge o final do intervalo.

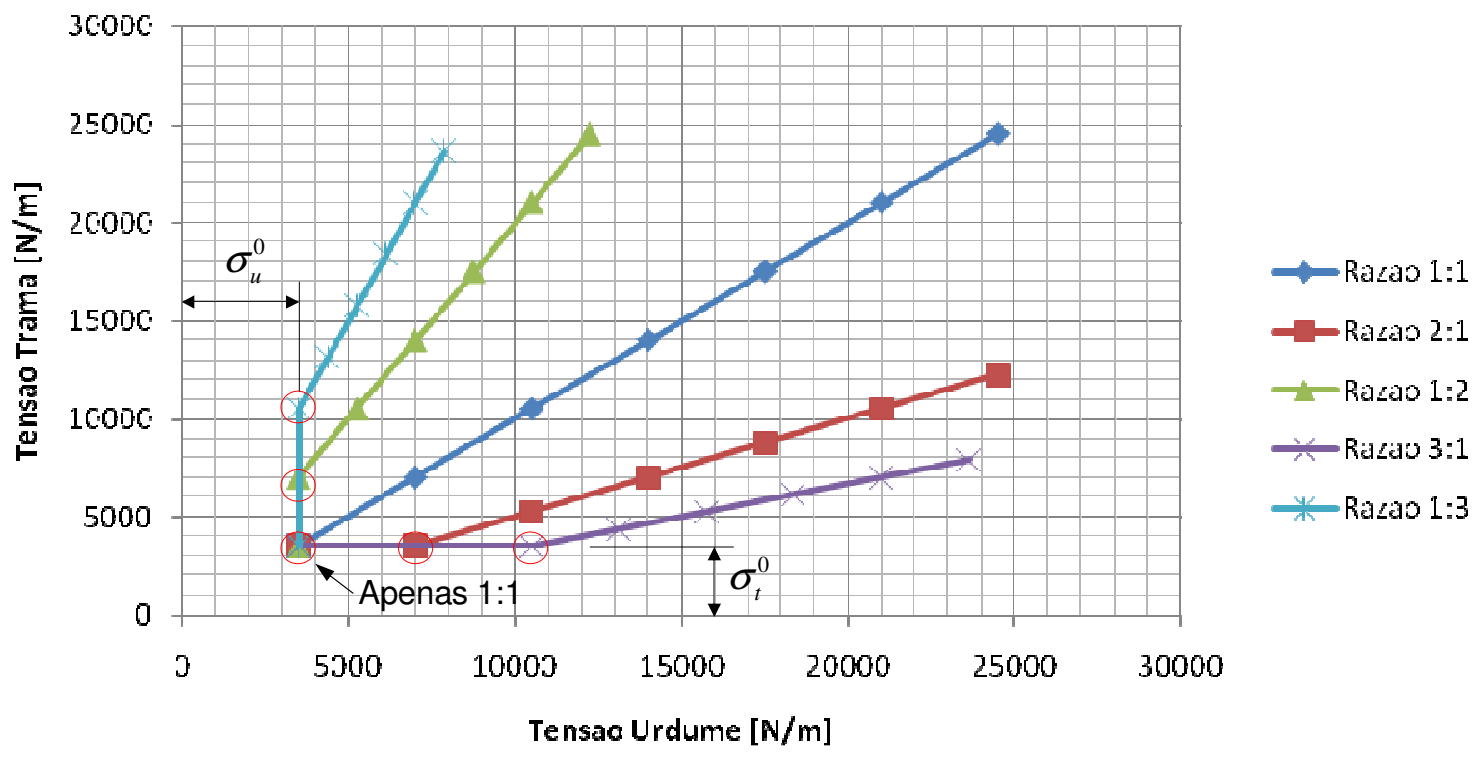

Figura 4.8 - Razões de carregamento utilizadas nos ensaios. Fonte: Acervo pessoal. 
Nota-se na figura 4.8 que os carregamentos nunca retornam à origem. Com discutido no item 4.2.2, um carregamento mínimo ( $\sigma_{u}^{0}$ no urdume e $\sigma_{t}^{0}$ na trama), equivalente à $3,5 \mathrm{kN} / \mathrm{m}$ é mantido durante o ensaio. Importante mencionar que as medições de deformação, para cada razão de carregamento, são tomadas apenas em alguns pontos na razão de carregamento em ensaio. Os pontos iniciais de medição são indicados por círculos na fígura. A figura 4.9 apresenta a distribuição no tempo da seqüência de aplicação dos carregamentos, seja no urdume quanto na trama. Nestes gráficos é possível identificar os carregamentos de condicionamento inicial e intermediário na amostra, bem como o trecho final, com razão de carregamento de 1:1, aumentado até a ruptura da amostra.
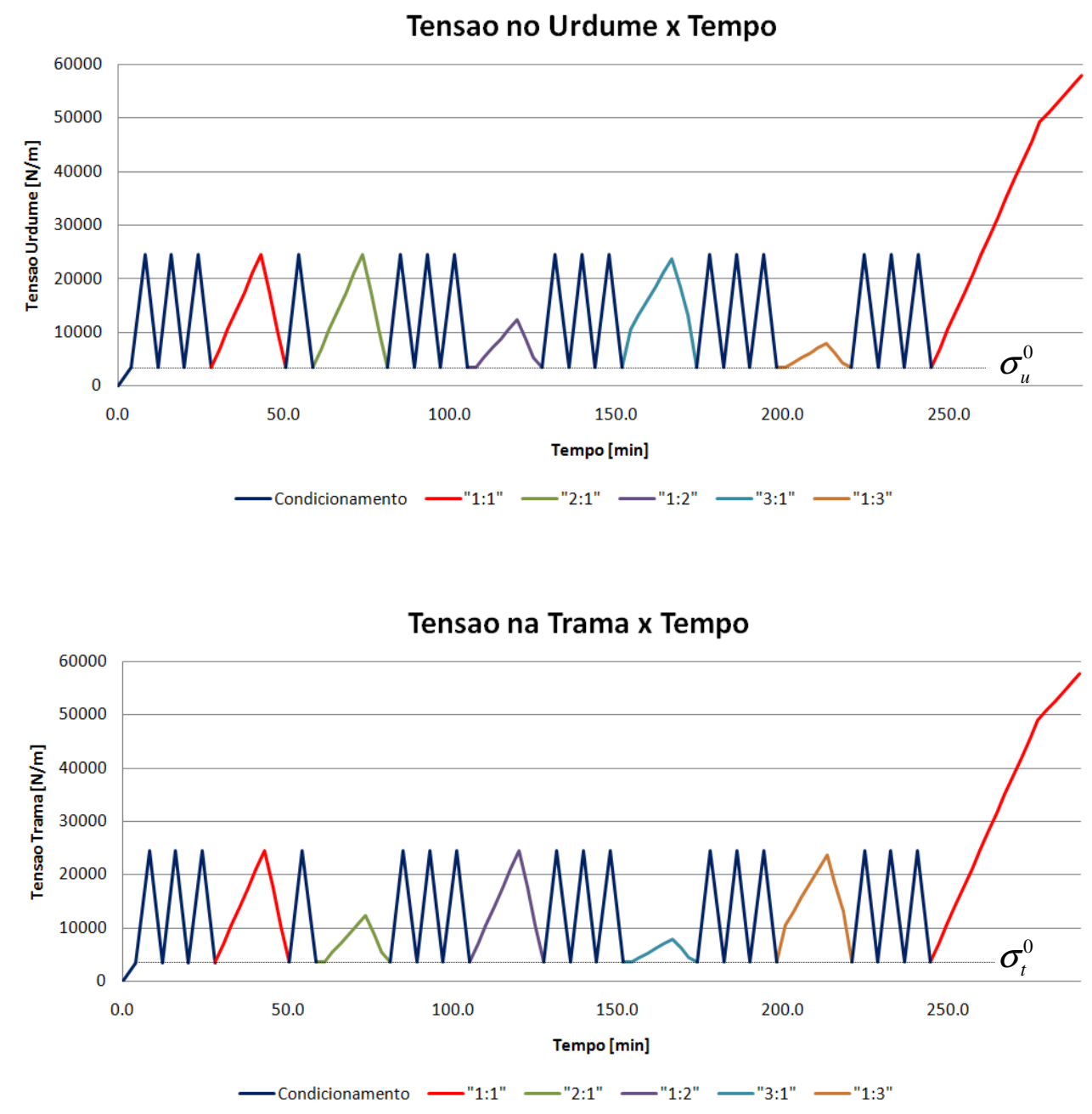

Figura 4.9: Seqüência de carregamento no Tempo

(a) Superior: urdume, (b) Inferior: trama

Fonte: Acervo pessoal. 


\section{ANÁLISES DOS RESULTADOS}

Os ensaios biaxiais foram realizados em três amostras diferentes de tecido, retiradas de três rolos distintos de material, e previamente condicionadas conforme o procedimento de condicionamento discutido no capítulo 4 .

\subsection{Resultados EXPERIMENTAIS OBtidos}

Os gráficos mostrados nas figuras 5.1 à 5.5 apresentam os resultados obtidos nos diversos ciclos de carga e descarga, em cada razão de carregamento, para cada uma das três amostras ensaiadas. A representação dos resultados pode ser feita de várias maneiras. Este trabalho adota gráficos bi-dimensionais tensão-deformação $(\sigma-\varepsilon)$, nos quais cada uma das três amostras ensaiadas, em cada uma das duas direções, encontram-se representadas por meio de diferentes tipos de linhas. A inspeção destes gráficos nos permite constatar que as três amostras apresentam diferentes deformações permanentes após o condicionamento. É possível que estas diferenças decorram do fato de as amostras terem sido extraídas de diferentes rolos de tecido, provenientes de diferentes lotes de fabricação. Pode-se ainda conjecturar a existência de discrepâncias na aplicação dos ciclos de condicionamento, embora todo cuidado tenha sido tomado no intuito de se eliminar este tipo de influência.

Em seu trabalho, Asselt (2007) utiliza o protocolo de ensaio definido por Bridgens et al (2004) que considera um processo de condicionamento da amostra com duração de 17,5 horas - muito superior ao adotado pela MSAJ. Os resultados finais publicados por Asselt apresentam uma maior uniformidade entre diferentes amostras, em comparação com o presente estudo. Entretanto, sabe-se que Asselt utilizou amostras de um mesmo rolo de material, fato que pode ter contribuido para esta uniformidade de resultados.

A figura 5.1 apresenta os resultados referentes à razão de carregamento de 1:1. 0 eixo vertical indica as tensões nas direções do urdume $\left(\sigma_{u}\right)$, neste caso, de mesma 
intensidade que as tensões da trama $\left(\sigma_{t}\right)$. As deformações no urdume $\left(\varepsilon_{u}\right)$ e na trama $\left(\varepsilon_{t}\right)$, em função das tensões do urdume, são mostradas em cores diferentes (vermelho para o urdume e azul para a trama).

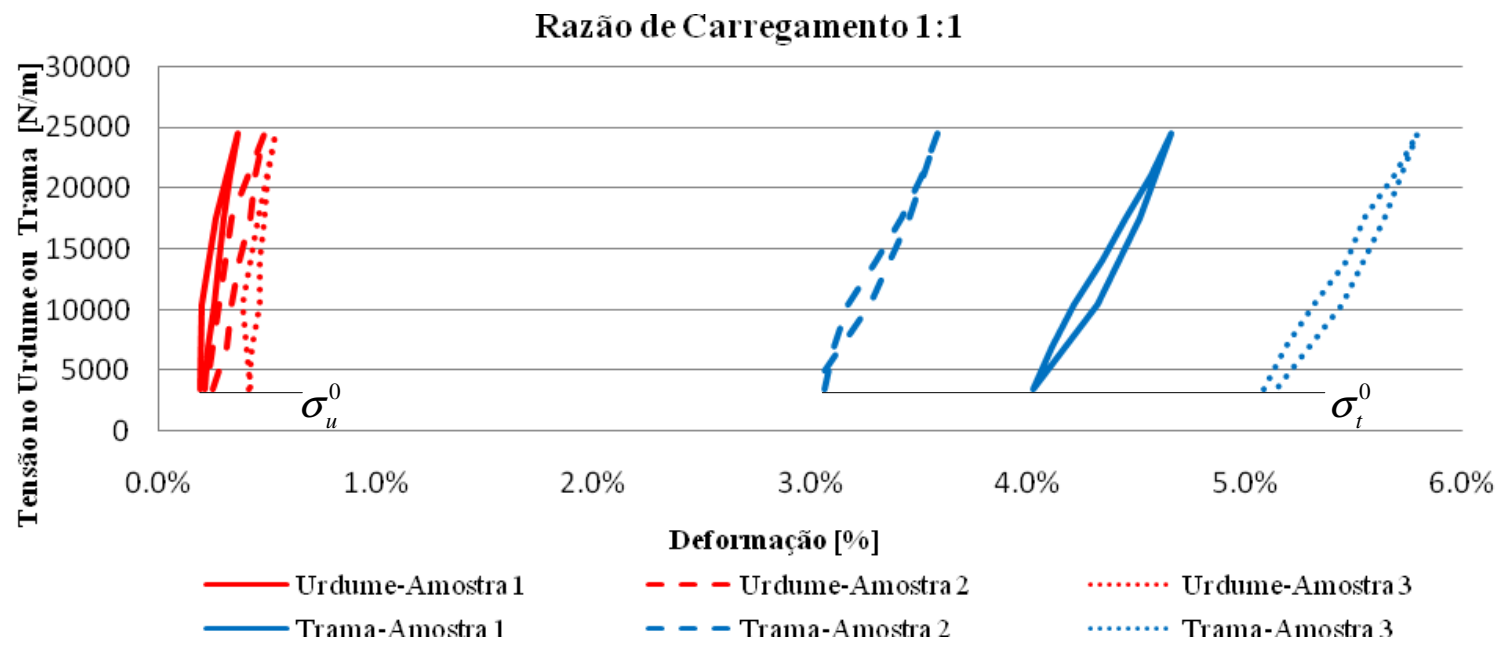

FIGURA 5.1 - Gráfico Tensão $\left(\sigma_{u}, \sigma_{t}\right) \times$ Deformação $\left(\varepsilon_{u}, \varepsilon_{t}\right)$, na razão $\left(\sigma_{u}: \sigma_{t}\right)=(1: 1)$ Fonte: Acervo Pessoal.

Nota-se na figura 5.1 que, devido à forma de construção do tecido de fibra de vidro, onde a direção do urdume pernanece esticada enquanto a trama é entrelaçada, as deformações totais na trama são consideravelmente superiores às do urdume, mesmo para uma razão de caregamento $\left(\sigma_{u}: \sigma_{t}\right)=1: 1$. Chama-se também a atenção para o fato de que a as curvas $\sigma-\mathcal{E}$ são representadas a partir de uma tensão inicial ( $\sigma_{u}^{0}$ ou $\sigma_{t}^{0}$ ). Embora não indicada nas figuras posteriores, elas também são representadas a partir de uma tensão inicial.

A figura 5.2 mostra as curvas $\sigma_{u} \times \varepsilon_{u}$ e $\sigma_{u} \times \varepsilon_{t}$ para na razão $\left(\sigma_{u}: \sigma_{t}\right)=2: 1$. As relações $\sigma_{t} \times \varepsilon_{u}$ e $\sigma_{t} \times \varepsilon_{t}$ diferem das curvas $\sigma_{u} \times \varepsilon_{u}$ e $\sigma_{u} \times \varepsilon_{t}$ apenas por um fator de escala definido pela razão de carregamento, de modo que não há necessidade de sua representação. 


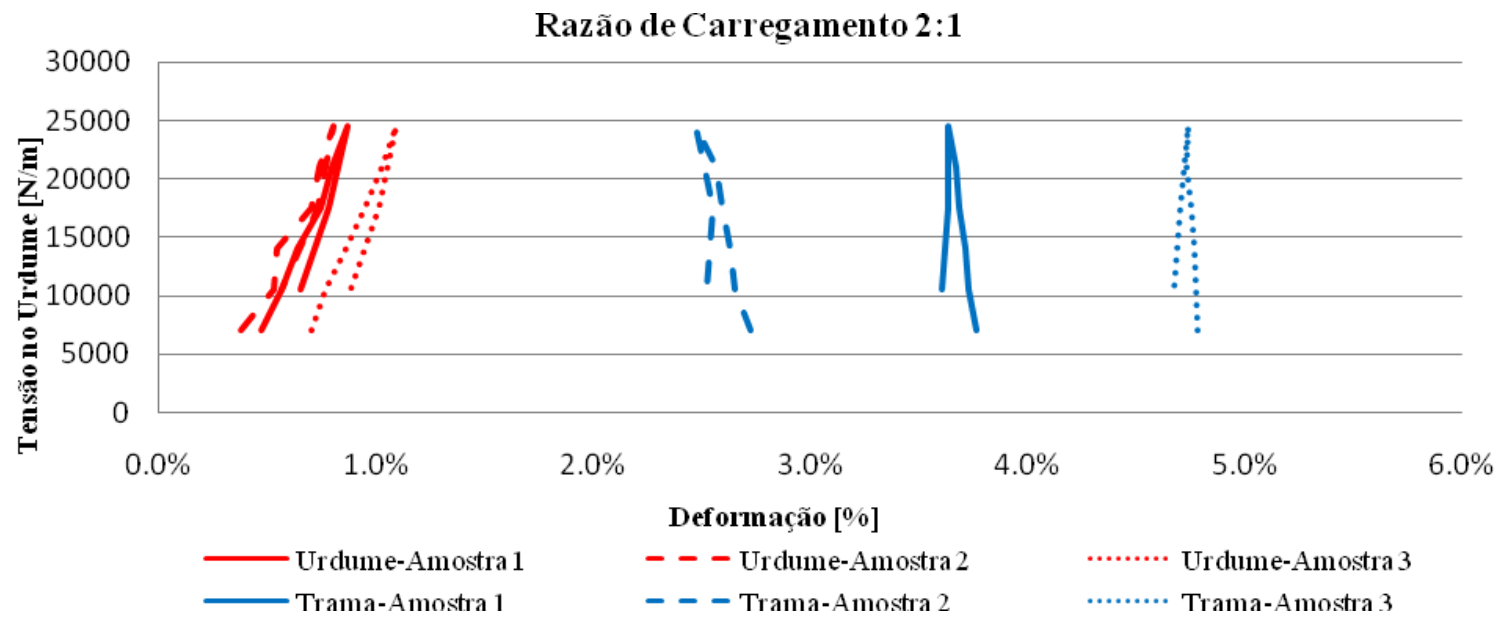

FIGURA 5.2 - Gráfico Tensão $\left(\sigma_{u}, \sigma_{t}\right) \times$ Deformação $\left(\varepsilon_{u}, \varepsilon_{t}\right)$, na razão $\left(\sigma_{u}: \sigma_{t}\right)=(2: 1)$

Fonte: Acervo Pessoal.

Uma vez que a direção mais solicitada é a do urdume, que é por natureza menos ondulada que a trama, não ocorre no caso apresentado pela figura 5.2 uma troca de ondulação apreciável entre as duas direções.

Ao contrário, no caso da razão $\left(\sigma_{u}: \sigma_{t}\right)=1: 2$, representada pela figura 5.3 , como a direção mais solicitada (trama) também é a mais ondulada, esta tende a retificar-se às expensas da introdução de ondulação no urdume, e como decorrência percebese o encurtamento da amostra nesta direção. O efeito da troca de entrelaçamento é mais pronunciado na fase inicial de ensaio, quando a amostra é levada da razão de carregamento de condicionamento $\left(\sigma_{u}^{0}: \sigma_{t}^{0}\right)=1: 1$ para a razão de ensaio $\left(\sigma_{u}: \sigma_{t}\right)=$ $1: 2$, o que se obtém incrementando-se a tensão $\sigma_{t}$, de $\sigma_{t}^{0}$ até $2 \sigma_{t}^{0}$ enquanto se mantém constante a tensão $\sigma_{u}=\sigma_{u}^{0}$. A partir deste ponto, as tensões em ambas as direções são incrementadas, proporcionalmente à razão de carregamento. A troca de entrelaçamento da trama para o urdume (neste caso) continua existindo, porém com influência decrescente com o aumento do carregamento. Por outro lado, passa a existir um efeito crescente das deformações dos fios e do recobrimento do material em ambas as direções. As deformações totais são decorrentes das deformações oriundas destes dois efeitos. 


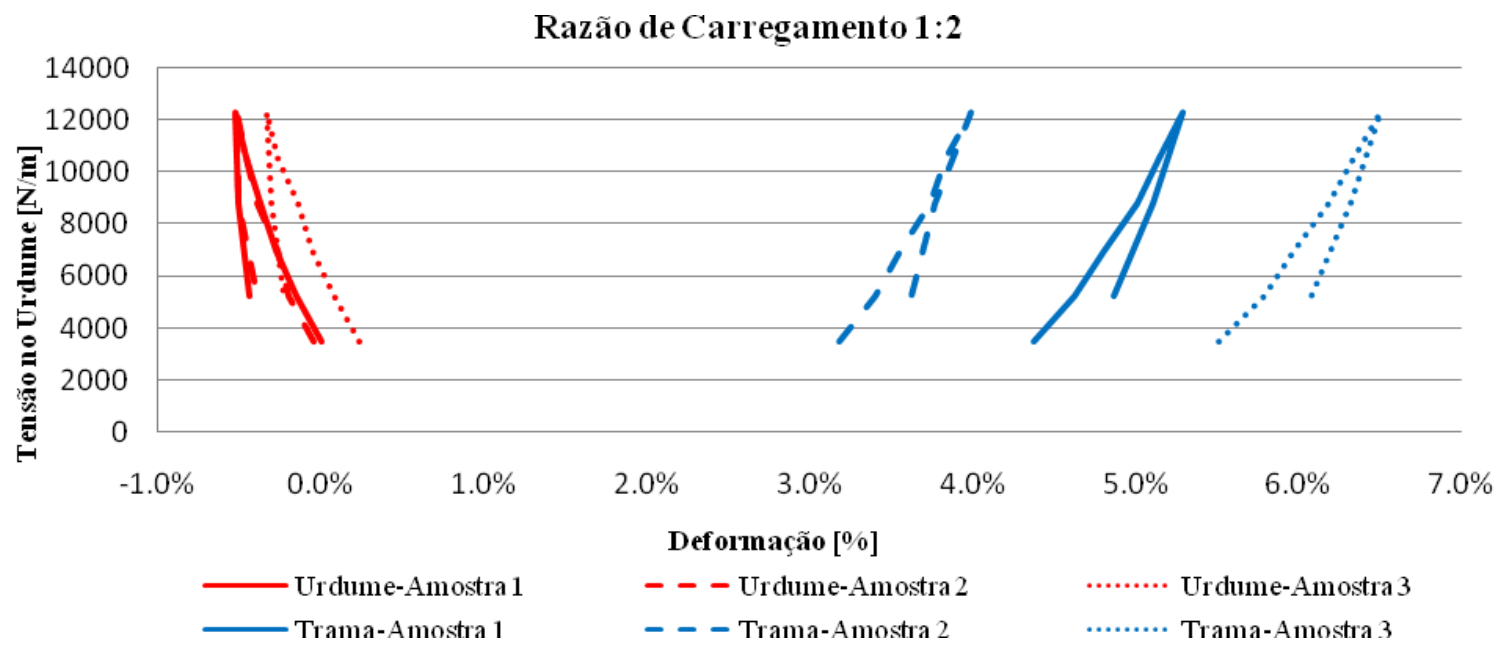

FIGURA 5.3 - Gráfico Tensão $\left(\sigma_{u}, \sigma_{t}\right) \times$ Deformação $\left(\varepsilon_{u}, \varepsilon_{t}\right)$, na razão $\left(\sigma_{u}: \sigma_{t}\right)=(1: 2)$ Fonte: Acervo Pessoal.

Estes mesmos efeitos são observados de forma ainda mais pronunciada nas figuras 5.4 e 5.5, que apresentam os ensaios nas razões $\left(\sigma_{u}: \sigma_{t}\right)=3: 1$ e $\left(\sigma_{u}: \sigma_{t}\right)=1: 3$, respectivamente.

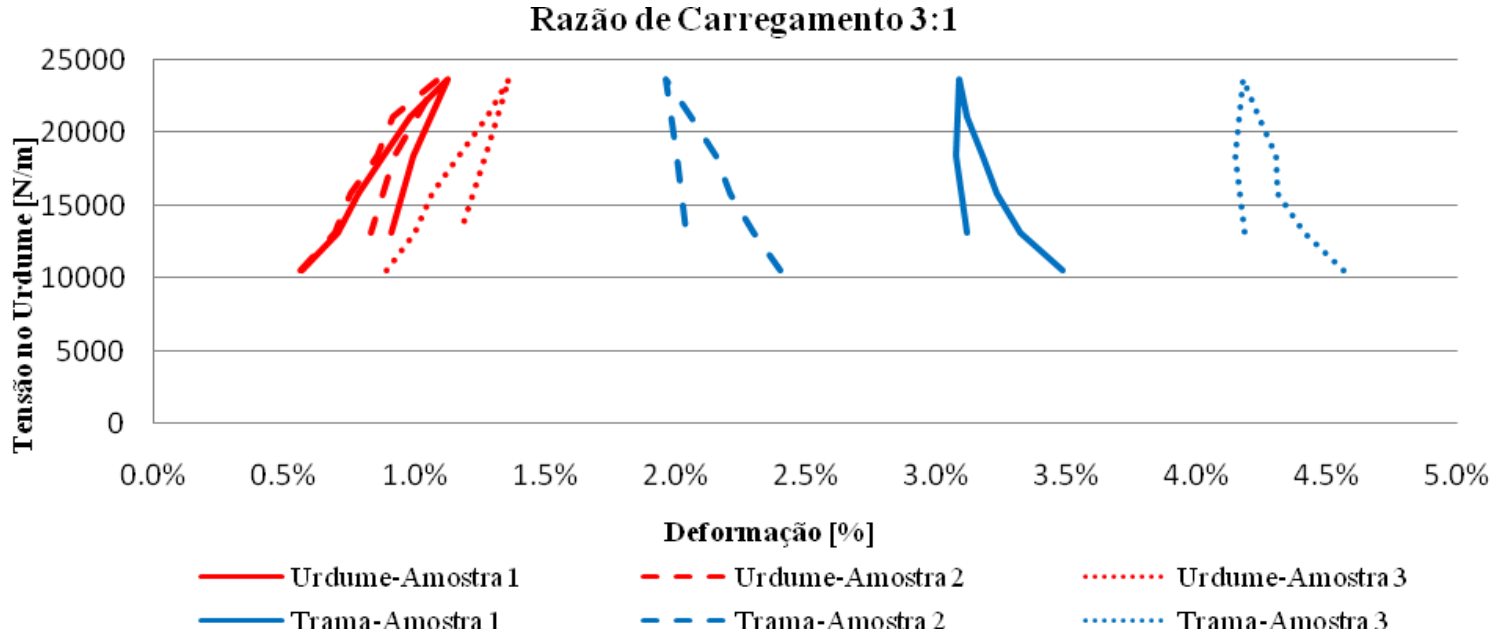

FIGURA 5.4 - Gráfico Tensão $\left(\sigma_{u}, \sigma_{t}\right) \times$ Deformação $\left(\varepsilon_{u}, \varepsilon_{t}\right)$, na razão $\left(\sigma_{u}: \sigma_{t}\right)=(3: 1)$ Fonte: Acervo Pessoal. 


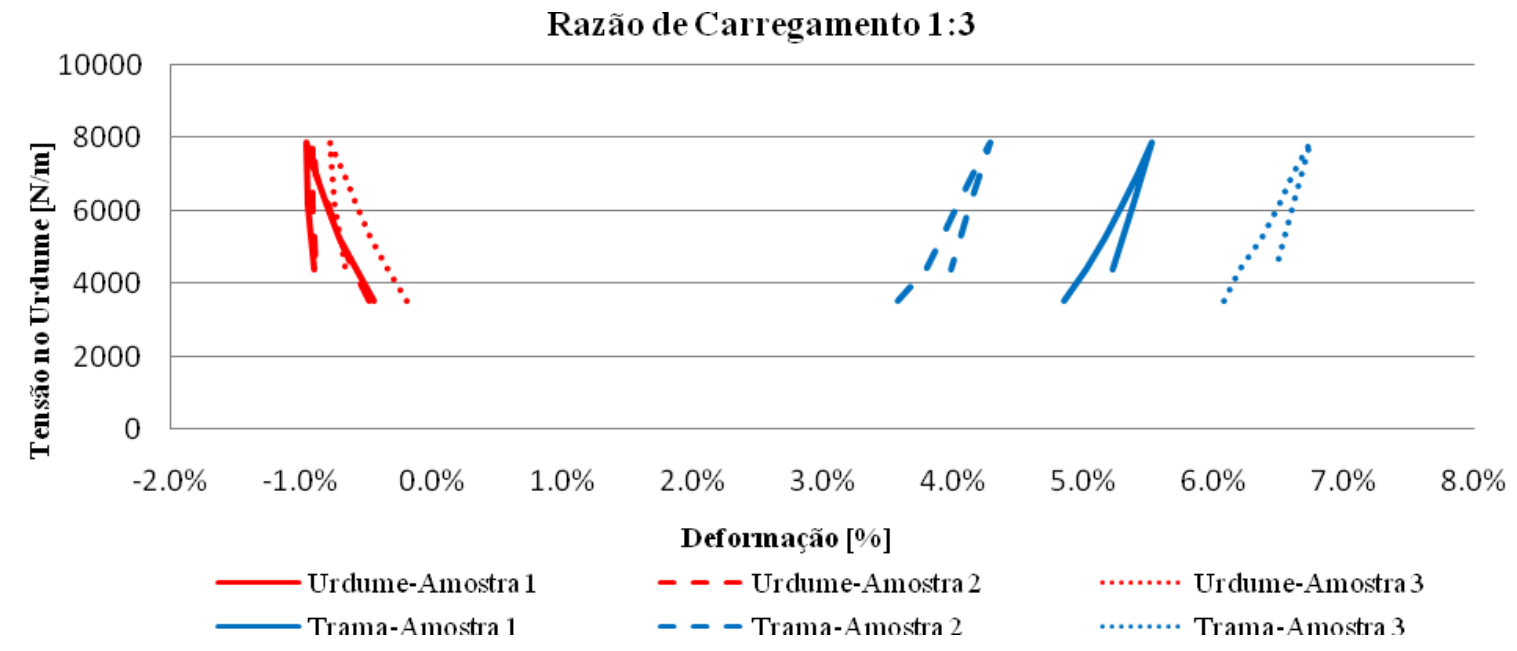

FIGURA 5.5 - Gráfico Tensão $\left(\sigma_{u}, \sigma_{t}\right) \times$ Deformação $\left(\varepsilon_{u}, \varepsilon_{t}\right)$, na razão $\left(\sigma_{u}: \sigma_{t}\right)=(1: 3)$ Fonte: Acervo Pessoal.

\subsection{CONDENSAÇÃo DOS RESULTADOS}

Os resultados obtidos nos ensaios foram condensados em uma tabela de dados que serviu de entrada para o ajuste do funcional que representa o modelo material escolhido para este trabalho.

Uma vez que o modelo de material hiperelástico é conservativo, não podem ser contemplados os fatores dissipativos (deformações permanentes e histerese), observados nos ensaios do tecido PTFE-vidro estudado. Por esta razão, o ajuste dos coeficientes que descrevem o funcional energia de deformação serão feitos considerando apenas os valores médios dos trechos ascendentes das curvas $\sigma-\varepsilon$ obtidas nos diversos ensaios realizados, conforme apresentados na tabela 1. 
Tabela 1 - Valores médios das deformações $\left(\varepsilon_{u}\right.$ e $\left.\varepsilon_{t}\right)$

Fonte: Acervo Pessoal

\begin{tabular}{|c|c|c|c|c|}
\hline \multirow{2}{*}{$\begin{array}{c}\text { Razão de } \\
\text { Carregamento }\end{array}$} & \multicolumn{2}{|c|}{$\begin{array}{c}\text { Tensão aplicada } \\
(\sigma)\end{array}$} & \multicolumn{2}{|c|}{$\begin{array}{l}\text { Deformação linear } \\
\text { calculada }(\varepsilon)\end{array}$} \\
\hline & $\begin{array}{l}\text { Urdume } \\
(\mathrm{N} / \mathrm{m})\end{array}$ & $\begin{array}{l}\text { Trama } \\
(\mathrm{N} / \mathrm{m})\end{array}$ & $\begin{array}{l}\text { Urdume } \\
\text { (\%) }\end{array}$ & $\begin{array}{c}\text { Trama } \\
(\%)\end{array}$ \\
\hline \multirow{7}{*}{$\check{r}$} & 3503 & 3503 & $0.210 \%$ & $4.020 \%$ \\
\hline & 7005 & 7005 & $0.223 \%$ & $4.108 \%$ \\
\hline & 10508 & 10508 & $0.254 \%$ & $4.206 \%$ \\
\hline & 14010 & 14010 & $0.276 \%$ & $4.340 \%$ \\
\hline & 17513 & 17513 & $0.301 \%$ & $4.449 \%$ \\
\hline & 21015 & 21015 & $0.327 \%$ & $4.566 \%$ \\
\hline & 24518 & 24518 & $0.364 \%$ & $4.660 \%$ \\
\hline \multirow{6}{*}{$\bar{i}$} & 7005 & 3503 & $0.467 \%$ & $3.761 \%$ \\
\hline & 10508 & 5254 & $0.565 \%$ & $3.726 \%$ \\
\hline & 14010 & 7005 & $0.635 \%$ & $3.711 \%$ \\
\hline & 17513 & 8756 & $0.743 \%$ & $3.685 \%$ \\
\hline & 21015 & 10508 & $0.799 \%$ & $3.668 \%$ \\
\hline & 24518 & 12259 & $0.869 \%$ & $3.634 \%$ \\
\hline \multirow{6}{*}{ ִִִ } & 3503 & 7005 & $0.005 \%$ & $4.370 \%$ \\
\hline & 5254 & 10508 & $-0.149 \%$ & $4.620 \%$ \\
\hline & 7005 & 14010 & $-0.272 \%$ & $4.804 \%$ \\
\hline & 8756 & 17513 & $-0.367 \%$ & $5.005 \%$ \\
\hline & 10508 & 21015 & $-0.460 \%$ & $5.144 \%$ \\
\hline & 12259 & 24518 & $-0.523 \%$ & $5.290 \%$ \\
\hline \multirow{6}{*}{$\bar{m}$} & 10508 & 3503 & $0.569 \%$ & $3.484 \%$ \\
\hline & 13135 & 4378 & $0.705 \%$ & $3.323 \%$ \\
\hline & 15761 & 5254 & $0.783 \%$ & $3.231 \%$ \\
\hline & 18388 & 6129 & $0.881 \%$ & $3.177 \%$ \\
\hline & 21015 & 7005 & $0.981 \%$ & $3.114 \%$ \\
\hline & 23642 & 7881 & $1.123 \%$ & $3.083 \%$ \\
\hline \multirow{6}{*}{$\stackrel{m}{r}$} & 3503 & 10508 & $-0.442 \%$ & $4.844 \%$ \\
\hline & 4378 & 13135 & $-0.576 \%$ & $5.015 \%$ \\
\hline & 5254 & 15761 & $-0.706 \%$ & $5.161 \%$ \\
\hline & 6129 & 18388 & $-0.814 \%$ & $5.297 \%$ \\
\hline & 7005 & 21015 & $-0.897 \%$ & $5.411 \%$ \\
\hline & 7881 & 23642 & $-0.968 \%$ & $5.526 \%$ \\
\hline
\end{tabular}




\subsection{Método dos Mínimos Quadrados e o AJuste do Funcional Energia DE DEFORMAÇÃO}

O principal objetivo do método dos mínimos quadrados encontra-se na definição dos parâmetros de uma função-modelo de tal forma que esta mais bem se ajuste a uma série de dados. Uma série de dados simples pode consistir de $\mathrm{n}$ pares de coordenadas $\left(x_{i}, y_{i}\right), i=1, \ldots, n$, onde $x_{i}$ representa a variável independente e $y_{i}$, a variável dependente. Coletando as variáveis independentes em um vetor $\mathbf{x}=\left[x_{i}\right], i=1, \ldots, n$, a função modelo possui a forma $f(\mathbf{x}, \boldsymbol{\beta})$, onde os parâmetros

ajustáveis encontram-se armazenados no vetor $\boldsymbol{\beta}=\left[\beta_{j}\right], j=1, \ldots, m$, que também pode ser entendido como um ponto no espaço dos parâmetros de ajuste.

Assim, o método define que os parâmetros $\beta_{j}$ que melhor se ajustam à série de dados são aqueles que minimizam a soma dos quadrados dos resíduos, conforme:

$$
Q=\sum_{i=1}^{n} r_{i}^{2}
$$

onde o resíduo $r_{i}$ é definido como a diferença entre os valores da variável dependente $y_{i}$ e os valores obtidos a partir do modelo estimado:

$$
r_{i}=f\left(x_{i}, \boldsymbol{\beta}\right)-y_{i}
$$

Os problemas de mínimos quadrados podem ser de duas categorias: os problemas lineares e os não-lineares. Os problemas lineares possuem um processo definido de solução, ao contrário dos problemas não-lineares. Estes últimos geralmente são resolvidos por meio de um processo iterativo de refinamento: a cada iteração o sistema é aproximado a um outro, linear, cuja solução é encontrada pelo processo mencionado anteriormente. Assim sendo, temos em termos gerais que ambos os casos possuem o mesmo processo de cálculo. 
A condição necessária para que um ponto $\boldsymbol{\beta}^{*}$, no espaco dos parametros de ajuste, minimize $Q$ é dada pela condição de que as derivadas parciais de $Q$ em relação aos parametros $\beta_{j}$ sejam todas nulas, em correspondência ao ponto $\boldsymbol{\beta}^{*}$, ou seja

$$
\left.\frac{\partial Q}{\partial \boldsymbol{\beta}}\right|_{\boldsymbol{\beta}^{*}}=\mathbf{0}
$$

O gradiente $\frac{\partial Q}{\partial \boldsymbol{\beta}}$ é um vetor cujas componentes são dadas por:

$$
\frac{\partial Q}{\partial \beta_{j}}=2 \sum_{i=1}^{n}\left(r_{i} \frac{\partial r_{i}}{\partial \beta_{j}}\right), j=1, \ldots, m
$$

Resulta um sistema linear de $m$ equações de gradiente com $m$ incógnitas, cuja solução apresenta os coeficientes do modelo ajustado pelo método dos mínimos quadrados.

No presente caso, o que se pretende minimizar são as diferenças entre as segundas tensões de Piola-Kirchhoff calculadas a partir dos ensaios de campo e as mesmas grandezas obtidas a partir de um modelo constitutivo hiperelástico, cujo funcional energia de deformação é descrito por um polinômio completo de quarto grau, definido por (3.16) e aqui repetido por conveniência:

$$
\begin{aligned}
& \phi\left(I_{11}, I_{12}\right)=\phi_{1} I_{11}+\phi_{2} I_{12}+\frac{1}{2} \phi_{3} I_{11}^{2}+\phi_{4} I_{11} I_{12}+\frac{1}{2} \phi_{5} I_{12}^{2}+\frac{1}{3} \phi_{6} I_{11}^{3}+\phi_{7} I_{11}^{2} I_{12}+\phi_{8} I_{11} I_{12}^{2}+ \\
& +\frac{1}{3} \phi_{9} I_{12}^{3}+\frac{1}{4} \phi_{10} I_{11}^{4}+\phi_{11} I_{11}^{3} I_{12}+\phi_{12} I_{11}^{2} I_{12}^{2}+\phi_{13} I_{11} I_{12}^{3}+\frac{1}{4} \phi_{14} I_{12}^{4}
\end{aligned}
$$

Os termos invariantes $I_{11}$ e $I_{12}$ são calculados a partir das medições experimentais em cada ponto $i$. Utilizando a relação definda por (3.1), podemos reescrever os termos do segundo tensor de Piola-Kirchhoff apresentados na equação (3.17) como:

$$
S_{11}^{i}=f\left(I_{11}^{i}, I_{12}^{i}, \phi_{j}\right)
$$

E, com auxílio da equação (3.18), como: 


$$
S_{22}^{i}=g\left(I_{11}^{i}, I_{12}^{i}, \phi_{j}\right)
$$

onde $j=1, \ldots, 14$, é a quantidade de termos que compõe o polinômio definido para o ajuste.

Deste modo, o resíduo quadrático total, considerando este sistema associado, é definido como:

$$
r^{i}=\left[f\left(I_{11}^{i}, I_{12}^{i}, \phi_{j}\right)-S_{11}^{i}\right]^{2}+\left[g\left(I_{11}^{i}, I_{12}^{i}, \phi_{j}\right)-S_{22}^{i}\right]^{2}
$$

Assim, utilizando a definição (5.1), temos:

$$
Q=\sum_{i=1}^{31}\left\{\left[f\left(I_{11}^{i}, I_{12}^{i}, \phi_{j}\right)-S_{11}^{i}\right]^{2}+\left[g\left(I_{11}^{i}, I_{12}^{i}, \phi_{j}\right)-S_{22}^{i}\right]^{2}\right\}
$$

onde $i$ são os 31 pontos coletados nos ensaios (7 na razão 1:1 e 6 em cada uma das demais razões de carregamento).

A função $\psi^{\prime}$ apresentada em (3.15) é função dos invariantes $I_{11}$ e $I_{12}$. Tais invariantes são escritos em função das deformações quadráticas de Green, conforme (3.7). recordando que as deformações de Green são dadas por (3.6) e que para os ensaios realizados, tem-se que:

$$
\mathbf{F}=\left[\begin{array}{cc}
\varepsilon_{u}+1 & 0 \\
0 & \varepsilon_{t}+1
\end{array}\right]
$$

resulta que:

$$
\mathbf{E}=\frac{1}{2}\left[\begin{array}{cc}
\left(\varepsilon_{u}+1\right)^{2}-1 & 0 \\
0 & \left(\varepsilon_{t}+1\right)^{2}-1
\end{array}\right]
$$

onde $\varepsilon_{u}$ e $\varepsilon_{t}$ são as deformações lineares nominais, nas direções do urdume e da trama, determinadas nos ensaios.

Além disso, o segundo tensor de Piola-Kirchhoff, definido por (3.1), pode ser escrito como uma função das tensões normais nominais $\sigma_{u}$ e $\sigma_{t}$ (referentes ao urdume e à 
trama), as quais, de fato, correspondem às componentes $P_{11}$ e $P_{22}$ do primeiro tensor de Piola-Kirchhoff, respectivamente.

A relação entre o primeiro e o segundo tensor de Piola-Kirchhoff é dada por:

$$
\mathbf{S}=\mathbf{F}^{-1} \mathbf{P}
$$

Resultando no segundo tensor tensor de Piola-Kirchhoff expresso em termos das tensões e deformações nominais obtidas nos ensaios:

$$
\mathbf{S}=\left[\begin{array}{cc}
\frac{\sigma_{u}}{\varepsilon_{u}+1} & 0 \\
0 & \frac{\sigma_{t}}{\varepsilon_{t}+1}
\end{array}\right]
$$

Finalmente, os valores de S e E dados por (5.11) e (5.13) são embutios na equação definida por (5.9). Utilizando o conceito definido por (5.4), obtemos um sistema linear de 14 equações com 14 incógnitas, cuja solução apresenta os termos $\phi_{j}$ que mais bem ajustam a função $\psi^{\prime}$ à massa de dados coletados. Este algoritmo foi implementado em uma planilha Excel, e os coeficientes determinados estão expressos na tabela 2.

Tabela 2 - Valores de $\phi_{i}$ para o Funcional Energia de Deformação

Fonte: Acervo Pessoal

\begin{tabular}{|c|c|}
\hline$\phi_{i}$ & Valor Ajustado \\
\hline$\phi_{1}$ & -1092.900246 \\
$\phi_{2}$ & 458.313216 \\
$\phi_{3}$ & 95255.923022 \\
$\phi_{4}$ & 25495.811075 \\
$\phi_{5}$ & -24696.822557 \\
$\phi_{6}$ & -1958920.539338 \\
$\phi_{7}$ & 1899.525035 \\
$\phi_{0}$ & -164.779987 \\
\hline
\end{tabular}




\begin{tabular}{|c|c|}
\hline$\phi_{i}$ & Valor Ajustado \\
\hline$\phi_{9}$ & -69904.977413 \\
$\phi_{10}$ & 20929641.351010 \\
$\phi_{11}$ & 0.023866 \\
$\phi_{12}$ & -13896830.676066 \\
$\phi_{13}$ & -1639.775281 \\
$\phi_{14}$ & 9628005.412646 \\
\hline
\end{tabular}

As figuras 5.6 e 5.7 a seguir apresentam as superficies $S_{11} \times\left(E_{11}, E_{22}\right)$ e $S_{22} \times\left(E_{11}, E_{22}\right)$, obtidas a partir da equação (3.1), considerando uma energia de deformação definida por (5.5) e os coeficientes $\phi_{j}$ apresentados na tabela 2. Na figura 5.6 observa-se que o intervalo de deformações apresentado é muito maior do que aquele de interesse para o estudo dos tecidos arquitetônicos. Esse artifício foi adotado no intuito de ressaltar as não-linearidades presentes na superfície.
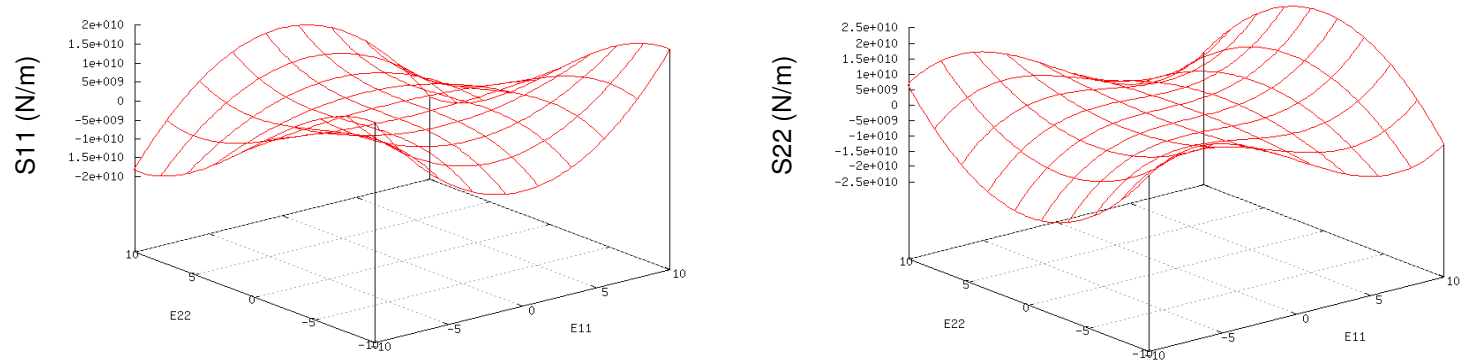

FIGURA 5.6 - (esq) Gráfico $S_{11} \times\left(E_{11}, E_{22}\right)$; (dir) Gráfico $S_{22} \times\left(E_{11}, E_{22}\right)$ Fonte: Acervo Pessoal.

As figuras 5.6 e 5.7 apresentam as superficies $S_{11}$ e $S_{22}$ derivadas do funcional energia de deformação ajustado aos dados experimentais, conforme os coeficientes $\phi_{j}$ apresentados na tabela 2. A figura 5.7 apresenta em detalhe a faixa onde as deformações $E_{11}$ variam de $\{-1 \%: 1 \%\}$ e $E_{22}$ variam de $\{3 \%: 5 \%\}$. Estas são as faixas de deformação de Green apresentadas nos ensaios de campo. Como podemos notar, as superfícies são quase planas nestes intervalos. 

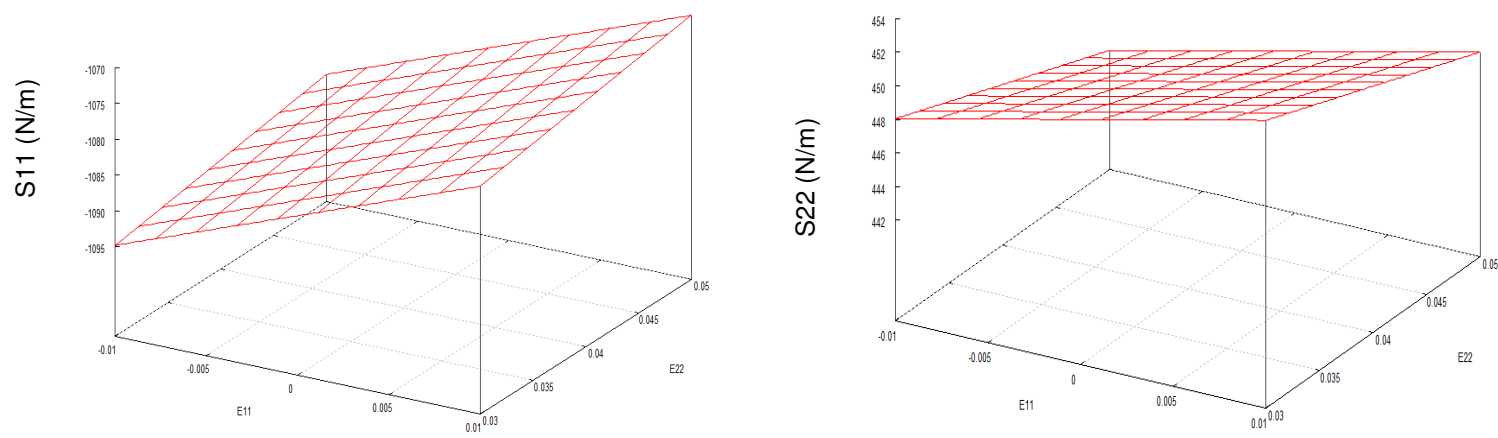

FIGURA 5.7 - (esq) detalhe do Gráfico $S_{11} \times\left(E_{11}, E_{22}\right)$; (dir) detalhe do gráfico $S_{22} \times\left(E_{11}, E_{22}\right)$ Fonte: Acervo Pessoal.

\subsection{Avaliação do Funcional AJuStado}

Os resultados experimentais dos ensaios biaxiais apresentados na tabela 1 podem também ser representados com a utilização de superficies $\sigma_{u} \times\left(\varepsilon_{u}, \varepsilon_{t}\right)$ e $\sigma_{t} \times\left(\varepsilon_{u}, \varepsilon_{t}\right)$, relacionando as tensões nominais (primeira tensão de Piola-Kirchhoff) com as deformações lineares. Contudo, os pares $\left(\varepsilon_{u}, \varepsilon_{t}\right)$ experimentais não geram um domínio de malha retangular completa, uma vez que estes pontos obedecem algumas poucas razões de carregamento prescritas. As figuras 5.8 e 5.9 limitam-se a apresentar a dispersão dos pontos $\left(\sigma_{u}, \varepsilon_{u}, \varepsilon_{t}\right)$ e $\left(\sigma_{t}, \varepsilon_{u}, \varepsilon_{t}\right)$, conforme determinados a partir dos ensaios.

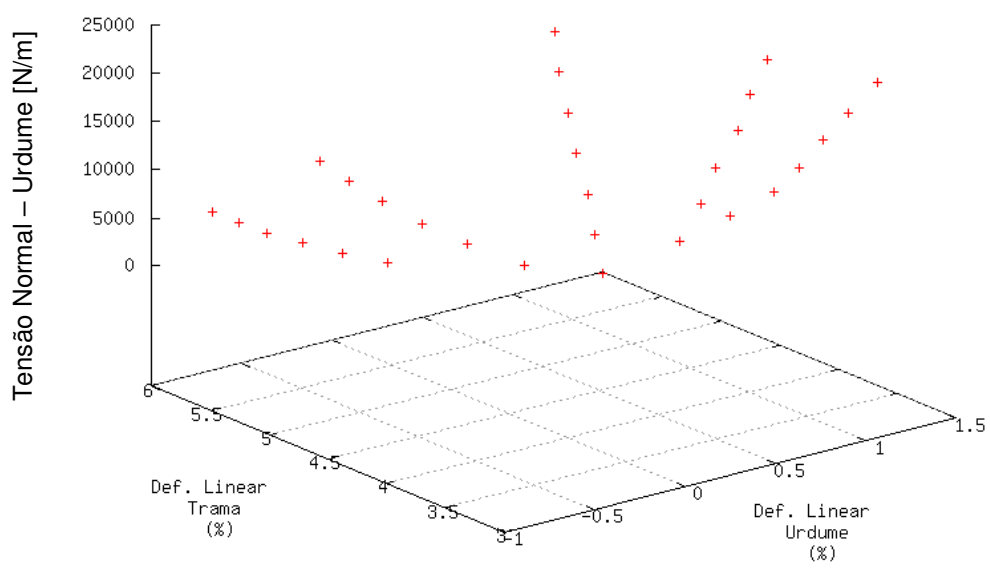

FIGURA 5.8 - Dispersão dos pontos $\left(\sigma_{u}, \varepsilon_{u}, \varepsilon_{t}\right)$ (Dados de Campo) Fonte: Acervo Pessoal. 


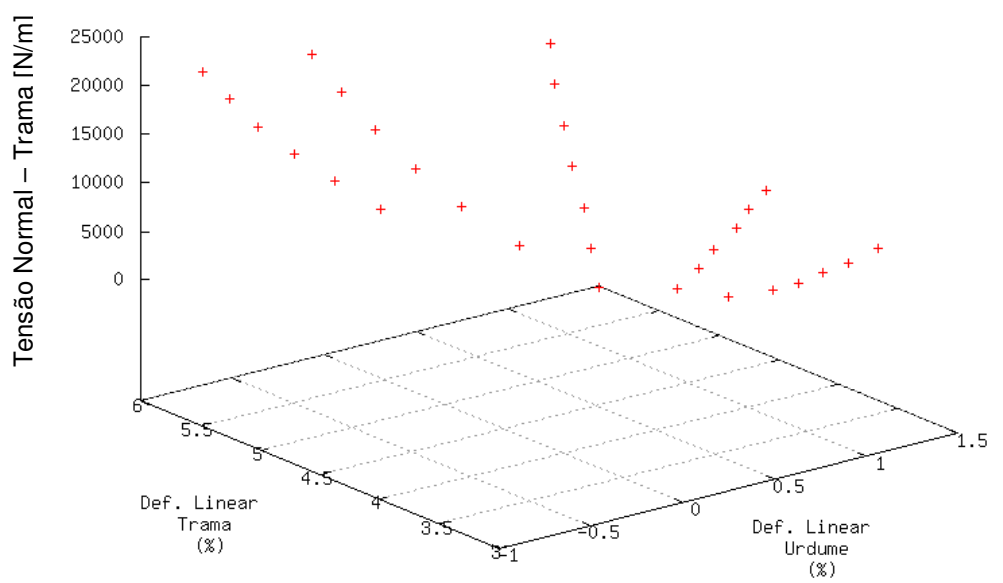

FIGURA 5.9 - Dispersão dos pontos $\left(\sigma_{t}, \varepsilon_{u}, \varepsilon_{t}\right)$ (Dados de Campo) Fonte: Acervo Pessoal.

O próximo passo é a comparação destes dados de campo ao funcional ajustado. As deformações lineares medidas em campo e apresentadas na tabela 1 são transformadas em deformações de Green com o auxílio de (5.11), e então inserida nas equações (3.17) e (3.18), que utilizam os coeficientes $\phi_{j}$ definidos na tabela 2 . Como resultado, obtemos componentes calculadas do segundo tensor de Piola Kirchhoff (indicadas neste trabalho por $\overline{\mathbf{S}}$, para distinguir das tensões $\mathbf{S}$ ), que são então transformadas, com o uso de (5.13), em tensões normais nominais, indicadas por $\left(\bar{\sigma}_{u}, \bar{\sigma}_{t}\right)$, para distinguir das tensões nominais $\left(\sigma_{u}, \sigma_{t}\right)$, medidas nos ensaios experimentais.

As figuras 5.10 e 5.11 apresentam as dispersões $\left(\bar{\sigma}_{u}, \varepsilon_{u}, \varepsilon_{t}\right)$ e $\left(\bar{\sigma}_{t}, \varepsilon_{u}, \varepsilon_{t}\right)$ geradas a partir dos coeficientes $\phi_{j}$ ajustados. Para cada razão de carregamento, os pontos adjacentes gerados foram ligados por uma linha poligonal no intuito de se facilitar a visualização dos resultados. As figuras 5.10 e 5.11 também mostram novamente os pontos $\left(\sigma_{u}, \varepsilon_{u}, \varepsilon_{t}\right)$ e $\left(\sigma_{t}, \varepsilon_{u}, \varepsilon_{t}\right)$ experimentais para que se possa inspecionar visualmente a qualidade do ajuste gerado. 


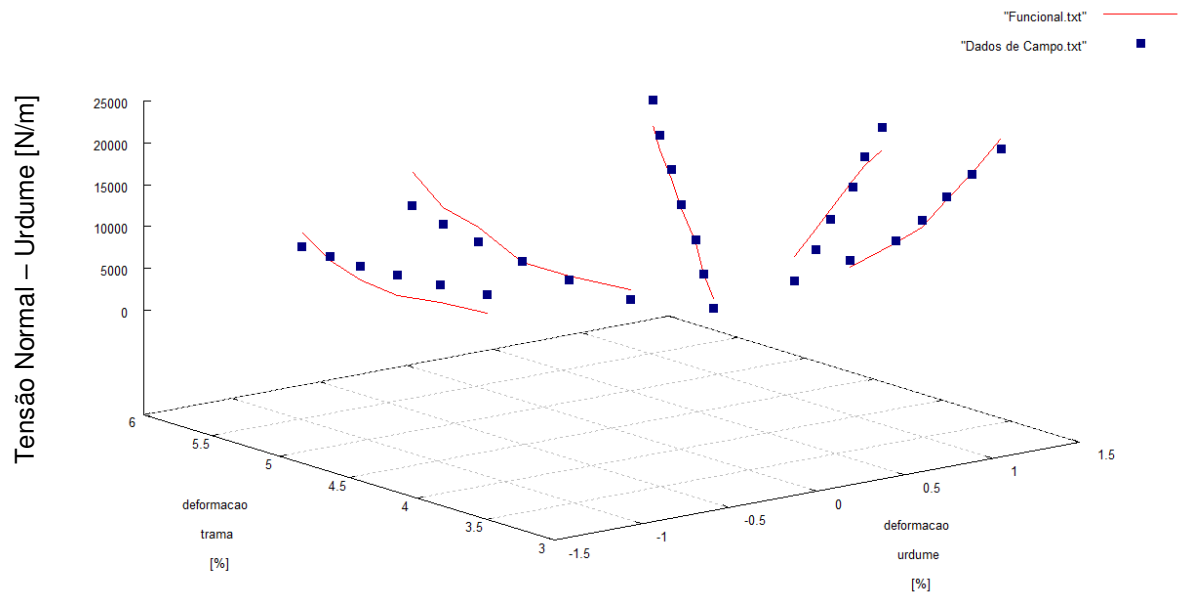

FIGURA 5.10 - Comparação entre as dispersões de pontos $\left(\bar{\sigma}_{u}, \varepsilon_{u}, \varepsilon_{t}\right)$ gerados (linhas vermelhas) e de pontos $\left(\sigma_{u}, \varepsilon_{u}, \varepsilon_{t}\right)$ obtidos experimentalmente (pontos em azul), para a diversas razões de carregamento.

Fonte: Acervo Pessoal.

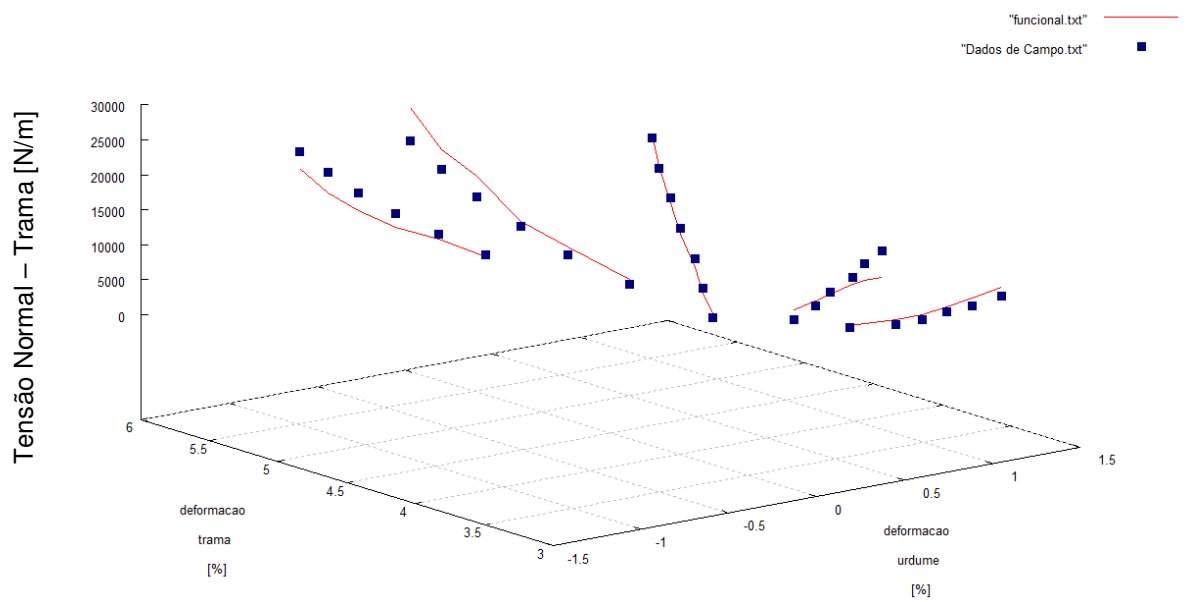

FIGURA 5.11 - Comparação entre as dispersões de pontos $\left(\bar{\sigma}_{t}, \varepsilon_{u}, \varepsilon_{t}\right)$ gerados (linhasvermelhas) e de pontos $\left(\sigma_{t}, \varepsilon_{u}, \varepsilon_{t}\right)$ obtidos experimentalmente (pontos em azul), para a diversas razões de carregamento

Fonte: Acervo Pessoal.

Podemos notar pelas figuras 5.10 e 5.11 que a função escolhida para modelar este fenômeno representa com limitada fidelidade o comportamento na relação de carregamento 1:1. Entretanto, diferenças significativas aparecem entre os resultados do modelo de ajuste e os dados de campo, quando as demais razões de carregamento são consideradas. 
Sob a razão de 1:1, os valores obtidos a partir do ajuste apresentam boa aderência aos resultados de campo. Entretanto, considerando as demais razões de carregamento testadas, as relações entre as deformações nas duas direções variam de tal modo que o polinômio adotado neste trabalho não consegue representá-las com fidelidade.

Deste modo, em uma avaliação inicial entre os dados de campo e o funcional ajustado, podemos concluir que a função escolhida não representa adequadamente o comportamento do material. Neste momento, uma segunda consideração deve ser feita antes de uma avaliação final. Confome apresentado no item 3.1.3, um outro método de modelagem utilizado atualmente encontra-se no ajuste direto de funções suaves que representem as superfícies $\sigma_{u} \times\left(\varepsilon_{u}, \varepsilon_{t}\right)$ e $\sigma_{t} \times\left(\varepsilon_{u}, \varepsilon_{t}\right)$

Neste caso, os dados de campo são diretamente ajustados à um polinômio completo do quarto grau $(\kappa)$, similar àquele definido para o funcional energia de deformação (5.5):

$$
\kappa=\hat{\kappa}\left(\varepsilon_{u}, \varepsilon_{t}\right)
$$

de tal modo que as tensões normais $\left(\overline{\bar{\sigma}}_{u}\right.$ e $\left.\overline{\bar{\sigma}}_{t}\right)$ possam ser representadas por:

$$
\begin{gathered}
\overline{\bar{\sigma}}_{u}=\frac{\partial \kappa}{\partial \varepsilon_{u}} \\
\overline{\bar{\sigma}}_{t}=\frac{\partial \kappa}{\partial \varepsilon_{t}}
\end{gathered}
$$

Onde as duas barras superiores $(\overline{\bar{\sigma}})$ servem para diferenciar as tensões obtidas pelo ajuste direto das curvas daquelas obtidas experimentalmente $(\sigma)$ e daquelas obtidas pelo ajuste do funcional energia de deformação $(\bar{\sigma})$.

Utilizando o método dos mínimos quadrados de modo similar àquele utilizado para ajuste do funcional energia de deformação em (5.8) e (5.9), os polinômios (5.15) e 
(5.16) são ajustados aos dados presentes na tabela 1, originando os coeficientes $\kappa_{j}, j=1, \ldots, 14$, que estão apresentados na tabela 3 a seguir.

Tabela 3 - Valores de $\kappa_{j}$ para o Funcional de Ajuste Direto dos Dados de Campo Fonte: Acervo Pessoal

\begin{tabular}{|c|c|}
\hline$\kappa_{i}$ & Valor Ajustado \\
\hline$\kappa_{1}$ & -1148.147429 \\
$\kappa_{2}$ & 673.875310 \\
$\kappa_{3}$ & 106125.782349 \\
$\kappa_{4}$ & 27302.370748 \\
$\kappa_{5}$ & -33799.191999 \\
$\kappa_{6}$ & -2356159.747549 \\
$\kappa_{7}$ & 2178.799668 \\
$\kappa_{8}$ & -220.579145 \\
$\kappa_{9}$ & -77768.048419 \\
$\kappa_{10}$ & 21601691.390307 \\
$\kappa_{11}$ & 0.030856 \\
$\kappa_{12}$ & -17049099.669948 \\
$\kappa_{1 \mathrm{R}}$ & -2264.427418 \\
$\kappa_{14}$ & 12320689.034242 \\
\hline
\end{tabular}

As curvas resultantes deste ajuste direto podem ser superpostas às figuras $5.10 \mathrm{e}$ 5.11, gerando as figuras 5.12 e 5.13, cuja inspeção visual nos mostra que tanto o funcional energia de deformação quanto o funcional de ajuste direto apresentam resultados próximos,ou seja, igualmente representando com limitada fidelidade 0 comportamento na relação de carregamento 1:1 e, novamente, com diferenças bastante significativas para outras razões de carregamento. 


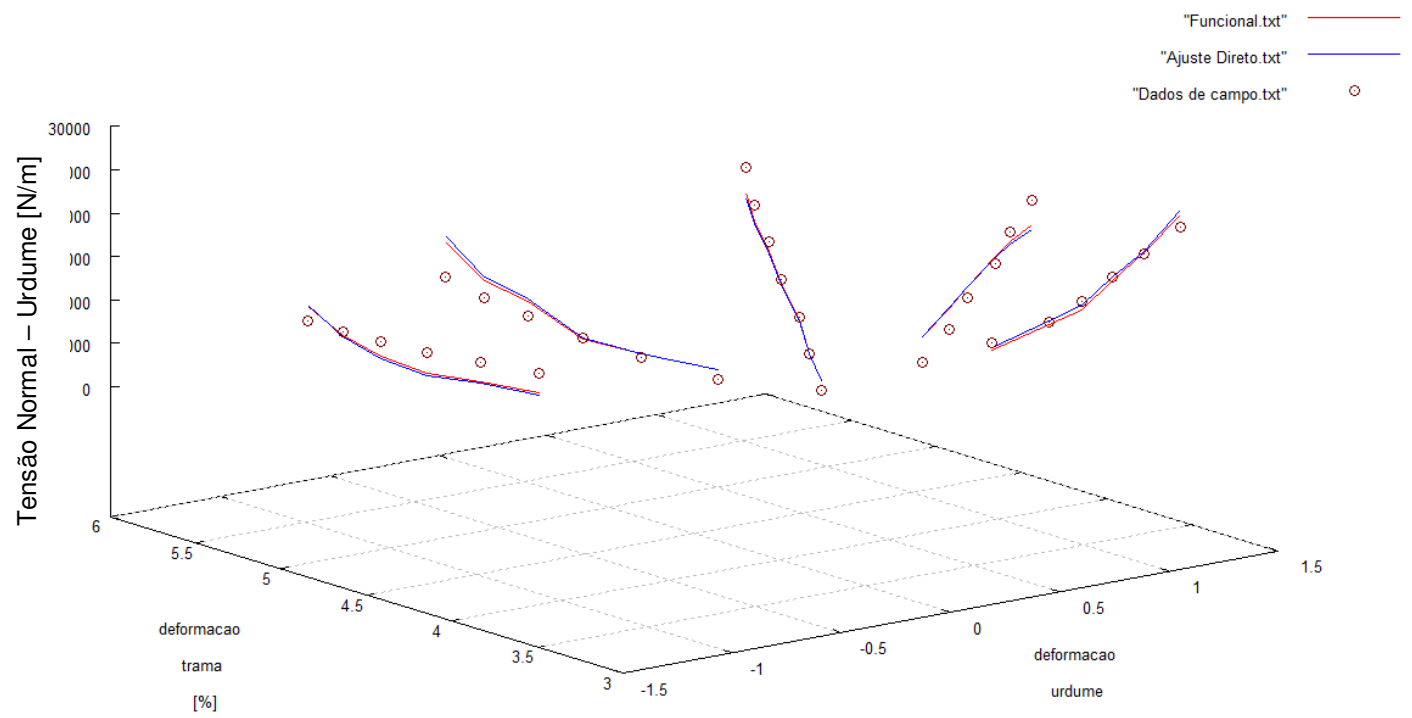

FIGURA 5.12 - Comparação entre as dispersões de pontos $\left(\overline{\bar{\sigma}}_{u}, \varepsilon_{u}, \varepsilon_{t}\right)$ gerados pelo ajuste direto (linhas azuis), $\left(\bar{\sigma}_{u}, \varepsilon_{u}, \varepsilon_{t}\right)$ gerados pelo ajuste do funcional (linhas vermelhas) e de pontos $\left(\sigma_{u}, \varepsilon_{u}, \varepsilon_{t}\right)$ obtidos experimentalmente (círculos), para a diversas razões de carregamento. Fonte: Acervo Pessoal.

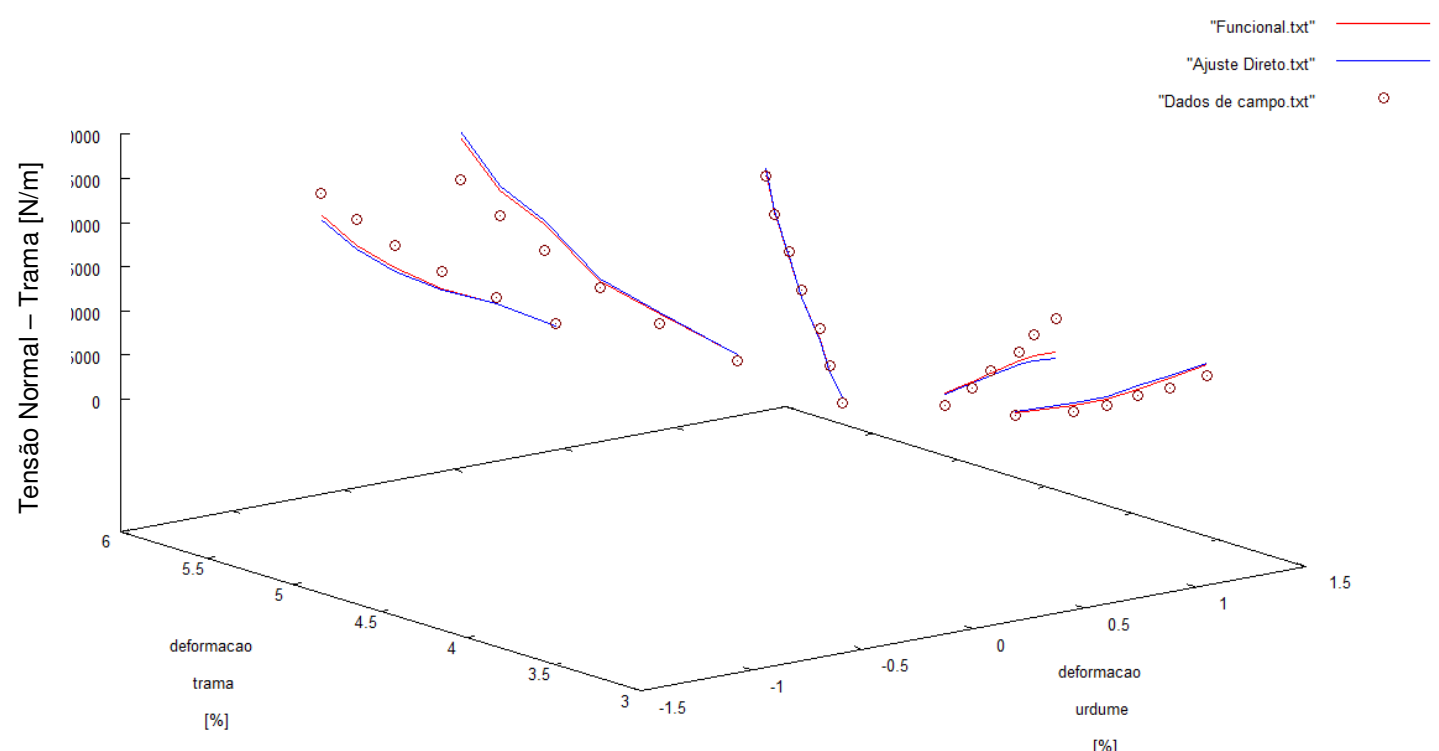

FIGURA 5.13 - Comparação entre as dispersões de pontos $\left(\overline{\bar{\sigma}}_{t}, \varepsilon_{u}, \varepsilon_{t}\right)$ gerados pelo ajuste direto (linhas azuis), $\left(\bar{\sigma}_{t}, \varepsilon_{u}, \varepsilon_{t}\right)$ gerados pelo ajuste do funcional (linhas vermelhas) e de pontos $\left(\sigma_{t}, \varepsilon_{u}, \varepsilon_{t}\right)$ obtidos experimentalmente (círculos), para a diversas razões de carregamento. Fonte: Acervo Pessoal.

No intuito de mais bem visualizar estas diferenças, uma série de gráficos $\sigma-\varepsilon$ foi gerada (para cada direção de ortotropia e para cada razão de carregamento), 
apresentando as relações entre as deformações $\left(\varepsilon_{u}\right.$ ou $\left.\varepsilon_{t}\right)$ medidas em campo, tanto com as tensões de campo $\left(\sigma_{u}\right.$ e $\left.\sigma_{t}\right)$, como com tensões calculadas a partir do funcional energia de deformação $\left(\begin{array}{lll}\bar{\sigma}_{u} & \text { e } & \bar{\sigma}_{t}\end{array}\right)$ e com aquelas calculadas a partir do ajuste direto $\left(\overline{\bar{\sigma}}_{u}\right.$ e $\left.\overline{\bar{\sigma}}_{t}\right)$. Este resultados são apresentados nas figuras 5.14 à 5.23 .

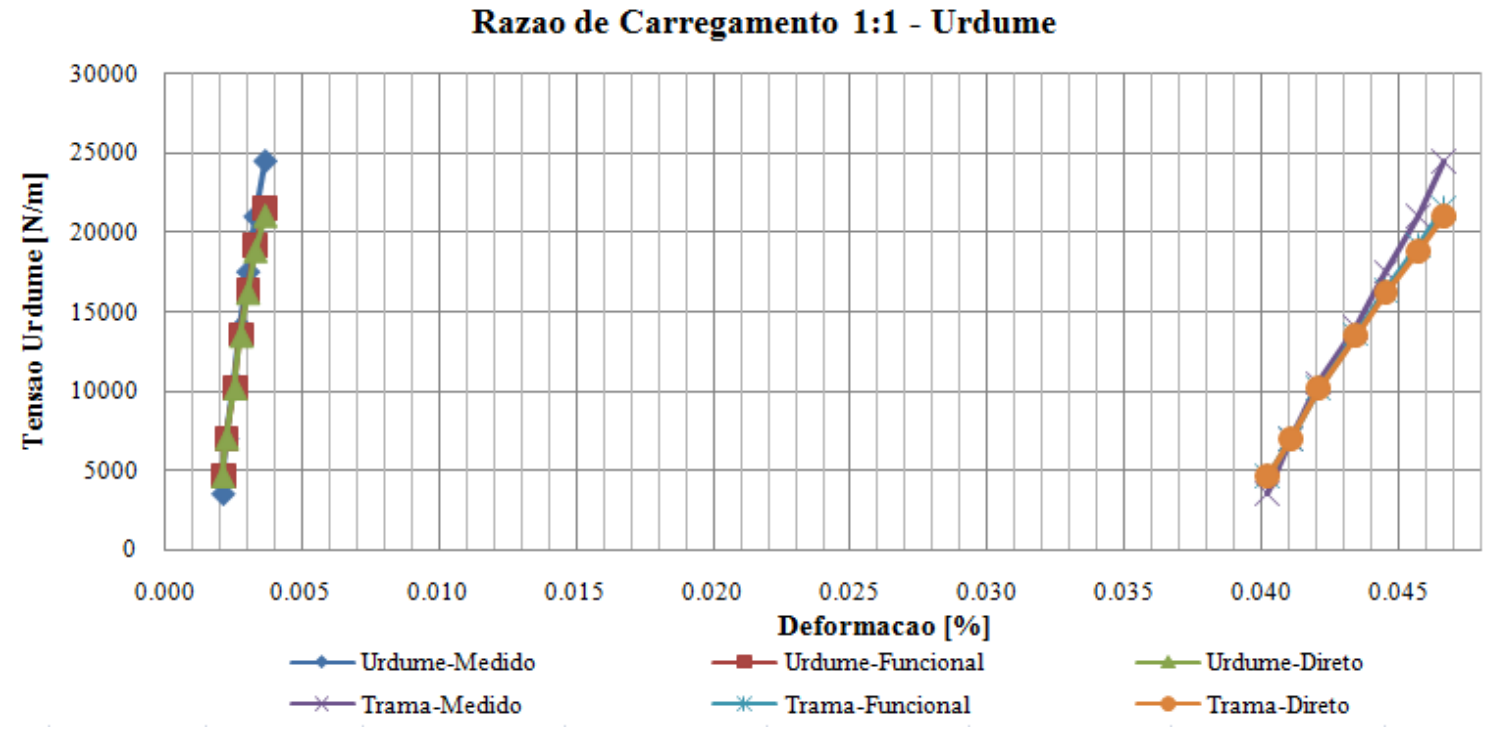

FIGURA $5.14-$ Gráficos $\sigma_{u}-\varepsilon_{u}, \bar{\sigma}_{u}-\varepsilon_{u}, \overline{\bar{\sigma}}_{u}-\varepsilon_{u}$ e $\sigma_{u}-\varepsilon_{t}, \bar{\sigma}_{u}-\varepsilon_{t}, \overline{\bar{\sigma}}_{u}-\varepsilon_{t}$, na razão $\left(\sigma_{u}: \sigma_{t}\right)=(1: 1)$ Fonte: Acervo Pessoal.

\section{Razao de Carregamento 1:1 - Trama}

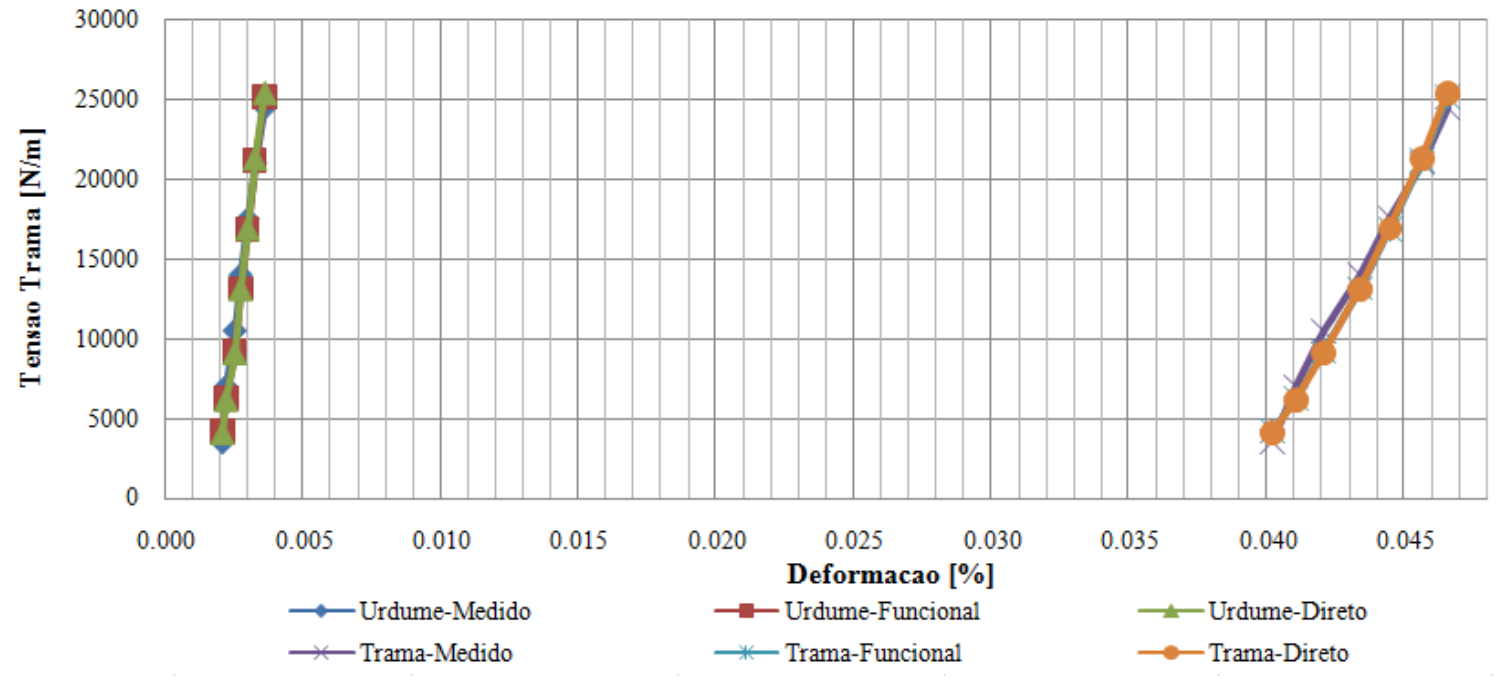

FIGURA 5.15 - Gráficos $\sigma_{t}-\varepsilon_{u}, \bar{\sigma}_{t}-\varepsilon_{u}, \overline{\bar{\sigma}}_{t}-\varepsilon_{u}$ e $\sigma_{t}-\varepsilon_{t}, \bar{\sigma}_{t}-\varepsilon_{t}, \overline{\bar{\sigma}}_{t}-\varepsilon_{t}$, na razão $\left(\sigma_{u}: \sigma_{t}\right)=(1: 1)$ Fonte: Acervo Pessoal. 
Os gráficos 5.14 e 5.15 representam os resultados para a razão $\left(\sigma_{u}: \sigma_{t}\right)=(1: 1)$. Observa-se que, neste caso, os fios das direções da trama e do urdume apresentam sempre alongamento (em relação ao comprimento de referência), conforme o aumento do carregamento. Este acréscimo consegue ser representado pelos ajustes porém, em carregamnetos mais elevados (principalmente com relação à tensão na direção do urdume), os resultados de ambos ajustes se afastam dos dados de campo. Esta diferença não é tão significativa no caso da tensão na direção da trama.

Os gráficos 5.16 e 5.17 apresentam os resultados para a razão $\left(\sigma_{u}: \sigma_{t}\right)=(2: 1)$. Neste caso, os fios do urdume apresentam alongamento (em relação ao comprimento de referência), enquanto os da trama se encurtam, conforme o aumento do carregamento. Novamente, o ajuste do funcional e o ajuste direto apresentam resultados similares. Avaliando primeiramente a figura 5.16, temos que os ajustes não representam adequadamente os valores mais baixos e nem os mais elevados das tensões na direção do urdume. Já na direção da trama (figura 5.17) estas diferenças são ainda mais evidentes.

Razão de Carregamento 2:1 - Urdume

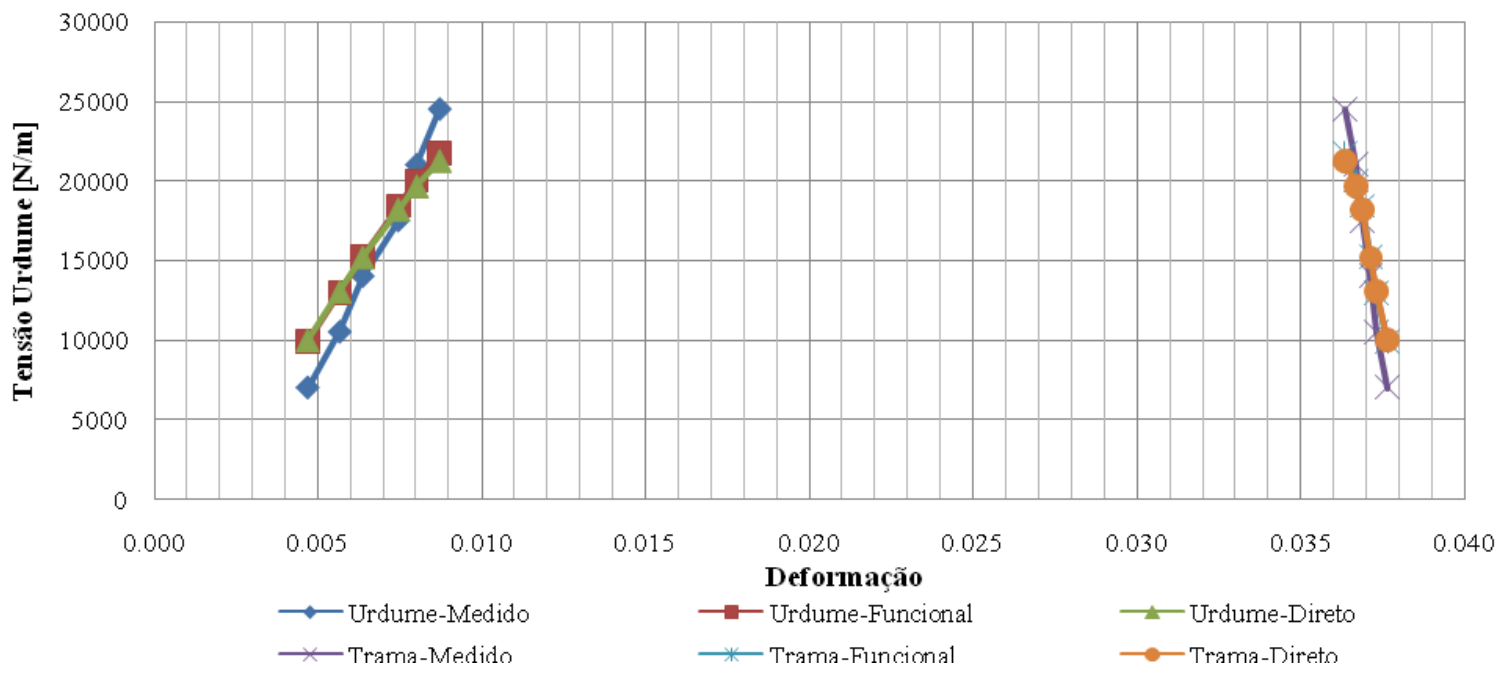

FIGURA 5.16 - Gráficos $\sigma_{u}-\varepsilon_{u}, \bar{\sigma}_{u}-\varepsilon_{u}, \overline{\bar{\sigma}}_{u}-\varepsilon_{u} \mathrm{e}$ $\sigma_{u}-\varepsilon_{t}, \bar{\sigma}_{u}-\varepsilon_{t}, \overline{\bar{\sigma}}_{u}-\varepsilon_{t}$, na razão $\left(\sigma_{u}: \sigma_{t}\right)=(2: 1)$ Fonte: Acervo Pessoal. 
Razão de Carregamento 2:1 - Trama

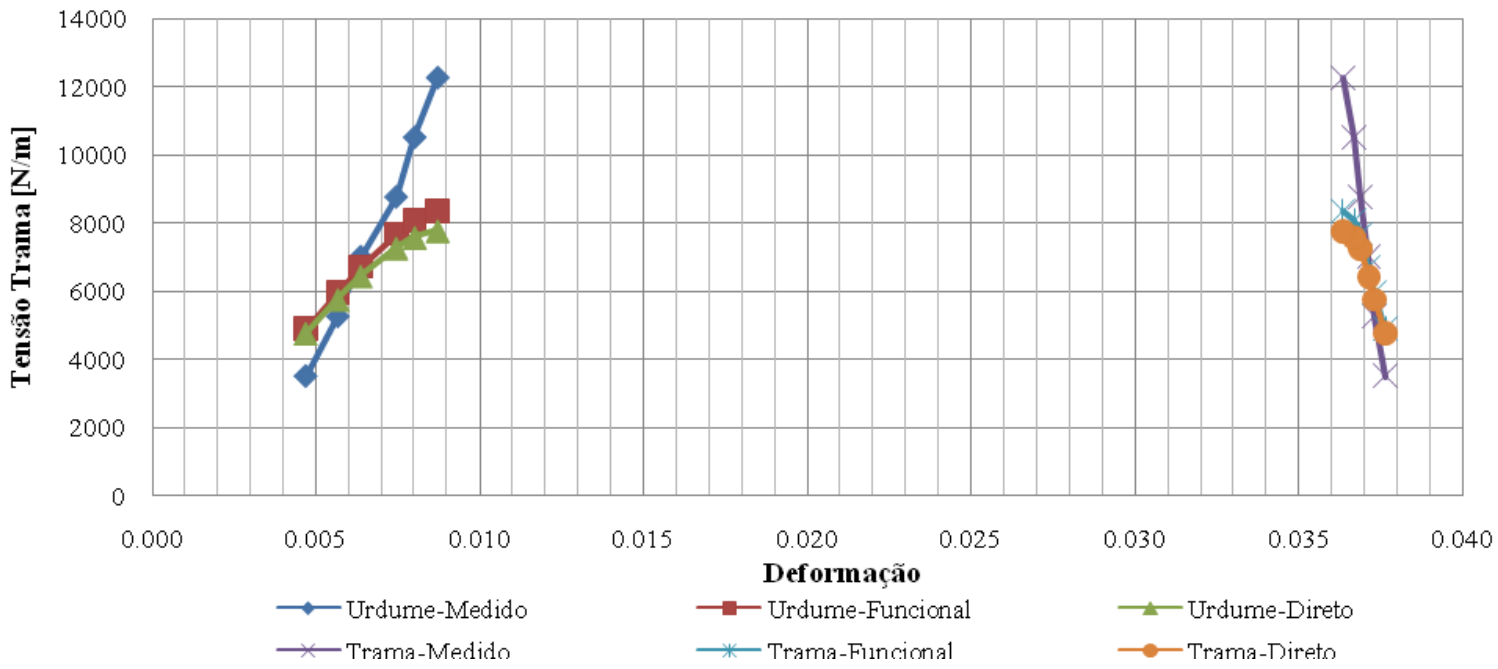

FIGURA 5.17 - Gráficos $\sigma_{t}-\varepsilon_{u}, \bar{\sigma}_{t}-\varepsilon_{u}, \overline{\bar{\sigma}}_{t}-\varepsilon_{u}$ e

$\sigma_{t}-\varepsilon_{t}, \bar{\sigma}_{t}-\varepsilon_{t}, \overline{\bar{\sigma}}_{t}-\varepsilon_{t}$, na razão $\left(\sigma_{u}: \sigma_{t}\right)=(2: 1)$

Fonte: Acervo Pessoal.

Razão de Carregamento 1:2 - Urdume

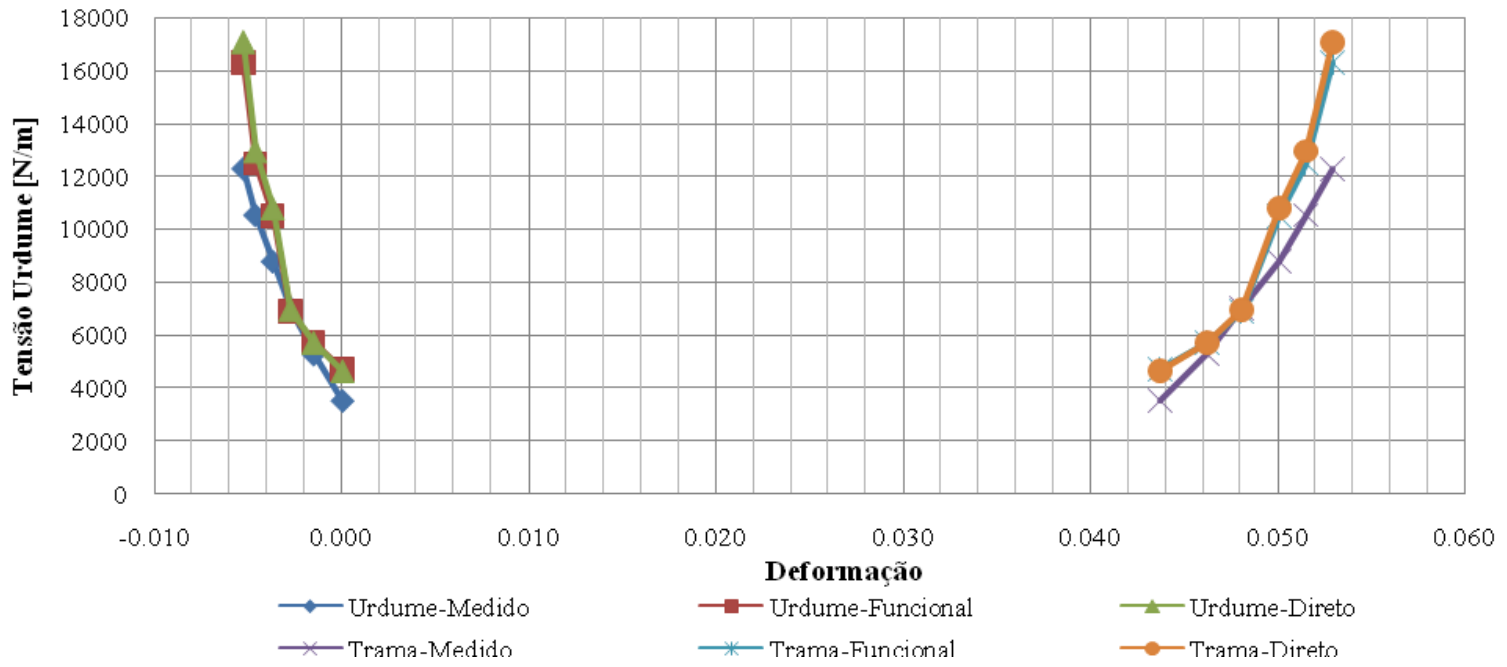

FIGURA 5.18-Gráficos $\sigma_{u}-\varepsilon_{u}, \bar{\sigma}_{u}-\varepsilon_{u}, \overline{\bar{\sigma}}_{u}-\varepsilon_{u}$ e $\sigma_{u}-\varepsilon_{t}, \bar{\sigma}_{u}-\varepsilon_{t}, \overline{\bar{\sigma}}_{u}-\varepsilon_{t}$, na razão $\left(\sigma_{u}: \sigma_{t}\right)=(1: 2)$

Fonte: Acervo Pessoal. 


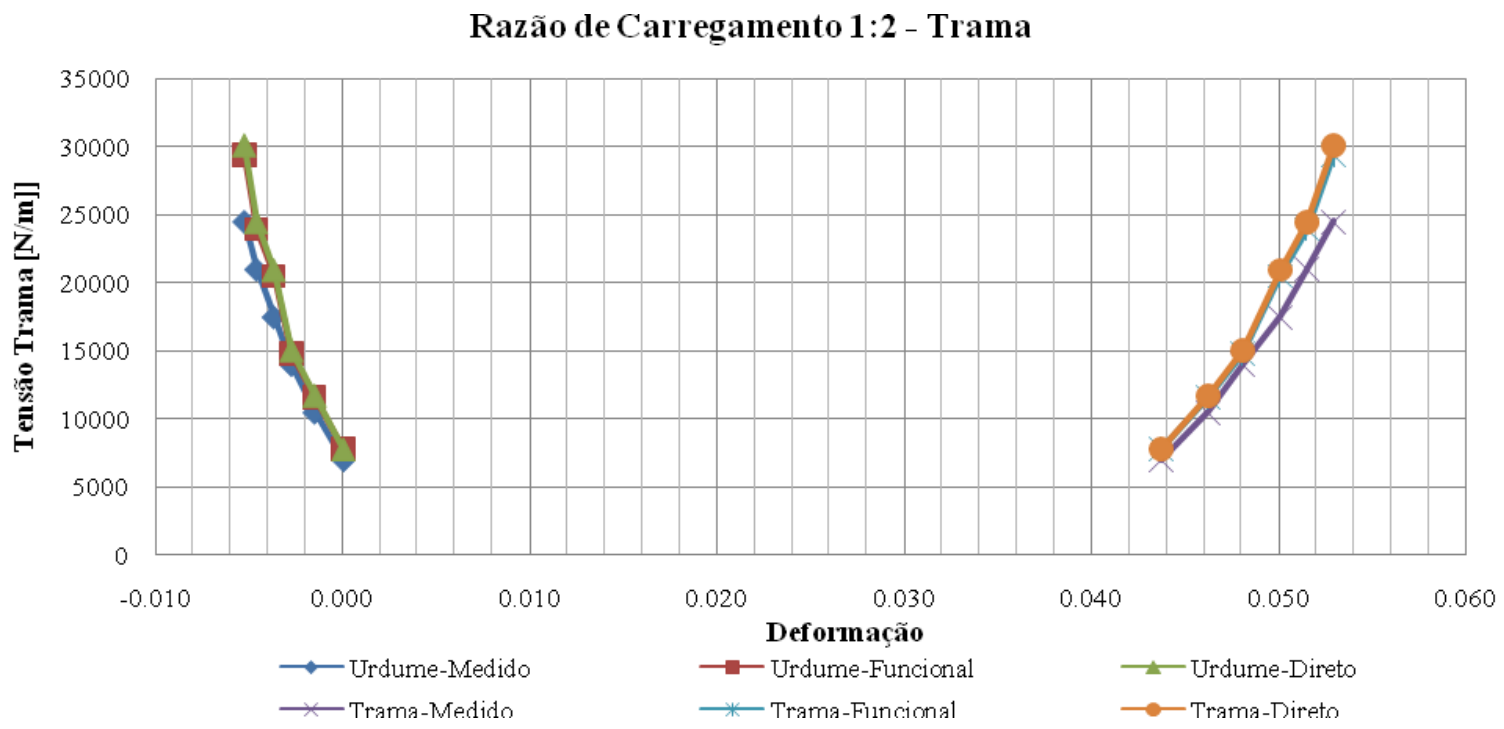

FIGURA $5.19-$ Gráficos $\sigma_{t}-\varepsilon_{u}, \bar{\sigma}_{t}-\varepsilon_{u}, \overline{\bar{\sigma}}_{t}-\varepsilon_{u}$ e

$\sigma_{t}-\varepsilon_{t}, \bar{\sigma}_{t}-\varepsilon_{t}, \overline{\bar{\sigma}}_{t}-\varepsilon_{t}$, na razão $\left(\sigma_{u}: \sigma_{t}\right)=(1: 2)$ Fonte: Acervo Pessoal.

Nos gráficos 5.18 e 5.19, o quais apresentam a razão $\left(\sigma_{u}: \sigma_{t}\right)=(1: 2)$, temos que, diferentemente do que foi encontrado na razão de $2: 1$, os fios do urdume apresentam um encurtamento, enquanto os da trama alongam, conforme o aumento do carregamento. Novamente, o ajuste do funcional e o ajuste direto apresentam resultados similares. Também neste caso temos que os ajustes não representam adequadamente os valores mais baixos e nem os mais altos das tensões na direção do urdume. Porém, desta vez, as tensões calculadas pelos ajustes são superiores àquelas encontradas em campo. Esta diferença se encontra mais evidente na tensão na direção do urdume. 
Razão de Carregamento 3:1 - Urdume

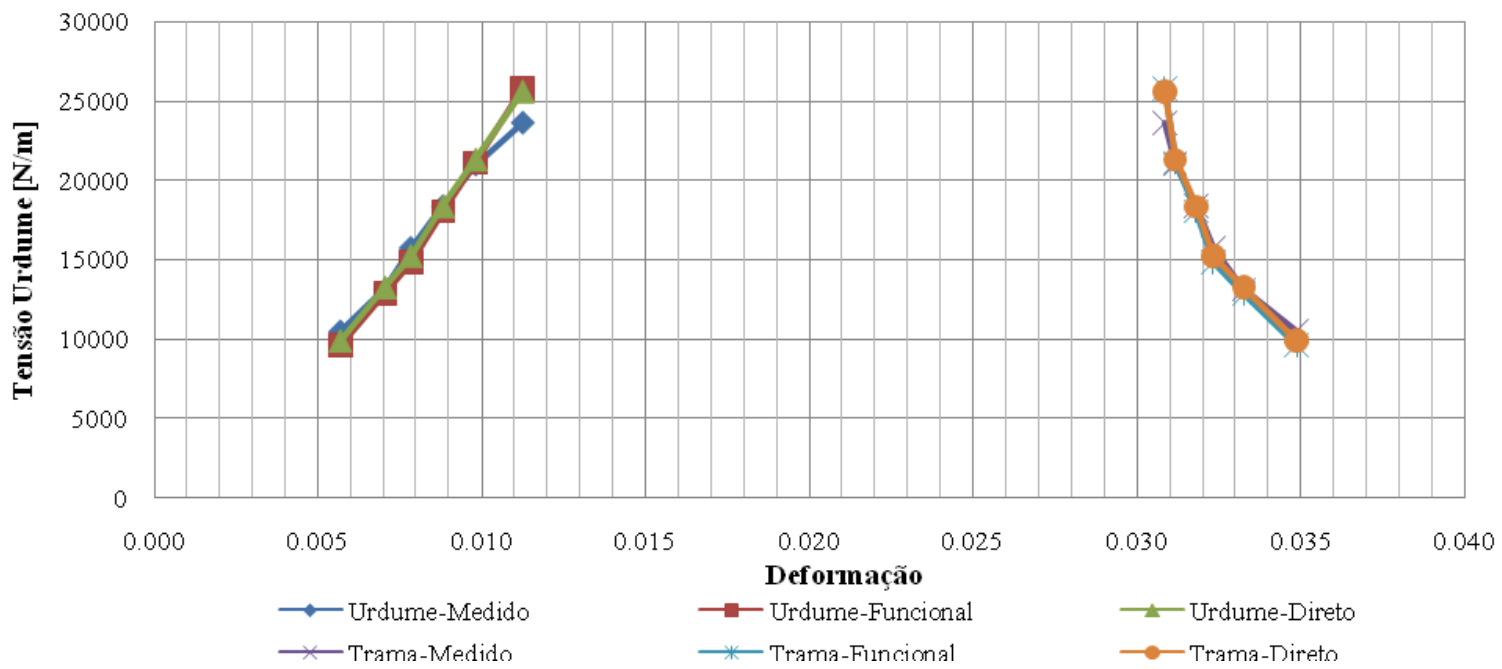

FIGURA 5.20 - Gráficos $\sigma_{u}-\varepsilon_{u}, \bar{\sigma}_{u}-\varepsilon_{u}, \overline{\bar{\sigma}}_{u}-\varepsilon_{u}$ e $\sigma_{u}-\varepsilon_{t}, \bar{\sigma}_{u}-\varepsilon_{t}, \overline{\bar{\sigma}}_{u}-\varepsilon_{t}$, na razão $\left(\sigma_{u}: \sigma_{t}\right)=(3: 1)$ Fonte: Acervo Pessoal.

Razão de Carregamento 3:1 - Trama

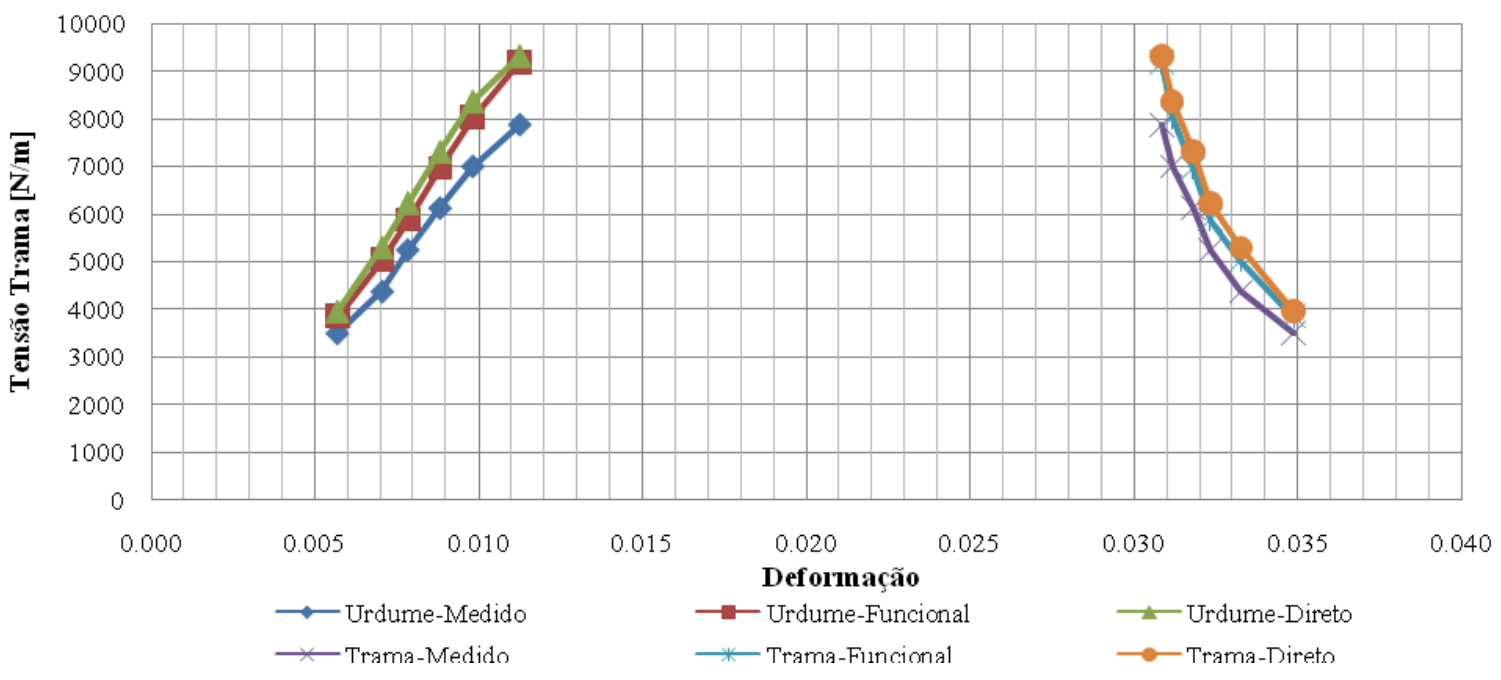

FIGURA 5.21 - Gráficos $\sigma_{t}-\varepsilon_{u}, \bar{\sigma}_{t}-\varepsilon_{u}, \overline{\bar{\sigma}}_{t}-\varepsilon_{u}$ e

$$
\sigma_{t}-\varepsilon_{t}, \bar{\sigma}_{t}-\varepsilon_{t}, \overline{\bar{\sigma}}_{t}-\varepsilon_{t} \text {, na razão }\left(\sigma_{u}: \sigma_{t}\right)=(3: 1)
$$

Fonte: Acervo Pessoal.

As figuras 5.20 e 5.21 representam a razão $\left(\sigma_{u}: \sigma_{t}\right)=(3: 1)$, onde os fios do urdume apresentam alongamento (em relação ao comprimento de referência), enquanto os da trama encurtam, conforme o aumento do carregamento. Novamente, o ajuste do funcional e o ajuste direto apresentam resultados similares. Desta vez, 
os funcionais representam com relativa fidelidade os resultados para as tensões na direção do urdume (figura 5.20). Porém, para a direção da trama, os resultados de tensão calculados são superiores aos encontrados nos ensaios.

\section{Razão de Carregamento 1:3 - Urdume}

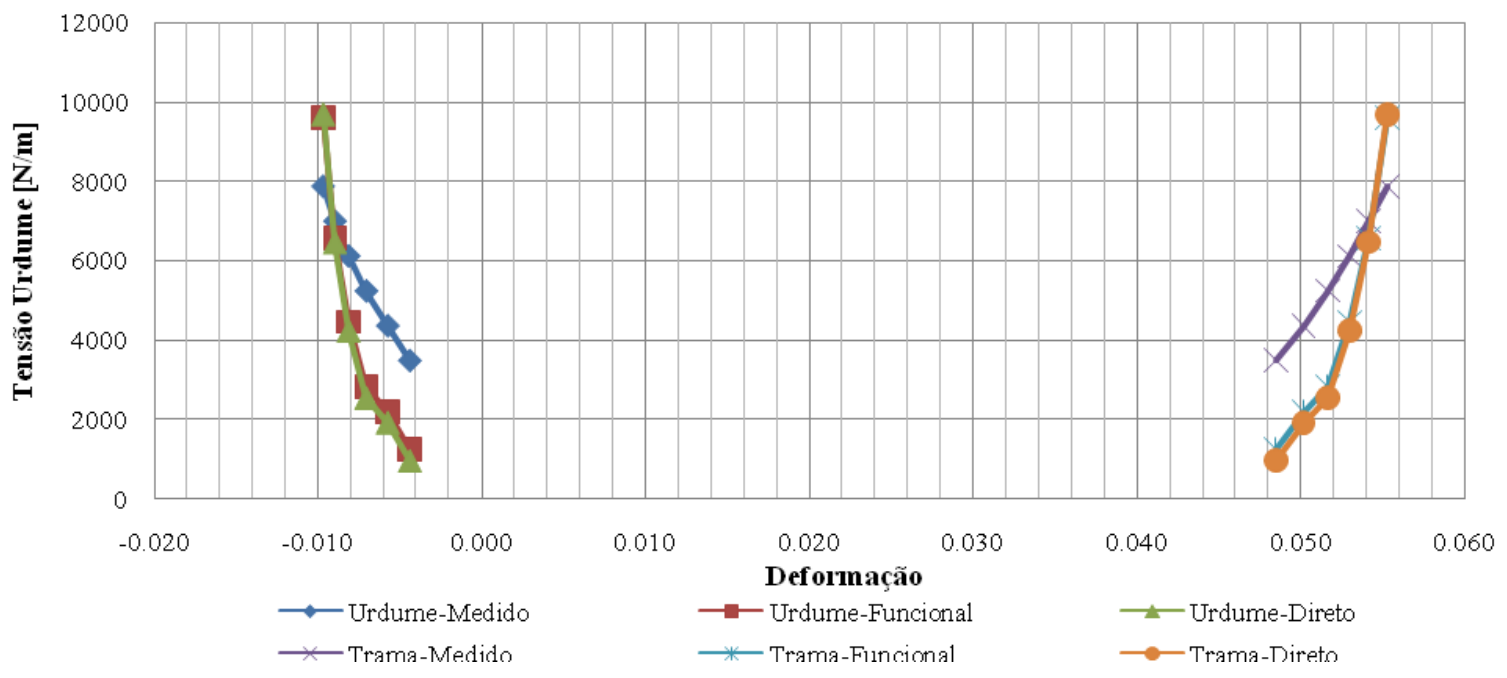

FIGURA 5.22 - Gráficos $\sigma_{u}-\varepsilon_{u}, \bar{\sigma}_{u}-\varepsilon_{u}, \overline{\bar{\sigma}}_{u}-\varepsilon_{u}$ e $\sigma_{u}-\varepsilon_{t}, \bar{\sigma}_{u}-\varepsilon_{t}, \overline{\bar{\sigma}}_{u}-\varepsilon_{t}$, na razão $\left(\sigma_{u}: \sigma_{t}\right)=(1: 3)$ Fonte: Acervo Pessoal.

Razão de Carregamento 1:3 - Trama

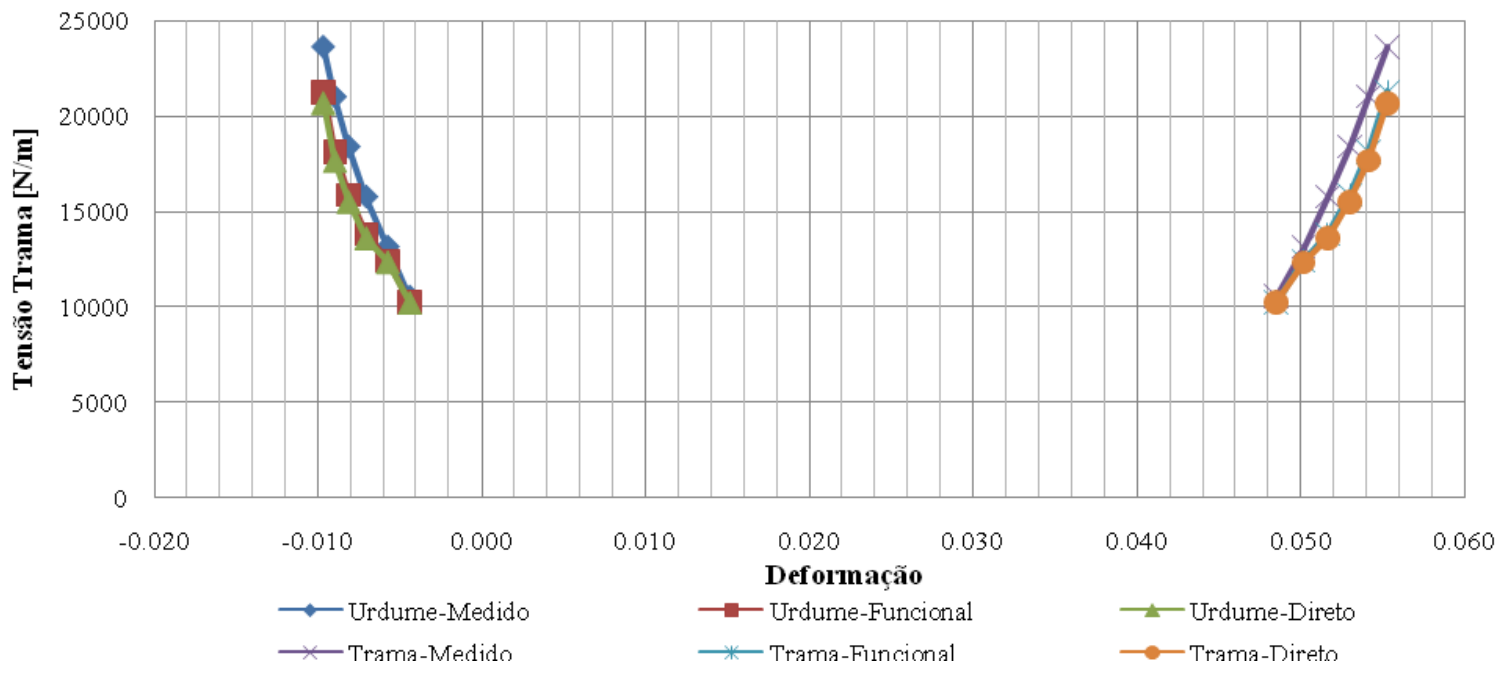

FIGURA 5.23 - Gráficos $\sigma_{t}-\varepsilon_{u}, \bar{\sigma}_{t}-\varepsilon_{u}, \overline{\bar{\sigma}}_{t}-\varepsilon_{u}$ e $\sigma_{t}-\varepsilon_{t}, \bar{\sigma}_{t}-\varepsilon_{t}, \overline{\bar{\sigma}}_{t}-\varepsilon_{t}$, na razão $\left(\sigma_{u}: \sigma_{t}\right)=(1: 3)$

Fonte: Acervo Pessoal. 
Finalmente, nas figuras 5.22 e 5.23 temos os resultados para a razão $\left(\sigma_{u}: \sigma_{t}\right)=$ (1:3), onde os fios da trama apresentam alongamento (em relação ao comprimento de referência), enquanto os do urdume encurtam, conforme o aumento do carregamento. Neste caso também o ajuste do funcional e o ajuste direto apresentam resultados similares. Desta vez, os funcionais representam com relativa adequação os resultados para as tensões na direção da trama (figura 5.23), excetuando-se as regiões com tensões mais elevadas, onde as tensões medidas são superiores às calculadas. Já para a direção do urdume, os resultados de tensão calculados são inferiores aos encontrados nos ensaios para as baixas deformações e superiores para as grandes.

Com base na comparação dos gráficos anteriores, temos que as funções escolhidas para ajuste do modelo não representam adequadamente o comportamento do material nas razões de carregamento diferentes de 1:1, havendo uma forte influência do comportamento de uma direção sobre a outra. Deste modo, a premissa apresentada em (3.15) que indica a não-influência das distorções nas tensões pode não ser a mais adequada para este tipo de material. A adoção de um modelo material hiperelástico, pode também ser insatisfatória, mesmo com a consideração de carregamentos monotonicamente crescentes, como os que foram considerados para o ajuste realizado neste trabalho. É possível que a consideração de modelos não conservativos, que contemplem as deformações permanentes e a histerese do tecido, conforme observadas nos ensaios, seja necessária para se atingir uma aderência satisfatório entre o modelo e os dados de campo. De todo modo, ainda dentro de um modelo hiperelástico, fica aberta a possibilidade da aplicação da metodologia descrita neste trabalho para outras famílias de funções de ajuste, considerando, por exemplo, polinômios com coeficiente não inteiros em termos dos mesmos invariantes adotados neste trabalho, ou de outras grandezas fundamentais, como os estiramentos.

Também devemos notar que, em todas as razões de carregamento, o ajuste definido pelo funcional energia de deformação apresenta resultados semelhantes ao ajuste direto. Entretanto, enquanto o ajuste direto representa apenas a superfície - não definindo uma correlação entre os coeficientes da função e as demais características 
do material, o funcional energia de deformação possui a vantagem de representar um modelo material consistente - no caso, um material hiperelástico. 


\section{CONSIDERAÇÕES FINAIS}

Com base no comportamento mecânico dos tecidos recobertos de PTFE-vidro, conforme publicações do meio científico, e em ensaios biaxias de tração, este trabalho apresentou um estudo sobre a relação tensão - deformação deste material, sob diferentes razões de carregamento.

O Capítulo 1 apresentou uma contextualização do tema. Foram citadas características gerais do material, bem como os fenômenos mecânicos que ocorrem no material quando solicitado. Os objetivos deste trabalho foram definidos neste capítulo.

O capítulo 2 buscou explorar o material de PTFE-vidro. Inicialmente foram apresentadas as características físicas das diferentes fases do material - o tecido de fios de fibra de vidro e o recobrimento em PTFE, incluindo o processo de fabricação e algumas propriedades físico-químicas. Na sequência, uma caracterização do comportamento mecânico do tecido de fibra de vidro recoberto com PTFE foi definida. Nesta segunda parte, características como a anisotropia, a não-linearidade física, a troca de ondulação, a não-elasticidade, o comportamento histerético e a variação do comportamento mecânico do material com a temperatura foram explorados. Também neste capítulo foram apresenadas as características de comportamento do material sob a ação de tensões normais e de cisalhamento.

O Capítulo 3 explorou alguns métodos para modelagem do comportamento deste material. Alguns modelos constitutivos foram estudados. Dentre eles temos a modelagem direta das superfícies tensão - deformação e a modelagem com o uso de um funcional energia de deformação. Este último foi o definido para representar o material neste trabalho por apresentar um modelo de material de membrana ortótropo para o tecido de PTFE-vidro.

O capítulo 4 apresentou o procedimento de teste para determinação da relação tensão-deformação do tecido arquitetônico adotado neste trabalho. Este 
procedimento foi baseado no protocólo japonês de ensaios biaxiais de tração para tecidos recobertos (MSAJ/M-02-1995) e em outros trabalhos sobre ensaios em tecidos PTFE-vidro.

O capítulo 5 apresentou os resultados obtidos pelos ensaios biaxiais e tração, bem como sua condensação. Foi também apresentado o método dos mínimos quadrados para o ajuste das curvas. O funcional energia de deformação definido no capítulo 3 foi ajustado e seus resultados comparados aos dados de campo e às superfícies tensão - deformação definidas de modo direto.

Este estudo permitiu desenvolver uma melhor compreensão sobre o comportamento mecânico do principal tipo de tecido empregado nas estruturas de membrana. Ele também auxiliou no entendimento das metodologias de ensaio existentes e das razões pela quais elas são feitas como são. O exercicio de ajuste de um funcional sujere que, embora não tenha sido quantitativamente satisfatório para razões de carregamento diferentes de 1:1, a metodologia adotada pode ser empregada para a pesquisa de outras familias de funções de interpolação que se revelem mais capazes de representar o comportamento empiricamente observado do material. De todo modo, mesmo na ausência do ajuste de um funcional totalmente satisfatório, os dados experimentais gerados neste trabalho podem ser empregados em situações práticas considerando, por exemplo, as interpolações lineares propostas por Minami et al (1986) e discutidas no item 3.1.2.

Assim, este trabalho, junto com outros como Day (1986), Toda (1986), Minami et al (1986), Pimenta (1993), Kato et al (1999), Pauletti (2003), Alvim (2003), CampeloPimenta-Wriggers (2003), Bridgens et al (2004), Oliveira (2006), Asselt (2007) e Bögner-Balz e Blum (2007), possue sua importância definida no compreendimento do complexo comportamento mecânico dos tecidos arquitetônicos recobertos. 
ALVIM, R. A. A. Avaliação Experimental de propriedades Mecânicas dos Tecidos Esruturais. Dissertação (Mestrado), Escóla Politécnica, Universidade de São Paulo, São Paulo, 2003.

ANSELL, M. P., et al, Architectural PTFE-Coated Glass Fabrics - Their Structure And Limitations, Textile research Journal, 1983, 53, p. 692-700.

ASSELT, P. H. van, Analysis of Stressed Membrane Structures - Implementation of Non-Linear Material Behaviour in Structural Analysis, Dissertação de Mestrado apresentada à Delft University of Technology, Holanda, 2007.

ASTM. Standard Method of Test for Breaking Load and Elongation of Textile Fabrics. D1682-59T. West Conshohocken, PA, 1975.

BERT, C. W. Anisotropic-material Behavior. In: JENKINS, C. H. (editor). Manual on Experimental Methods of Mechanical Testing of Composites. Society for Experimental Mechanics, Inc. Chapter 12, p101-110, 2 edição, Lilburn, GA, 1998.

BLUM, R. Material Properties of Coated Fabrics for Textile Architecture. In: MOLLAERT, M (editor). The Design of Membrane and Lightweight Structures. Proceedings do Simpósio em Vrije Universiteit Brusel, Bélgica, Setembro de 2000.

BLUM, R., Bögner, H., Némoz, G., Material Properties And Testing, em Forster,B., Mollaert, M., European Design Guide for Tensile Surface Structures, Tensinet, Bruxelas, 2004.

BÖGNER-BALZ, H., BLUM, R., Materials for Textile Architecture, Master Membrane Materials, HS Anhalt Dessau, Alemanha, 2007.

BRADSHAW, R., Characteristics of fabrics, In: Shaeffer, R. E., editor, Tensioned fabric structures, a practical introduction, ASCE, 1996, Capítulo 4.

BRIDGENS, B. N., GOSLING, P. D. A New Biaxial Protocol for Architectural Fabrics. Proceedings of IASS symposium: shells, membranes and space frames, Montpellier, 2004. 
BRIDGENS (2), B.N., GOSLING, P.D., BIRCHALL, M.J.S. Membrane Material Behaviour: Concepts, Practice \& Developments. The Structural Engineer, 82 (14), p.28-33, 2004.

CAMPELlO, E. M. B, PIMENTA, P. M., WRIGGERS, P., A Triangular Finite Shell Element Based on a Fully Nonlnear Shell Formulation, Computational Mechanics, 31, p. 505-518, 2003.

CARRIÓ, Juan M., Introducción a la Arquitectura Textil - Cubiertas Colgadas. Colégio Oficial de Arquitectos, Madrid, 1990.

CUSICK, G. E., The resistance of fabrics to shearing forces, Journal of the Textile Institute, 1961, 52, p.395 a 406.

DAY, A. S. Stress Strain Equations for Non-Linear Behavior Of Coated Woven Fabrics. In: HEKI, K. Shells, Membranes and Space Frames. Proceedings of the IASS Symposium on Membrane Structures and Space Frames, Osaka, Japan, 15 a 19 de Setembro de 1986, Volume 2: Membrane an Cable Structures, Elsevier, 1986.

DESAI, C. S., SIRIWARDANE,H. J. Constitutive Laws for Engineering materials, with emphasis on geological materials. Prentice-Hall, 1984

DOBNIK, E (Verseidag-Indutex GmbH). Glass/PTFE for Textile Structures. In: MOLLAERT, M (editor). The Design of Membrane and Lightweight Structures. Proceedings do Simpósio em Vrije Universiteit Brusel, Bélgica, Setembro de 2000.

GROBERG,P., PARK, B. J., The mechanical properties of woven fabrics. Part V: The initial modulus and the frictional restraint in shearing of plain weave fabrics. Textile Research Journal, 1966, 36, p.420 a 431.

HOLZAPFEL, G. A., Nonlinear Solid Mechanics: A Continuun Approach for Engineering, John Wiley \& Sons Ltda, 2000

HUNTINGTON, C. G., The Tensioned Fabric Roof. American Society of Civil Engineers, Virginia, 2004. ISBN 0-7844-0428-3

IFJU, P. Instrumentation Practices for Tension and Shear Testing of Textile Composite Materials. In: JENKINS, C. H. (editor). Manual on Experimental Methods of Mechanical Testing of Composites. Society for Experimental Mechanics, Inc. Chapter 12, p101-110, 2 edição, Lilburn, GA, 1998. 
KATO, S., YOSHINO, T., MINAMI, H. Formulation of constitutive equations for fabric membranes based on the concept of fabric lattice model. Engineering Structures, 21, p.691-708, 1999.

$\mathrm{KUDOH}, \mathrm{K}$. An Analysis of Cutting Pattern and the Fabrication of Membrane Panels for the Membrane Structure. In: HEKI, K. Shells, Membranes and Space Frames. Proceedings of the IASS Symposium on Membrane Structures and Space Frames, Osaka, Japan, 15 a 19 de Setembro de 1986, Volume 2: Membrane an Cable Structures, Elsevier, 1986.

MACK, C., TAYLOR, H. M., The fitting of woven cloth to surfaces. Journal of the Textile Institute, 1956, 47, p. 477 a 488.

MINAMI, H., TOYODA, H., KOTERA, K., SEGAWA, S. Some Reviews on Methods for Evaluation of Performance of Membrane Materials Being Used for Membrane Structures. In: HEKI, K. Shells, Membranes and Space Frames. Proceedings of the IASS Symposium on Membrane Structures and Space Frames, Osaka, Japan, 15 a 19 de Setembro de 1986, Volume 2: Membrane an Cable Structures, Elsevier, 1986.

MOLLAERT, M. (ed.), The Design of Membrane and Lightweight Structures, Proceedings of the symposium at the rije Universiteit Brussels 2000, 2002.

MSAJ/M-01-1993, Testing Method for in-Plane Shear Properties of Membrane Materials, Standard of the Membrane Structures Association of Japan, Tokyo, Japão, 1993.

MSAJ/M-02-1995, Testing Method for Elastic Constants of Membrane Materials, Standard of the Membrane Structures Association of Japan, Tokyo, Japão, 1995.

NEDERPELT, C. A. G., Silicon Coalted Fiberglass for Architectural Structures, Dissertação de Mestrado apresentada à Delft University of Technology, Holanda, 2004.

OLIVEIRA, Igor P., Análise Não Linear de Membranas: Ortotropia e Enrugamento. Dissertação (Mestrado), Escóla Politécnica, Universidade de São Paulo, São Paulo, 2006.

PARGANA, J. B. et al, Advanced material model for coated fabrics used in tensioned fabric structures, Engineering Structures, 29, 2007, p. 1323-1336. 
PAULETTI, R. M. O., História. Análise e Projeto de Estruturas Retesadas. Tese de livre-Docência. Escola Politécnica da Universidade de São Paulo, 2003.

PIMENTA, P. M., On a Geometrically-exact Finite-Strin shell model. Proceedings of the $3^{\text {rd }}$ Pan-American Congress on Applied Mechanics, III PACAM, São Paulo, 1993.

PIMENTA, P. M., PAULETTI, R. M. O., Análise Não-Linear de Estruturas Compostas de Cabos e Membranas, I Simpósio Nacional sobre Tensoestruturas, São Paulo, 5-6 de maio de 2002, Anais do Simpósio.

PIMENTA, P. M., Fundamentos da Mecânica dos Sólidos e das Estruturas, Apostila do curso de pós-graduação em estruturas de Escola Politécnica da Universidade de São Paulo, 2006.

PUDENZ, J. Materials and Workmanship. In: KOCH, K. M.(editor). Membrane Structures, Innovative Building with Film and Fabric. Ed. Prestel, Berlin, 2004.

SEAMAN, R., BRADENBURG, F. Utilization of vinyl coated polyester fabrics for architectural applications. Journal of Industrial. Textiles, 30 de Julho de 2000, pp. 6381.

SKELTON, J. Shear in woven fabrics, In: Proceedings of the advanced study institute program, mechanics of flexible fiber assemblies, 1979, p. 211 a 226.

SKELTON, J. Mechanical Properties of Coated Fabrics. In: HARLE, J., THWAITES, J., AMIRBAYAT, J., RIJN, A. (Editores). Mechanics of Flexible Fiber Assemblies. Sijthoff \& Noordhoff, Países Baixos, p.461-469, 1980.

TAN, K. Y., BARNES, M. R. Numerical Representation of Stress-Strain Relations for Coated Fabrics. Institution of Structural Engineers symposim on the design of air supported structures, Bristol, p.162-174, 1980.

TODA, I., SUZUKI, T., KIKUSHIMA, M., SAITOH, Y. The Influence of Directional Property of the Membrane Materials on the Membrane Analysis. In: HEKI, K. Shells, Membranes and Space Frames. Proceedings of the IASS Symposium on Membrane Structures and Space Frames, Osaka, Japan, 15 a 19 de Setembro de 1986, Volume 2: Membrane an Cable Structures, Elsevier, 1986.

WILLY, W., MARIJKE, M., IRIS, T. Some problems Encountered in the Use of Composite Materials and Textiles in Cable Stayed Membrane Structures. In: HEKI, K. 
Shells, Membranes and Space Frames. Proceedings of the IASS Symposium on Membrane Structures and Space Frames, Osaka, Japan, 15 a 19 de Setembro de 1986, Volume 2: Membrane an Cable Structures, Elsevier, 1986.

WILLE, J. Material Aspects in PVC coated fabrics. In: MOLLAERT, M (editor). The Design of Membrane and Lightweight Structures. Proceedings do Simpósio em Vrije Universiteit Brusel, Bélgica, Setembro de 2000. 